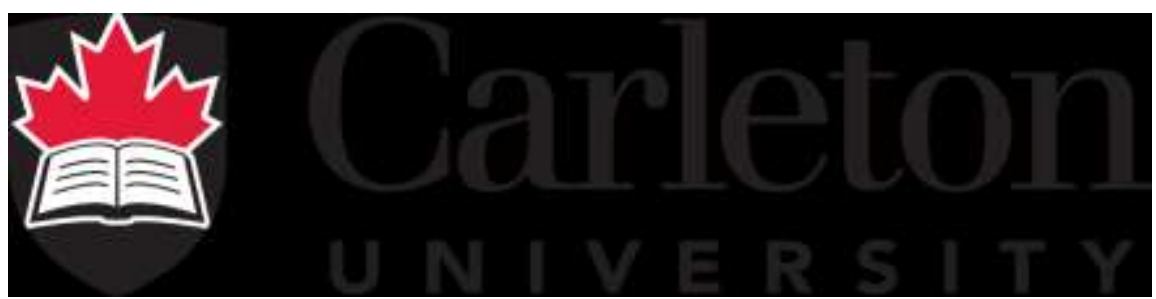

\title{
Inference of Hydroxyl Radical Abundances from Combined Satellite and Ground-Based Hydrochlorofluorocarbon Observations
}

By

\section{Rufes Stephen John Sundarraj}

A thesis submitted to the Faculty of Graduate and Postdoctoral Affairs in partial fulfilment of the requirements for the degree of

Master

of

Applied Science

Carleton University

Ottawa, Ontario

(C) 2021

Rufes Stephen John Sundarraj 


\begin{abstract}
Until recently, Methyl Chloroform was used as a bellwether to determine $\mathrm{OH}$ levels but due to its declining concentrations, the need for other means to calculate $\mathrm{OH}$ levels is imminent. This work proposes a new way of using three different tracers (HFC134a, HCFC141b, and HCFC142b) to determine hydroxyl levels in the atmosphere using a 9box model. The annual trends of each gas were obtained and it was found that there has not been a significant drop but an increase in two of the tracers' levels despite the implementation of Montreal Protocol. The tropopause was defined around $13 \mathrm{kms}$ in the northern and southern latitudes and around $17 \mathrm{kms}$ in the tropics. With the regions of each box defined, and the concentrations of the tracers obtained from ACE-FTS instrument and NOAA, the $\mathrm{OH}$ levels in the atmosphere were obtained through least-squares estimation. The surface regions showed the closest estimates at $5.35 \times 10^{5}$ molecules $/ \mathrm{cm}^{3}$ over the tropics and around $1.1 \times 10^{5}$ molecules $/ \mathrm{cm}^{3}$ over the other two bands. The global averages across troposphere and stratosphere were about 10 and 12 times lower than the traditionally observed values of about $10 \times 10^{5}$ molecules $/ \mathrm{cm}^{3}$ and $1 \times 10^{5}$ molecules $/ \mathrm{cm}^{3}$. However, future works could potentially lead to the model observing closer estimates.
\end{abstract}




\section{Acknowledgements}

My heartfelt thanks to my parents P. Roseline and D. John Sundarraaj, without whom I wouldn't be where I am now. Thanks, mom and dad! Your constant love and support throughout the years, especially in the past two years from the other side of the world meant everything in the middle of the global pandemic. Both of you bet it all on me and I did the best I could. Hope I made you proud. I don't know how I am going to repay you both for giving me the boost I needed to start this new chapter in my life. Loads of love, now and always!

I would also like to sincerely thank my supervisor, Dr. Thomas W. Walker, who helped me understand the concepts involved in this research and provided me with the guidance and materials that I needed to complete this literature. Thank you, sir, for being extremely patient with me and pushing me to achieve the knowledge that I have today. I was instantly hooked on to your Winter 2020 class - Climate Change and Adaptability which led to me completing this research 14 months later, and possibly shaping my future. Thank you so much for everything you've done for me so far.

Lastly, I'd like to thank the Department of Civil Engineering, the FGPA, and my friends who were there for me whenever I needed them the most. 


\section{Table of Contents}

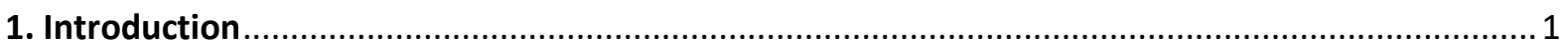

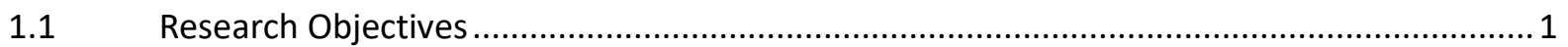

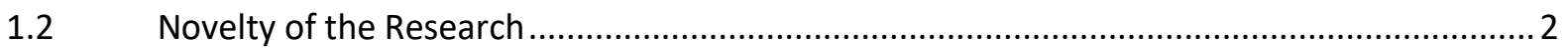

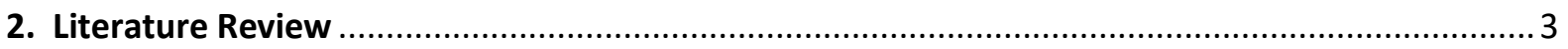

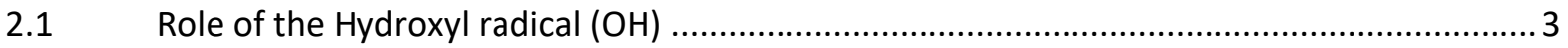

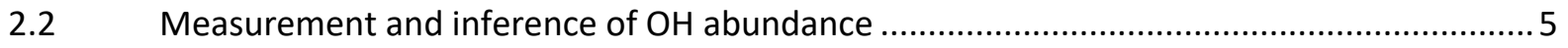

2.3 Methyl Chloroform and the need for its alternative ........................................................ 7

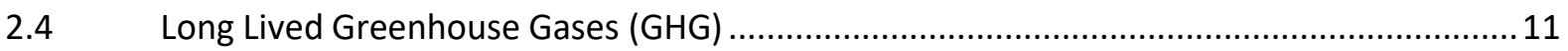

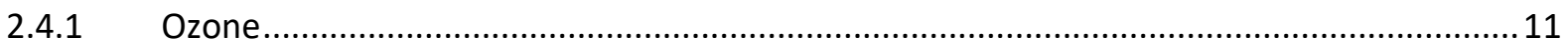

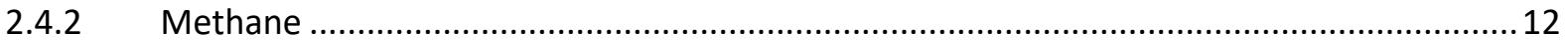

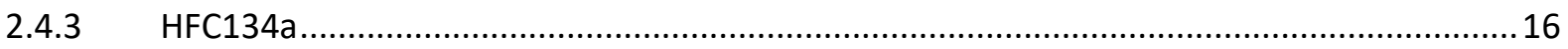

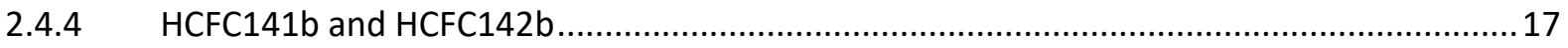

2.5 Rationale behind the choice of tracers and number of tracers ......................................... 18

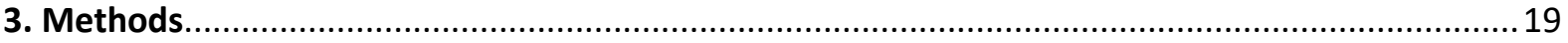

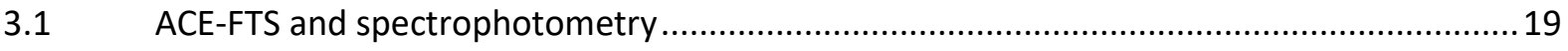

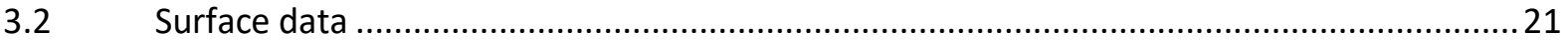

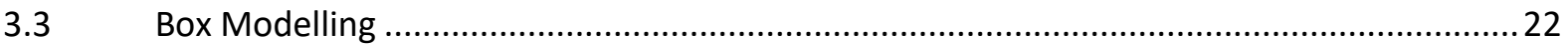

3.4 Linkage between the use of surface and satellite datasets within the box model ..............23

3.5 Potential biases between surface and satellite data and their impacts ..............................24

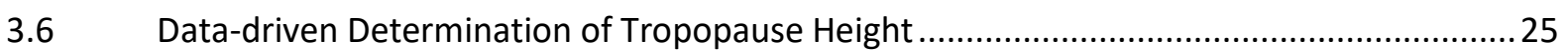

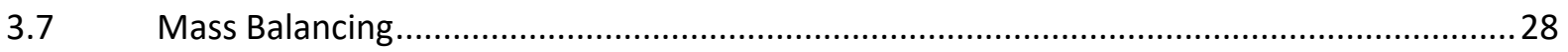

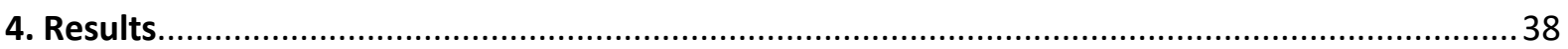

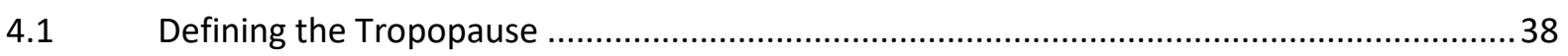

4.2 Time series of the long-lived greenhouse gases used in the literature ................................ 40

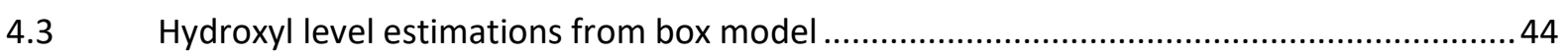

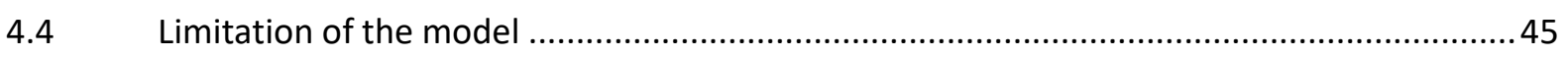

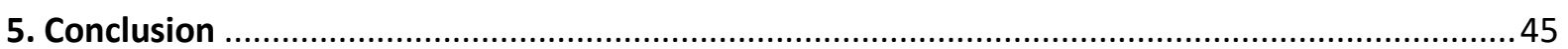

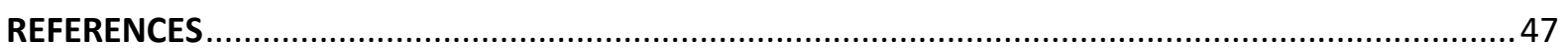

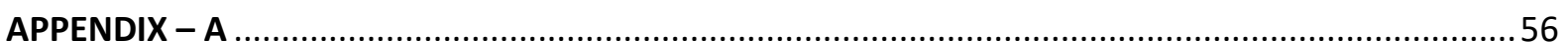

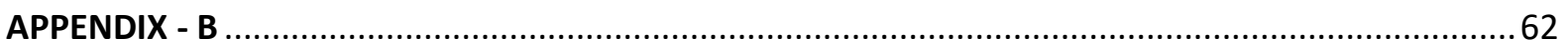

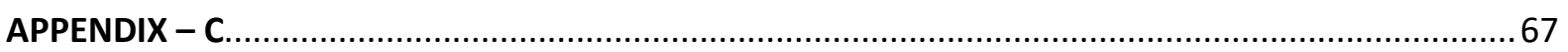

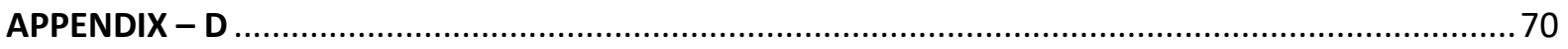




\section{List of Figures}

Figure 2.1 SolidWorks model of ground-based FAGE OH detection cell (University of Leeds, n.d.,) .. 6 Figure 2.2 Figure showing the global annual methane levels. Dashed lines denote the mole fraction and the solid lines denote the growth rate of the gas. Bar charts represent the decadal surface emissions and sinks calculated from top-down (Kirschke et al., 2013).....

Figure 3.3 - Image depicting the orbital inclination of a satellite with respect to the Earth's Equator

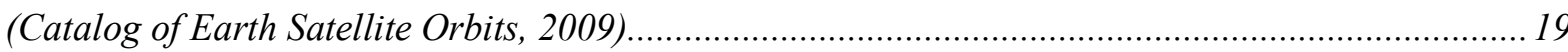

Figure 3.4 Figure illustrating the solar occultation geometry (Toon et al., 2019) ............................. 20

Figure 3.5 Plot of data from NASA's Spitzer Space Telescope indicating the presence of Carbon molecules in the exoplanet WASP-12b (Signature of a Carbon-Rich Planet, 2010) ........................... 21

Figure 3.6 Illustration of a part of a box model system from (Jacob, 1999) ..................................... 22

Figure 3.7 Figure illustrating the 9 box model system used in the research to calculate OH radical levels.....

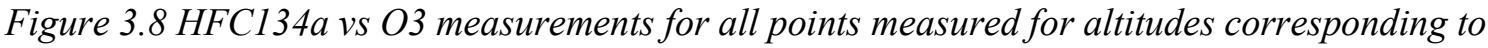
potential temperatures between $350 \mathrm{~K}$ and $360 \mathrm{~K}$ from 2004 to 2020. Plots were prepared for each $10 \mathrm{~K}$ interval of potential temperatures. Other plots obtained for different potential temperature ranges can be found in Appendix $B$

Figure 3.9 Total Means and total Standard deviations of HFC134a vs O3 concentrations as measured by ACE-FTS for each $10 \mathrm{~K}$ Potential temperatures between $300 \mathrm{~K}-400 \mathrm{~K}$ Potential temperatures in the

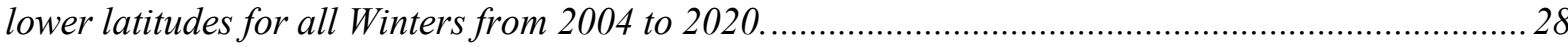
Figure 3.10 Concentration of a gas in a simple one box model with a first order loss (Jacob, 1999). 29 Figure 3.11 Figure illustrating the 9 box model with conversion factors for each gas for each region

Figure 4.12 Figure showing the positive correlation between the mean annual HFC134a concentrations immediately above and below the established tropopause from 2004 to 2020 between $90^{\circ} \mathrm{N}$ and $30^{\circ} \mathrm{N}$ with an outlier at 2016

Figure 4.13 Figure showing the positive correlation between the mean annual HFC134a

concentrations immediately above and below the established tropopause from 2004 to 2020 between $90^{\circ} \mathrm{S}$ and $30^{\circ} \mathrm{S}$.

Figure 4.14 Figure showing the positive correlation between the mean annual HFC134a

concentrations immediately above and below the established tropopause from 2004 to 2020 between

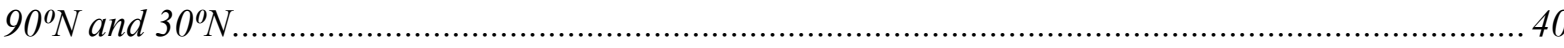

Figure 4.15 Time series plot of surface level Ozone concentrations from different sites around the

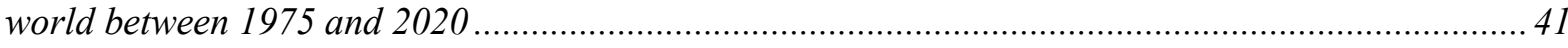

Figure 4.16 Time series plot of surface level HFC134a concentrations (in ppt) from different sites around the world from 1996 to 2020

Figure 4.17 Time series plot of surface level HCFC141b concentrations (in ppt) from different sites around the world between 1992 and 2020

Figure 4.18 Time series plot of surface level HCFC142b concentrations (in ppt) from different sites around the world between 1992 and 2020. 


\section{Introduction}

Greenhouse gases (GHGs) play a central role in the Earth's climate system by altering the radiative balance of the atmosphere. The impact of a given GHG depends on i) how effective it is at absorbing infrared (IR) radiation and ii) its residence time in the atmosphere. GHGs like methane, chlorofluorocarbons (CFCs), and hydrochlorofluorocarbons (HCFCs) are all removed from the atmosphere primarily through their respective reactions with hydroxyl radicals $(\mathrm{OH})$. Therefore, by knowing the concentration of $\mathrm{OH}$ and its variability in time and space, it would be possible to determine the amount of GHGs and other pollutants removed from the atmosphere. Such an insight would help in understanding the changes in the global radiative budget and in better constraining the emissions of GHGs into the atmosphere.

Direct measurements of $\mathrm{OH}$ are challenging because these radicals are extremely reactive and therefore have a very short lifetime, ranging from 0.1-1s. However, multiple methods have been developed to calculate $\mathrm{OH}$ concentrations at a global scale through inverse measurements. Traditionally, methyl chloroform $\left(\mathrm{MCF}\right.$, or $\left.\mathrm{CH}_{3} \mathrm{CCl}_{3}\right)$ has been used as a bellwether for mean hydroxyl radical concentrations (Montzka et al., 2011). But following the Montreal Protocol (1987), MCF was banned from production. Consequently, its concentrations have plummeted since the 1990s and the gas will soon be unusable for the purposes of inverse calculation of global mean $\mathrm{OH}$. This research attempts to provide an alternative approach where a combination of HCFCs (HFC134a, HCFC141b, and HCFC142b) is proposed to find mean $\mathrm{OH}$ concentrations across different parts of the atmosphere by making use of a box model, surface, and satellite observations.

\subsection{Research Objectives}

The objectives of this thesis research are to:

- Develop an observation-based method for separating satellite profile observations into points with chemical characteristics matching the troposphere and those matching the stratosphere; and,

- Estimate mean $\mathrm{OH}$ concentrations spanning the global troposphere and lower stratosphere at a finer than hemispheric resolution. 
The results from the first objective lays the groundwork for the second. The processes that govern $\mathrm{OH}$ and $\mathrm{HCFC}$ abundances in the two domains (troposphere and stratosphere) are

sufficiently distinct that air masses belonging to either domain need to be analyzed separately. The boundary between the two domains vary with latitudes, being closest to the mean sea level at the poles and farthest near the equator. A rationale for separating these domains on a perprofile basis is presented in a later chapter.

\subsection{Novelty of the Research}

\section{Overcoming uncertainties in HCFC emissions}

The use of HCFCs as a means of estimating global hydroxyl radical abundance is not new; however, previous attempts have made use primarily of surface observations (Li et al., 2018). By leveraging the highly precise measurements of the ACE-FTS instrument for observations of upper tropospheric HCFC concentrations, this work aims to improve on this idea. Combining the satellite and surface observations is a novel way to observe air that has been aged since being in contact with the surface, and therefore the HFCs contained in the air will have been exposed to hydroxyl-driven loss. This approach hopes to eliminate the previous works' difficulties in separating information about the loss from the uncertain emissions of HCFCs.

\section{Determining the tropopause altitude based on chemical data}

World Metrological Organization's (WMO) definition of tropopause is the altitude after which the vertical lapse rate does not exceed $2^{\circ} \mathrm{C} \mathrm{km}^{-1}$ (WMO, 1957). This research, however, defined the tropopause based on the concentrations of the three tracers and ozone. Pockets of air specific to the stratosphere can sometimes enter into the troposphere through atmospheric folding. This wouldn't necessarily affect the change in the lapse rate but the chemistry of the two layers will be different. Moreover, the occurrence of multiple tropopauses is also possible and have been observed many times (Bischoff et al., 2007; Schmidt et al., 2006; Seidel \& Randel, 2006). In these cases, the lapse rate would be erratic, and a definite boundary cannot be obtained. But, by separating the satellite profiles using the tracer data itself, it was possible to obtain a more defined boundary between the two layers with fairly distinctive atmospheric compositions. 


\section{Literature Review}

\subsection{Role of the Hydroxyl radical (OH)}

The hydroxyl radical acts as a primary sink for numerous gases in the atmosphere, many of which are greenhouse gases and volatile organic compounds. $\mathrm{OH}$ is formed in the daytime through the photo-dissociation of ozone in the presence of water vapour. Incident UV radiation, with a wavelength between $290 \mathrm{~nm}$ and $340 \mathrm{~nm}$ breaks down an ozone molecule, which dissociates into an oxygen molecule and a metastable atomic oxygen (A). The latter reacts either with an air molecule to be "quenched" (C) or with water vapour to form hydroxyl radicals (B) (Levy, 1971). This is the primary source of $\mathrm{OH}$. Any $\mathrm{OH}$ radicals formed beyond this reaction are considered to be the secondary sources of $\mathrm{OH}$.

$$
\begin{gathered}
\mathrm{O}_{3}+\mathrm{hv}(\lambda<330 \mathrm{~nm}) \rightarrow \mathrm{O}\left({ }^{1} \mathrm{D}\right)+\mathrm{O}_{2} \\
\mathrm{O}\left({ }^{1} \mathrm{D}\right)+\mathrm{H}_{2} \mathrm{O} \rightarrow 2 \mathrm{OH} \\
\mathrm{O}\left({ }^{1} \mathrm{D}\right)+\mathrm{M} \rightarrow \mathrm{O}\left({ }^{3} \mathrm{P}\right)+\mathrm{M}
\end{gathered}
$$

The $\mathrm{OH}$ radicals so formed will react with volatile organic compounds (VOCs), and gases like methane $\left(\mathrm{CH}_{4}\right)$ and carbon monoxide $(\mathrm{CO})$. The chemical reaction between $\mathrm{CO}$ and $\mathrm{OH}$ ends with the production of $\mathrm{NO}_{2}$ and $\mathrm{OH}$.

$$
\begin{gathered}
\mathrm{CO}+\mathrm{OH} \rightarrow \mathrm{CO}_{2}+\mathrm{H} \\
\mathrm{H}+\mathrm{O}_{2}(+\mathrm{M}) \rightarrow \mathrm{HO}_{2}(+\mathrm{M}) \\
\mathrm{HO}_{2}+\mathrm{NO} \rightarrow \mathrm{NO}_{2}+\mathrm{OH}
\end{gathered}
$$

During night time, there are numerous reservoirs for hydroxyl radicals such as the peroxy-methane $\left(\mathrm{CH}_{3} \mathrm{OOH}\right)$, hydrogen peroxide $\left(\mathrm{HO}_{2}\right)$, reaction of alkenes with ozone, etc. Under circumstances where the concentrations of $\mathrm{NO}_{2}$ is high, Nitrous acid (HONO) levels can increase. These molecules undergo photolysis, breaking down at 400nm culminating in the formation of $\mathrm{OH}$ radicals but its effect is small and does not have a major effect the global abundance of the gas (Kurtenbach et al., 2001).

\section{Hydroxyl radicals on VOCs and CO}

Hydroxyl radicals are responsible for the removal of methane (CH4), carbon monoxide (CO), HFCs, and several VOCs. Hydroxyl radicals have a very short atmospheric lifetime of 
about $0.1-2$ seconds and hence are highly reactive. They attack and oxidize partly oxidized gases such as CO, VOCs, and $\mathrm{CH}_{4}$ (Levy, 1971).

Murray et al., (2014) showed that though there has been a sharp decline in methane concentrations from the last glacial maxima to the pre-industrial era, tropospheric $\mathrm{OH}$ mean has seen little change in its levels $(0.5 \pm 12 \%)$. Stratospheric ozone and tropospheric water were the two major parameters that influenced the hydroxyl radical concentrations in the troposphere during the glacial-interglacial periods. Lightning NOx emissions were also a minor factor. But compared to preindustrial era (ca. 1770s), the simulated present day $\mathrm{OH}$ levels increased by $+7.0 \pm 4.3 \%$. The linear relationship between the hydroxyl radical concentrations and mean tropospheric ozone photolysis frequency, water vapour concentration (or specific humidity) explained $72 \%$ of the simulated variability in tropospheric mean $\mathrm{OH}$. The oxidative capacity was also directly proportional to the global NOx emissions $\left(\mathrm{R}^{2}=0.81\right)$ and inversely proportional to the global VOC sources. It was also found that fire emissions had little effect on tropospheric mean $\mathrm{OH}$.

\section{Sensitivity of $\mathbf{O H}$}

Apart from the seasonal and temporal variability in its predecessor ozone, $\mathrm{OH}$ also has its variability dependant on the UV radiation from the Sun. The UV radiation levels are usually about one hundredth of the total solar influx. The terrestrial UV levels are also dependant on the total ozone column amount. If the stratospheric and tropospheric ozone concentrations are known the resulting UV levels can be calculated. Cloud covers also play a significant role in the UV levels. The more the cloud cover, the less the UV incidence. The linear correlation can, however, be quantified to some extent by an empirical formula. This is how UV indices are forecasted. It was also found that the influx of UV radiation varied with time over the course of a calendar year (Chadyšiene et al., 2005; Johnson et al., 1976). Another factor that affects the UV levels is the solar zenith angle - the higher the angle, the lower the transmittance (ElNouby Adam, 2011). So varying levels of UV radiation also plays a major role in the production of hydroxyl radicals. OH primary production is highest in the upper troposphere and lower stratosphere over the tropics (Lelieveld et al., 2016).

The $\mathrm{NOx} / \mathrm{CO}$ ratio is one of the most important parameters in determining the $\mathrm{OH}$ levels in the local atmosphere. Recent studies have shown that NOx emissions have been steadily decreasing while the $\mathrm{CO}$ emissions have remained relatively unchanged (Hoesly et al., 2018). An increasing $\mathrm{NOx} / \mathrm{CO}$ ratio indicates that the $\mathrm{OH}$ levels have been increasing. But the 
reduced NOx emissions indicate a declining trend of the hydroxyl radicals. In addition to this, $\mathrm{OH}$ abundance in a region is also buffered by the levels of other gases such as methane. It should also be noted that the hydroxyl radicals are subject to local environments (Dalsøren et al., 2016; Lelieveld et al., 2004, 2016).

\subsection{Measurement and inference of $\mathrm{OH}$ abundance}

$\mathrm{OH}$ plays a vital role in the chemistry of the troposphere, and its measurement to understand how it affects the atmosphere is of high priority. However, being an extremely reactive molecule with a lifetime of only 0.1s - 1s (SPARC, 2013), combined with its low concentrations, hydroxyl radical concentration has been difficult to accurately ascertain through direct measurements.

With high variability in mixing ratio among its predecessors such as ozone and NOx compounds, the hydroxyl radical is also subject to inconsistent concentrations. At the surface, the concentrations can be anywhere from $10^{5}$ to $10^{7} \mathrm{~cm}^{-3}$ (Hoell et al., 1984). Previously, the annual mean concentrations (from several estimates) had been reported to be between $3 \times 10^{8}$ to $5 \times 10^{8}$ radicals per ml (Crutzen, 1974; McElroy et al., 1974).

Before onsite measurements, $\mathrm{OH}$ concentrations were calculated using virtual models. Rudimentary models were found to be inconsistent with observed data mainly due to a limited understanding of the $\mathrm{OH}$ chemistry. But with continuous research and improvements in modelling techniques, current models vastly outperform their pioneers and have paved way for a new generation of predictive tools. Some such papers and their results are briefly explained below.

In August 2003, a heat wave resulted in the development of smog in southern UK, and northern parts of Netherlands, France, and Germany. This led to excess deaths and efforts were undertaken to study the effect on free radical concentrations in the local environment. This study by Emmerson et al., (2007) has been one of the most extensive field campaigns of free radical concentration and chemistry. A zero-dimensional box model based on Master Chemical Mechanism (MCM), which also incorporated photochemistry, was used to explain the concentrations of $\mathrm{OH}, \mathrm{HO}_{2}$, and $\mathrm{RO}_{2}$. The model overestimated the $\mathrm{OH}$ concentration by about $24 \%$, the hydroperoxy radical concentration by $7 \%$, and underestimated the total peroxy levels by $22 \%$. A few possible explanations for these differences may include uncertainties in rate coefficients used in MCM, uncertainties in FAGE measurements, and of course the limited 
understanding of $\mathrm{OH}$ chemistry. But despite several challenges, the results prove adequate confidence in the model.

Jackson et al. (2009) attempted to make use of two Generalized Additive Models (GAMs) to create a final model that predicted the $\mathrm{OH}$ trends where a majority of their deviances were explained. One GAM was fitted with $\mathrm{OH}$ concentrations that were measured during the Tropospheric ORganic Chemistry Campaign (TORCH). The other was fitted with a zero dimensional box model that was used to compute the $\mathrm{OH}$ levels in the atmosphere by Emmerson et al., (2007). The fitted (or measured) GAM reproduced mean diurnal concentration results that varied by only about $0.2 \%$ compared to $16.3 \%$ overestimation by MCM. The modelled GAM performed better than the measured GAM where the former explained $83.1 \%$ of the variation while the latter did about $78 \%$. Some of the main advantages in both these models are:

i) both recognised the importance of photolysis in influencing the $\mathrm{OH}$ levels; and,

ii) both included primary and secondary pollutants.

Although MCM models perform well in their own way, GAMs can be powerful supplements to have more precise predictions

\section{The FAGE Technique}

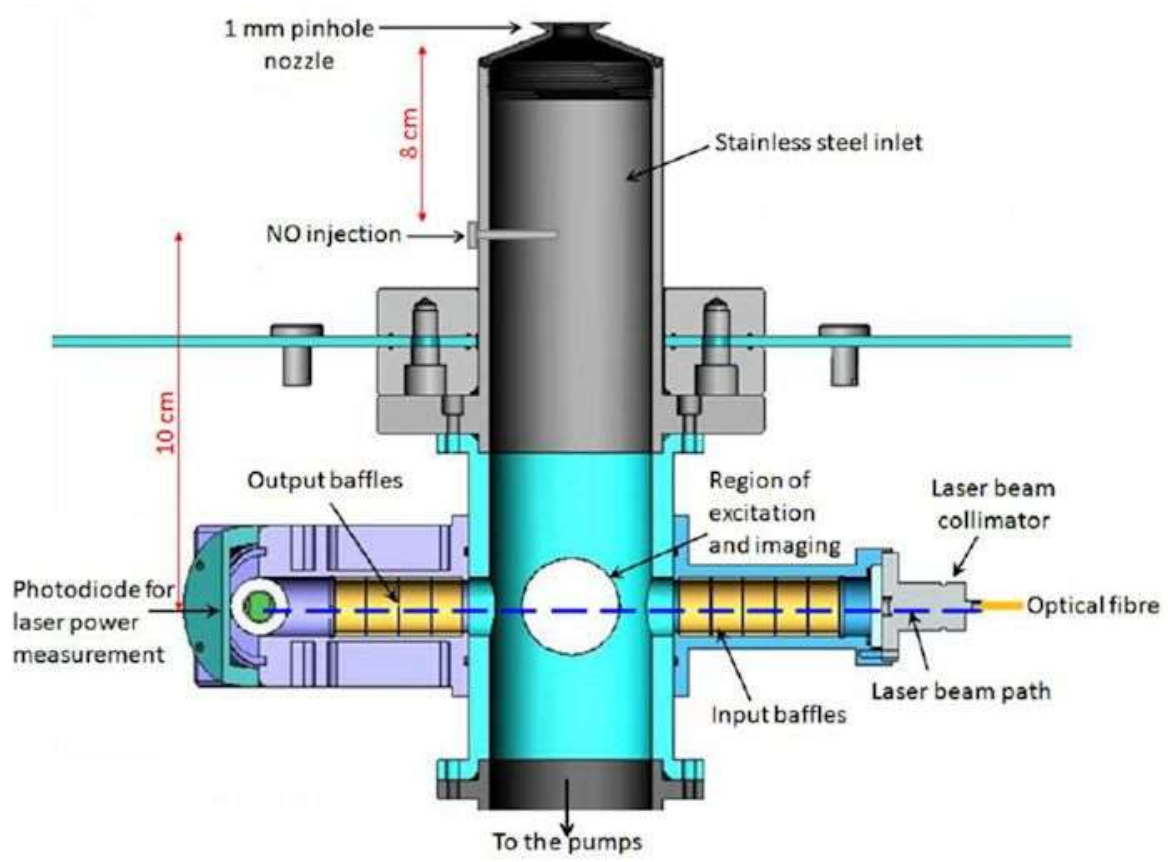

Figure 2.1 SolidWorks model of ground-based FAGE OH detection cell (University of Leeds, n.d.,) 
The Fluorescence Assay by Gas Expansion (FAGE) technique has been a common way to determine the concentration of hydroxyl radicals for many years. This method is highly sensitive and hence an excellent option for field measurements of $\mathrm{OH}$ levels. Hard et al., (1984) was the first to use this technique and marked an important milestone in direct measurement of the gas. Originally intended to measure the hydroxyl levels, adaptations and adjustments were made to the rudimentary apparatus to include $\mathrm{HO}_{2}$ (Mather et al., 1997), NO and IO (Bloss et al., 2003), $\mathrm{N}_{2} \mathrm{O}_{5}$ (Matsumoto et al., 2005), and $\mathrm{RO}_{2}$ (Fuchs et al., 2008) measurements as well. Besides the field measurements, there have also been several attempts to measure gas radicals such as $\mathrm{OH}, \mathrm{HO}_{2}$, and $\mathrm{RO}_{2}$ in the stratosphere by aircrafts. These measurements provide vital information in understanding the chemistry of the atmosphere. There are different variations of the technique and one such apparatus that is used by the University of Leeds is shown in Figure 2.1

The general principle of the FAGE is as follows: air is drawn into a stainless-steel gas chamber through a small opening. The inlet chamber has a very low pressure of about 1.5 Torr. As the gas passes through the chamber, a dye laser pulse of $308 \mathrm{~nm}$ excites the radicals and induces fluorescence. Since the chamber has low pressure, the gas expands, and collisional quenching of the excited atoms is reduced. This increases the lifetime of the fluorescence and enables a more accurate measurement. The increased lifetime also helps to identify any light entering the detector from sources other than the fluorescence, such as light passing erroneously from the laser to the detector. A photon detector collects the fluorescence signal from the gas, from which the concentrations of $\mathrm{OH}$ in the surroundings can be determined.

Amedro et al. (2012) tried passing the laser pulse parallel to the chamber instead of perpendicular to it in a recently developed model at the University of Lille. It was found that the parallel approach inhibited energy dependence studies. The latter approach was comparatively much successful. The model achieved a detection limit of $3 \times 10^{5} \mathrm{~mol} / \mathrm{cm}^{3}$ for a one-minute average.

\subsection{Methyl Chloroform and the need for its alternative}

Methyl Chloroform, commonly referred to as MCF, is a chemical that has no known natural sources. It was first produced in the early 1840 from vinyl chloride and later introduced into the commercial market during the early 50s. Its primary use was in metal cleaning (vapor degreasing and cold cleaning) which accounted to almost $50 \%$ of its total use. Other uses included aerosols, adhesives, coating $\&$ ink, textiles, electronics, and miscellaneous uses 
(Midgley \& Mcculloch, 1995). This compound was entertained as a replacement to some of the other chemicals at the time as it was believed to be less toxic and less harmful compared to its counterparts.

Methyl Chloroform was widely used as a bellwether for measuring the global mean $\mathrm{OH}$ concentration in the troposphere. The gas is purely anthropogenic and does not have any known natural sources. As such, its sources were claimed to be known and its emissions carefully monitored (Midgley \& Mcculloch, 1995). Most of its sources were located in the northern hemisphere. The rapid growth in northern sources, combined with the slow interhemispheric transport of gases has led to an imbalanced distribution of MCF between the two hemispheres. This is true for a number of trace gases which have chiefly anthropogenic sources, including HFC134a, HCFC141a, and HCFC141b.

$\mathrm{OH}$ is the major sink for MCF with stratospheric photolysis and ocean uptake taking up $12 \%$ and $6 \%$ of the losses respectively. With the total mass of MCF and its reaction rate constant for $\mathrm{OH}$ known, the calculations for the latter's concentrations were made through inverse measurements. By measuring the total emissions of $\mathrm{MCF}$, it is possible to deduce the $\mathrm{OH}$ levels present in the atmosphere, since the hydroxyl radical is its major sink. Such an approach is called an "inverse measurement" or an "inversion". Other variables considered in these calculations include the lifetime of MCF and the interhemispheric transport time.

Between the mid-90s through the mid-2000s, there was a substantial decrease in MCF levels due to reduced emissions as a result of the revisions and amendments on the Montreal Protocol on Substances that Deplete the Ozone Layer (1987). This reduction in its emissions led to a constant decline in its burden and the gas levels dropped from about 100ppt in the 90s to about 3.5ppt by mid 2010s (Rigby et al., 2017). With the Montreal protocol still in effect, and with an atmospheric lifetime of 5 years (SPARC, 2013), the concentrations of the gas are expected to drop further to less than $0.5 \mathrm{ppt}$ by 2025 (Liang et al., 2017). Such low concentrations make it even more challenging for the gas to be used in $\mathrm{OH}$ level calculations to understand how $\mathrm{OH}$ is changing the atmosphere. Soon, MCF will not be a viable gas for this purpose.

Hence the need for another method or another gas for $\mathrm{OH}$ level calculations is imminent. In this research, a combination of HCFCs is proposed as a better alternative to MCF as a bellwether for determining $\mathrm{OH}$ levels. This would work the same way as MCF did wherein 
an inverse measurement is used to determine the hydroxyl radical concentrations in the troposphere.

It was widely assumed that Europe and the United States have had near zero emissions of MCF since 2000. However, a study found that the concentrations of MCF were higher than $20 \mathrm{Gg} \mathrm{yr}^{-1}$ (Krol et al., 2003). But the precise amount of the calculated emissions was not stated in the study. Nevertheless, even with emissions of $20 \mathrm{Gg} \mathrm{yr}^{-1}$, its effects on $\mathrm{OH}$ level estimations would be insignificant. Hence MCF was not used in this research.

\section{Montreal Protocol, 1987}

In the mid-20th century, the use of gases (such as MCF, certain Chlorofluorocarbons (CFCs), methyl bromide etc.) were becoming more and more common as they were used in cooling services like refrigeration, air conditioning, etc. These halocarbons have long atmospheric lifetimes and do not get destroyed until they escape the troposphere and enter into the stratosphere.

The United States Environmental Protection Agency was one of the first organizations to officially declare that MCF was a safer substance. It was a replacement for Tricholorothylene $\left(\mathrm{CHClCHCl}_{2}\right)$. By 1976, a few years into its advertisements as a safer substance, the global capacity of MCF was around $5.3 \times 10^{5}$ tons with 90 percent of it being used. The U.S. was the leading manufacturer, doubling the concentrations of the next two countries. In just three years, the mixing ratio of the gas was estimated to rise to levels of about $9.1 \times 10^{5}$ tons (Chemical Marketing Report, 1977). The main reason why it was classified as a relatively safe chemical was because its rate constant for reaction with $\mathrm{OH}$ radicals was only one percent of tricholorothylene's (i.e.,) it was comparatively inert in the troposphere.

A few replacements for halocarbons were proposed and Hydrochlorofluorocarbons (HCFCs) replaced halocarbons (CFCs). HCFCs were thought to be better than CFCs as HCFCs are relatively more reactive and would thus get destroyed before reaching the stratosphere (Watson, 1990). However, despite their shorter atmospheric lifetimes, HCFC's have been measured in the stratosphere and contribute to ozone depletion.

In 1974, it was found that the chlorofluorocarbon (CFC) compounds $\mathrm{CFCl}_{3}$ and $\mathrm{CF}_{2} \mathrm{Cl}_{2}$ which were released into the atmosphere were harmful to the ozone layer in the stratosphere. These gases, similar to ozone, are destroyed through photodissociation and their destruction produces significant amount of free chlorine atoms. These chlorine atoms then combine with 
free oxygen atoms that are products of ozone photodissociation. This interference of Chlorine atoms in the ozone-oxygen cycle inhibits the rate of production of ozone in the stratosphere, culminating in reduced levels of ozone. The situation was exacerbated due to the fact that the levels of Chlorofluoromethane (CFM) were increasing at an alarming rate.

The effects were significant over the Antarctic where ozone levels were so low that the term 'Ozone hole' was coined to stress the severity. This was an early warning on the harmful effects of CFCs on the atmosphere. Although scientists at that time called for replacement of CFCs by HCFCs, it wasn't until the introduction of the Montreal Protocol that almost all of the countries came forward to reduce and eventually discontinue the production of CFMs, CFCs, and other Ozone Depleting Substance (ODS). Several researches over the years narrowed down on a few ODSs that were deemed to be extremely harmful to the environment. In addition to destroying ozone concentrations in the stratosphere, these ODSs also directly accounted for positive radiative forcing (Velders et al., 2007). In order to overcome the accumulating forcing, and to preserve the ozone layer, the Montreal Protocol was agreed upon in 1987 and it came into effect in 1989. As of January 2021, 198 countries have ratified the multilateral, international treaty (UNTC, 2021).

It was projected that following the ban of Chlorofluoromethanes (CFMs) in 1978, if there were no MCF emissions after 1990, the decrease in annual mean global $\mathrm{O}_{3}$ concentrations could be reduced from $1.4 \%$ to $0.5 \%$. This change in ozone reductions due to instant zero emissions from 1990 is due to the short lifetime of MCF. CFCs do not have the same effect as they are destroyed top-down (stratosphere-troposphere) whereas MCF is destroyed bottom-up (troposphere-stratosphere). In other words, it takes longer for ozone to reach steady state values due to zero emissions of CFMs compared to MCF (McCONNELL \& Schiff, 1978). Hence why MCF was seen as a better alternative.

As a result of the one of its regulation, no. 517/2014, all refrigerants with a GWP of more than 150 were banned in domestic refrigerators, as domestic refrigerators were the major applications for several greenhouse gases (EUR-Lex, 2014). So now that MCF has also been phased out, its concentrations will plummet in the next few years and the gas will soon become unusable to determine $\mathrm{OH}$ levels. Therefore, it is important to find new and viable methods for the same. 


\subsection{Long Lived Greenhouse Gases (GHG)}

\subsubsection{Ozone}

Ozone is easily one of the most important gases responsible for creating a habitable environment for life on Earth. The stratospheric ozone protects the living organisms by absorbing the harmful high energy radiation from the Sun, which, if left unabsorbed, would reach the surface and cause damage to life, ecosystems, and property. However, any ozone concentrations in the troposphere (i.e., near the surface of the Earth) is regarded as a pollutant and can cause serious problems if present in high levels. These are primarily formed in the presence of sunlight from Nitrogen Oxides ( $\mathrm{NO}_{\mathrm{x}}$ compounds) and volatile organic compounds (VOCs). Nitric Oxide (NO) and Nitrogen Dioxide $\left(\mathrm{NO}_{2}\right)$ are commonly referred to as $\mathrm{NO}_{\mathrm{x}}$ compounds. Ozone in the troposphere is responsible for many deaths globally due to shortterm or long-term illnesses as a result of prolonged exposure.

The concentrations of ozone in the stratosphere is significantly higher at $15 \mathrm{ppm}$ than that in the troposphere at 10ppb (Nasa Ozone Watch, 2015). This is because most high energy (UV) radiation from the sun is absorbed by the oxygen atoms present in the higher layers of the atmosphere, which results in photodissociation of oxygen molecules and subsequent production of ozone. Closer to surface, there is significantly less UV radiation and hence there is a lower concentration of ozone. In this research, ozone is only used as a marker to define the tropopause which will be used in box modelling that follows later.

The formation of ozone is a complex process that involves the chapman mechanism as well as reactions with $\mathrm{NO}_{\mathrm{x}}$, Hydrogen oxide radicals $\left(\mathrm{HO}_{\mathrm{x}}\right)$, and Chlorine Oxide $\left(\mathrm{ClO}_{\mathrm{x}}\right)$ radicals. Since the only use of ozone in this research is to define the tropopause, only the oxygen-ozone cycle is explained briefly and none of the other processes are discussed in any further detail.

Radiations with wavelength below $240 \mathrm{~nm}$ are capable of breaking the double bonded oxygen molecules $\left(\mathrm{O}_{2}\right)$. This would result in the $\mathrm{O}_{2}$ molecules present in the stratosphere to split up into two excited oxygen atoms.

$$
\mathrm{O}_{2}+\mathrm{hv} \rightarrow \mathrm{O}+\mathrm{O}(\lambda<240 \mathrm{~nm})
$$

Such radiation generally does not penetrate through to the troposphere as most of it is lost in the aforementioned photo-dissociation of $\mathrm{O}_{2}$ molecules in the stratosphere. But some manage to reach the surface and long exposures to these high energy radiations can prove to 
be harmful and in some cases, cause skin cancer (Ananthaswamy, 1997). The free oxygen atoms so formed will eventually lose the energy that was absorbed from the solar radiation and bond weakly with any available oxygen atoms to form ozone.

$$
\mathrm{O}_{2}+\mathrm{O}+\mathrm{M} \rightarrow \mathrm{O}_{3}+\mathrm{M}
$$

where $\mathrm{M}$ is a third body. A third body can be any inert molecule in the atmosphere and its primary function is to absorb or remove any excess energy from the reaction. This energy is then dissipated as heat (Jacob, 1999).

\subsubsection{Methane}

Methane $\left(\mathrm{CH}_{4}\right)$ is one of the most powerful greenhouse gases with a global warming potential (GWP) of 28 for a 100 year period (Myhre et al., 2013). Global warming potential is the ratio of the radiative forcing of $1 \mathrm{~kg}$ of a gas $\mathrm{X}$ over a certain period of time to the radiative forcing of $1 \mathrm{~kg}$ of $\mathrm{CO}_{2}$ over the same period of time.

$$
G W P=\frac{\int_{t_{0}}^{t_{0}+\Delta t} \Delta F_{1 k g X} d t}{\int_{t_{0}}^{t_{0}+\Delta t} \Delta F_{1 k g C O_{2}} d t}
$$


From the preindustrial era to the $1980 \mathrm{~s}$, the $\mathrm{CO}_{2}$ increase due to anthropogenic activities caused a warming of the planet by about $0.5 \mathrm{~K}$. This was further amplified by up to $50 \%$ by methane, tropospheric Ozone, and a few other CFCs. In addition to this, a model projected that from 1980 to 2030, increased influx of methane concentrations would exacerbate global warming by $0.1 \mathrm{~K}$ to $0.2 \mathrm{~K}$ (Ramanathan et al., 1985). Global trends of methane have been studied in many ways and it was generally found that the methane growth rate plummeted between 2000 and 2007 as shown in figure 2.2

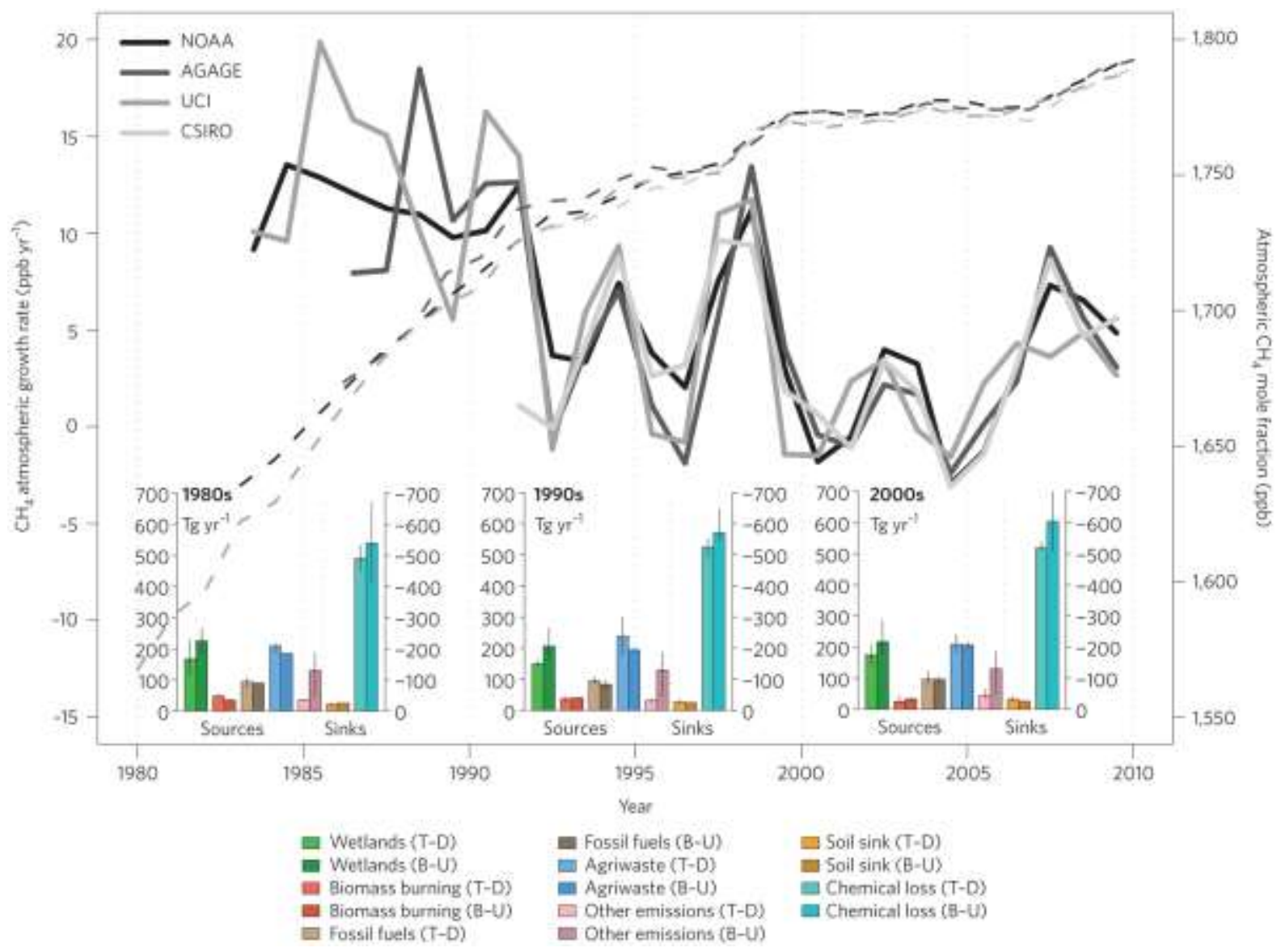

Figure 2.2 Figure showing the global annual methane levels. Dashed lines denote the mole fraction and the solid lines denote the growth rate of the gas. Bar charts represent the decadal surface emissions and sinks calculated from top-down (Kirschke et al., 2013)

However, since 2007, the concentration of methane began to rise and grew rapidly since 2014. By the end of $2006, \mathrm{CH}_{4}$ level was around $1.77 \mathrm{ppmv}$ but by the end of 2017 , it rose to $1.85 \mathrm{ppmv}$. This sudden increase is still unclear but some plausible reasons include: increased ruminant and wetland emissions, increased fossil fuel emissions or decreased biomass burning while the sinks remained unchanged, and decreased oxidation capacity of the atmosphere. 
There have not been any definitive conclusions on why there was a sudden surge in global methane concentrations (Nisbet et al., 2019). It is possible that this is due to a combination of increased anthropogenic activities such as rice cultivation, fossil fuel use, and cattle farming. Wetlands are the major natural sources of methane emissions and they are directly affected by climate change. Warmer wetlands are prone to more efficient methanogenesis and this is evident from the fact that tropical wetlands emit more methane than those located in higher latitudes. Such a scenario leads to a positive feedback loop which exacerbates global warming.

But the upsurge is likely that a combination of increased fossil fuel use and increased microbial emissions played a major role in the sudden rise in $\mathrm{CH}_{4}$ levels in the last 15 years. The stabilization prior (in the early 2000s) is probably due to decreased or plateaued fossil fuel use combined with plateaued or increased microbial emissions (Kirschke et al., 2013). Regardless, the relative significance of the various sources and sinks of methane are still under debate.

Methane has both anthropogenic and natural sources. The former includes domesticated ruminants (such as cows), rice fields, burning of biomass, decay of waste, coal mining, and the use of fossil fuels. These sources add up to about $334 \mathrm{Tg} \mathrm{CH}_{4} \mathrm{yr}^{-1}$. Natural sources are predominantly the decay of organic matter in wetlands. Other important sources include termites, wildlife, oceans, geological activities, hydrates, and wildfires. The natural sources account to about $238 \mathrm{Tg} \mathrm{CH}_{4} \mathrm{yr}^{-1}$ (Denman et al., 2007). Table 1 gives a more recent data on methane sources calculated for both top-down and bottom-up methods.

\begin{tabular}{|c|c|c|c|c|c|c|}
\hline \multirow{2}{*}{$\begin{array}{l}\text { Latitudinal band } \\
\text { Approach }\end{array}$} & \multicolumn{2}{|c|}{$90 \circ \mathbf{S}-30^{\circ} \mathrm{N}$} & \multicolumn{2}{|c|}{$30-60 \circ N$} & \multicolumn{2}{|c|}{$60-90^{\circ} \mathrm{N}$} \\
\hline & Bottom-up & Top-down & Bottom-up & Top-down & Bottom-up & Top-down \\
\hline Natural sources & $228\left[\begin{array}{lll}155 & 340\end{array}\right]$ & 160 [130-189] & 115 [70-192] & 42 [29-54] & 31 [18-55] & 16 [11-20] \\
\hline $\begin{array}{l}\text { Natural } \\
\text { wetland }\end{array}$ & $116[71-146]$ & 135 [116-155] & 25 [10-43] & $33[24-48]$ & $9[2-18]$ & $13[7-16]$ \\
\hline Other natural & 112 [84-194] & 25 [14-36] & 90 [60-149] & 9 [4-14] & $22[16-37]$ & $3[2-4]$ \\
\hline $\begin{array}{l}\begin{array}{l}\text { Anthropogenic } \\
\text { sources }\end{array} \\
\end{array}$ & 202 [183-217] & 208 [186-229] & $152[148-157]$ & 144 [117-170] & $12[8-8]$ & $6[2-10]$ \\
\hline $\begin{array}{l}\text { Agriculture } \\
\text { \& waste }\end{array}$ & 130 [121-137] & 139 [127-157] & 80 [77-84] & 78 [67-87] & $1[1-1]$ & $1[1-2]$ \\
\hline Fossil fuels & 53 [43-71] & 47 [37-52] & 67 [61-71] & 60 [34-85] & $10[6-15]$ & $4[2-7]$ \\
\hline $\begin{array}{r}\text { Biomass \& } \\
\text { biofuel burning }\end{array}$ & 20 [18-22] & 22 [18-28] & $7[6-9]$ & $6[5-8]$ & $1[0-1]$ & $1[1-1]$ \\
\hline Sum of sources & 430 [338-557] & 368 [337-399] & 267 [218-349] & $186[166-204]$ & 43 [26-72] & 22 [17-29] \\
\hline
\end{tabular}

Table 1 Global methane emissions (in Tg) categorized into different latitudinal bins, type of approach, and type of source (Saunois et al., 2020) 


\section{Sensitivity of Methane}

Methane is heavily linked with NOx compounds, Ozone, and hydroxyl radicals. Any reduction in the emissions of NOx compounds will result in a proportionate reduction of ozone because NOx compounds are precursors of ozone. Since ozone is a precursor of OH, the latter's concentration in the atmosphere will also be lowered. $\mathrm{OH}$, which is often referred to as the detergent of the atmosphere for its role in oxidizing gases which in large concentrations could be harmful to the environment.

$\mathrm{OH}$ is a major sink for $\mathrm{CH}_{4}$. Higher than normal concentrations of $\mathrm{CH}_{4}$ would result in lower levels of $\mathrm{OH}$. Should the emissions of methane accelerate, the $\mathrm{OH}$ levels would be reduced further, which would result in methane being in the atmosphere for longer periods of time. The excess $\mathrm{CH}_{4}$ present would absorb radiation from the Sun and culminate in a positive radiative forcing. It should also be noted that $\mathrm{OH}$ can be formed through subsequent reactions following the oxidation of methane. Though this forms a feedback loop, the net result is that methane would suppress the $\mathrm{OH}$ levels in the troposphere, which would increase its lifetime in the lower atmosphere (Lelieveld et al., 2016).

$$
\begin{aligned}
\mathrm{CH}_{4}+\mathrm{OH} & \rightarrow \mathrm{CH}_{3} \mathrm{O}_{2}+\mathrm{H}_{2} \mathrm{O} \\
\mathrm{CH}_{3} \mathrm{O}_{2}+\mathrm{HO}_{2} & \rightarrow \mathrm{CH}_{3} \mathrm{OOH}+\mathrm{O}_{2} \\
& \rightarrow \mathrm{CH}_{3} \mathrm{O}+\mathrm{O}_{2}+\mathrm{OH}
\end{aligned}
$$

So, higher ozone levels would lead to higher $\mathrm{OH}$ levels, which would remove methane. But tropospheric ozone is also a greenhouse gas and any reduction in its concentration would induce a negative radiative forcing on the planet. Interestingly, the net result is that the positive radiative forcing by one gas (ozone or methane) will either cancel out or exceeds the negative radiative forcing by the other (Berntsen et al., 2005; Fiore et al., 2002; Fuglestvedt, 1999; Naik et al., 2013; Shindell et al., 2005; Wild et al., 2001). So, on top of the uncertainty in its sources and seasonal variations, methane is also heavily sensitive to the emissions of other gases. Thus, methane plays a pivotal role in global atmospheric chemistry and has an intricate connected with ozone and $\mathrm{OH}$.

Most of $\mathrm{CH}_{4}$ emitted into the troposphere is removed solely by the hydroxyl radicals. So, by measuring the amount of $\mathrm{CH}_{4}$ destroyed, it could be possible to determine the amount of $\mathrm{OH}$ present through inverse measurements. The result can be calculated up to a certain degree of certainty even though methane has a few other sinks, such as chlorine atoms, 
stratospheric oxidation, and soil uptake (Lelieveld et al., 2016). But this is tedious, as the exact emissions of $\mathrm{CH}_{4}$ are still unknown, mainly because it has both natural and anthropogenic sources.

Similar to ozone, methane is also subject to seasonal variations. Since $\mathrm{OH}$ is a major sink for methane, it varies inversely with $\mathrm{OH}$. This was experimentally shown by Halogen Occultation Experiment (HALOE) satellite observations. In the troposphere, the $\mathrm{CH}_{4}$ maximum is observed between August and September while the $\mathrm{CH}_{4}$ minimum is observed between December and January. Likewise, in the stratosphere, the $\mathrm{CH}_{4}$ maximum is in March - April while the minimum is between August and October (Park et al., 2004; Zhou et al., 2018). This correlates with the maxima-minima of ozone abundances.

\subsubsection{HFC134a}

1,1,1,2-Tetrafluoroethane, more commonly referred to as HFC134a, was first introduced in the late $90 \mathrm{~s}$ as a replacement for ozone depleting substances that were prevalent at that time. Its primary use was in cooling systems. In most cases, the gas being replaced was CFC-12. HFC134a is a volatile compound and the main sink for the gas is through reaction with hydroxyl radicals.

$$
\mathrm{CF}_{3} \mathrm{CH}_{2} \mathrm{~F}+\mathrm{OH} \rightarrow \mathrm{CF}_{3} \mathrm{CHF}+\mathrm{H}_{2} \mathrm{O}
$$

Due to the rapid shift from conventional gases to HFC134a, its emissions increased rapidly, and it is currently the most abundant HFC in the atmosphere, followed by HFC-23. Its notable role in global warming was soon recognized.

Though it has near zero ozone depleting potential, it was included in the list of gases to be phased out under the Kyoto Protocol due to its contribution to climate change (The Montreal Protocol emphasized more on ozone depleting substances). The GWP of HFC134a is 1300 for a 100-year period (Myhre et al., 2013). With a lifetime of 14 years (SPARC, 2013) that is beyond the interhemispheric transport time, it is assumed to be uniformly distributed in the atmosphere. However, in reality, since a majority of the emissions take place in the northern hemisphere, the concentrations are slightly higher above the equator.

Research is currently being undertaken to find a suitable replacement for HFC134a. So far Hydrofluoroolefins (HFOs) seem to be produce the best results. Among them, HFO1234yf and HFO1234ze appear highly promising as they have a combination of both zero ozone depleting potential and very low global warming potential. Test results have shown that using 
these gases improved the efficiency of the refrigerators and had a relatively lower environmental impact. Moreover, they can be used as a drop-in replacement in both new and existing refrigerators (Aprea et al., 2018).

In January 2019, the Kigali Amendment to the Montreal Protocol came into effect. Under the Amendment, several developed and developing countries agreed to reduce about $80 \%-85 \%$ of their total consumption of HFC134a by the years 2036 and 2045 respectively. But it was found that rather than a decline in the overall emissions of the gas, there was a rapid increase in both HFC134a as well as HFC-23. The former increased by $4.9( \pm 0.1)$ years while the latter increased by $0.75( \pm 0.02)$ years (Fernando et al., 2019).

\subsubsection{HCFC141b and HCFC142b}

1,1-Dichloro-1-fluoroethane, similar to HFC134a was introduced as a replacement to the fully halogenated hydrocarbons that were conventionally used at that time. Its primary use is as a blowing agent in the production of polyurethane and insulation foams. It is also used in refrigeration. HCFC $141 \mathrm{~b}$ is highly volatile and has a low boiling point of about $32^{\circ} \mathrm{C}$. Due to its lower ozone depleting potential (0.065) and significantly lower residence time (17.9 years), it was encouraged to be a better product compared to its counterparts. But in addition to its contribution to global warming, it can also be toxic to humans and other animals at high concentrations.

$$
\mathrm{OH}+\mathrm{CH}_{3} \mathrm{CFCl}_{2} \rightarrow \mathrm{CH}_{2} \mathrm{CFCl}_{2}+\mathrm{H}_{2} \mathrm{O}
$$

1-Chloro-1,1-difluoroethane, more commonly referred to as Freon-12b or HCFC 142b, was among the few HCFCs that replaced CFCs in their role as a refrigerant. Its ozone depleting potential was 0.065 - only half of that of HCFC141b. Although it was relatively better compared to CFCs, its global warming potential was determined to be 1980 , more than double the value of HCFC 141b (Myhre et al., 2013). Combined with a long lifetime of about 18 years, this gas has a significant role among the rest of the hydrochlorofluorocarbons in global warming.

$$
\mathrm{OH}+\mathrm{CH}_{3} \mathrm{CFCl} \rightarrow \mathrm{CH}_{2} \mathrm{CFCl}+\mathrm{H}_{2} \mathrm{O}
$$

Efforts have been undertaken to phase out HCFCs similar to the phasing out of CFCs in the previous century. The United States has also adhered to the Montreal Protocol and has since reduced its emissions of $\mathrm{HCFC} 141 \mathrm{~b}$ and $\mathrm{HCFC} 142 \mathrm{~b}$. It has set its target of no production or import of the gas by the year 2030. The production of HCFCs have already been banned in the U.S. (US EPA, 2015). Even though HCFC141b and HCFC142b levels had been increasing 
slowly up to the mid-2010s, the growth rate has been rapidly declining. This is a positive sign showing that the amendments are being implemented. If the trend follows, in the next few decades, their concentrations should match the proposed levels of the Montreal Protocol (Simmonds et al., 2017).

\subsection{Rationale behind the choice of tracers and number of tracers}

All three tracers have a significantly higher lifetime compared to MCF and since their lifetimes are longer than the mixing timescale within the full atmosphere, these tracers will be globally well-mixed. Similar to MCF, these tracers are purely anthropogenic in origin and hence their emission values in the troposphere and stratosphere are exactly zero, reducing the number of variables in the calculation.

Using three gases with similar characteristics allows us to exploit the common factors such as transport times in order to extract information about their differences, such as their loss rates and emissions. The three tracers in a given gas parcel measured at the surface and then transported to the upper troposphere will experience a certain amount of chemical loss that is solely a function of the $\mathrm{OH}$ abundance it encounters and the transport time. Since the transport time is common to all three gases, we can isolate for the unknown $\mathrm{OH}$ abundance. Using only one tracer would result in the system having a total of 23 values (in terms of mass of the tracer) and 23 variables (9 $\mathrm{OH}$ levels and 14 net mass transport coefficients). Adding another tracer would double the number of values in the system and adding a third would triple the values while the number of variables remain the same. Having three tracers would provide a closer estimate of $\mathrm{OH}$ levels than using only one or two.

In addition to these, the following are a few other reasons for selecting these specific set of gases:

- Hydroxyl radicals are the main sink for all three gases (Myhre et al., 2013) and hence this validates the assumption that $\mathrm{OH}$ is the only sink for the gases. Such an assumption will further simplify calculations by not including other variables representing the minor losses.

- The concentrations of the gases are also higher than MCF levels and because of their longer lifetimes, they can be used for $\mathrm{OH}$ estimates for another three decades, despite regulations limiting their production from the Kigali Amendment. 
- Consistent measurements of the gases were available for the surface from the NOAA GMD network, and in the upper troposphere and lower stratosphere from ACE-FTS between the years 2004 and 2020.

\section{Methods}

\subsection{ACE-FTS and spectrophotometry}

Launched on 12 August 2003, the Canadian satellite SCISAT-1 has a primary objective of analysing the processes that are involved in the ozone distribution along the upper troposphere and stratosphere. It follows a low-Earth orbit at $650 \mathrm{~km}$ from the mean sea level (MSL) with an inclination of $74^{\circ}$.

The inclination angle is the angle of the satellite with respect to the equator. If the satellite follows a ground track along the equator, then the inclination angle of that satellite is zero. The higher the inclination angle, the closer the satellite's orbit will move towards the poles. The inclination angle of any satellite depends on its purpose. For example, if a satellite was launched to monitor the tropics, it will have a lower inclination angle $\left(\sim 30^{\circ}\right)$. At $180^{\circ}$, the satellite's spin will be opposite to that of the Earth's (Catalog of Earth Satellite Orbits, 2009). The trajectory of the satellite is in such a way that it covers higher altitudes so that it can observe and measure atmospheric data in regions closer to the poles. This would provide a much better understanding of the transport of gases from the lower latitudes to the higher latitudes. Figure 3.3 gives illustrates the aforementioned property of a satellite's design.

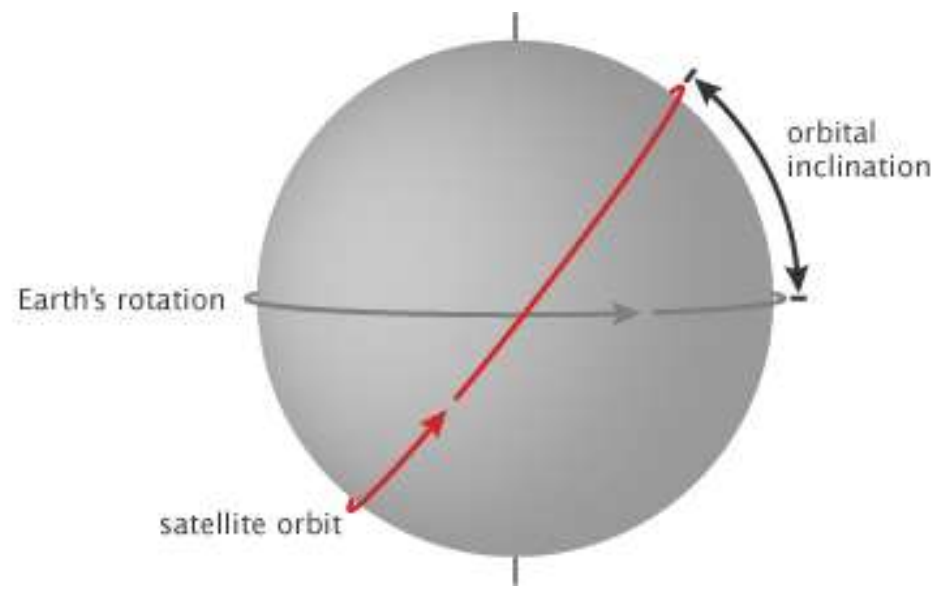

Figure 3.3 - Image depicting the orbital inclination of a satellite with respect to the Earth's Equator (Catalog of Earth Satellite Orbits, 2009) 
With an orbital time of 95 minutes, SCISAT circles the Earth about 15 times per day. Throughout these orbits, the satellite goes through its own sunrises and sunsets every time it crosses the dark side of the planet. The instruments on SCISAT measure the transmitted solar radiation through the Earth's atmosphere as it passes through a sunrise or sunset; each of these measurements is called an occultation (see Figure 3.4). On average, SCISAT experiences about 6016 solar occultations per year (Bernath, 2005). During each occultation, it measures and records the sunlight passing through the Earth's atmosphere.

A single recording over a region is a straight line stretching from $0.5 \mathrm{kms}$ to $149.5 \mathrm{kms}$ with an interval of $1 \mathrm{~km}$ between successive altitudes. With multiple recordings over a period of time, they can be consolidated into four-dimensional data.

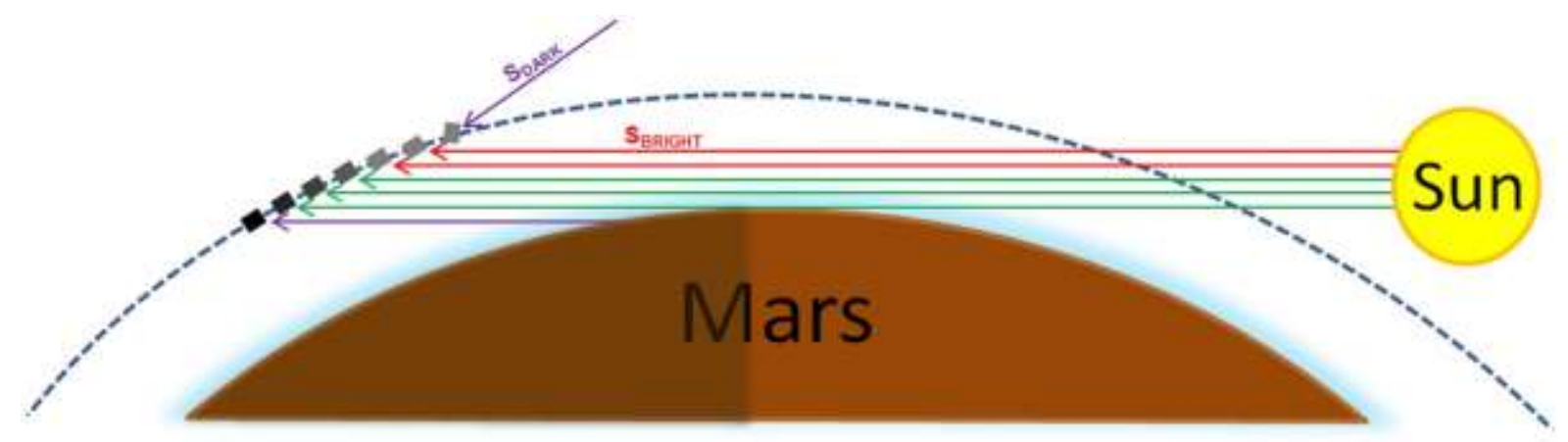

Figure 3.4 Figure illustrating the solar occultation geometry (Toon et al., 2019)

The ACE-FTS instrument is a Fourier transform spectrometer measuring in the wavelength region (2.22 to 13.33 microns) with a spectral resolution of (5000 microns) (Bernath, 2005). The instrument measures absorption features in the solar spectrum due to atmospheric trace gases. Each trace gas absorbs at specific wavelengths, which makes it easier to identify individual gases when there is a mix of large number of gases. This technique is called occultation spectroscopy and is widely used to study the composition of planets in the Milky Way galaxy and beyond (See Figure 3.5). 


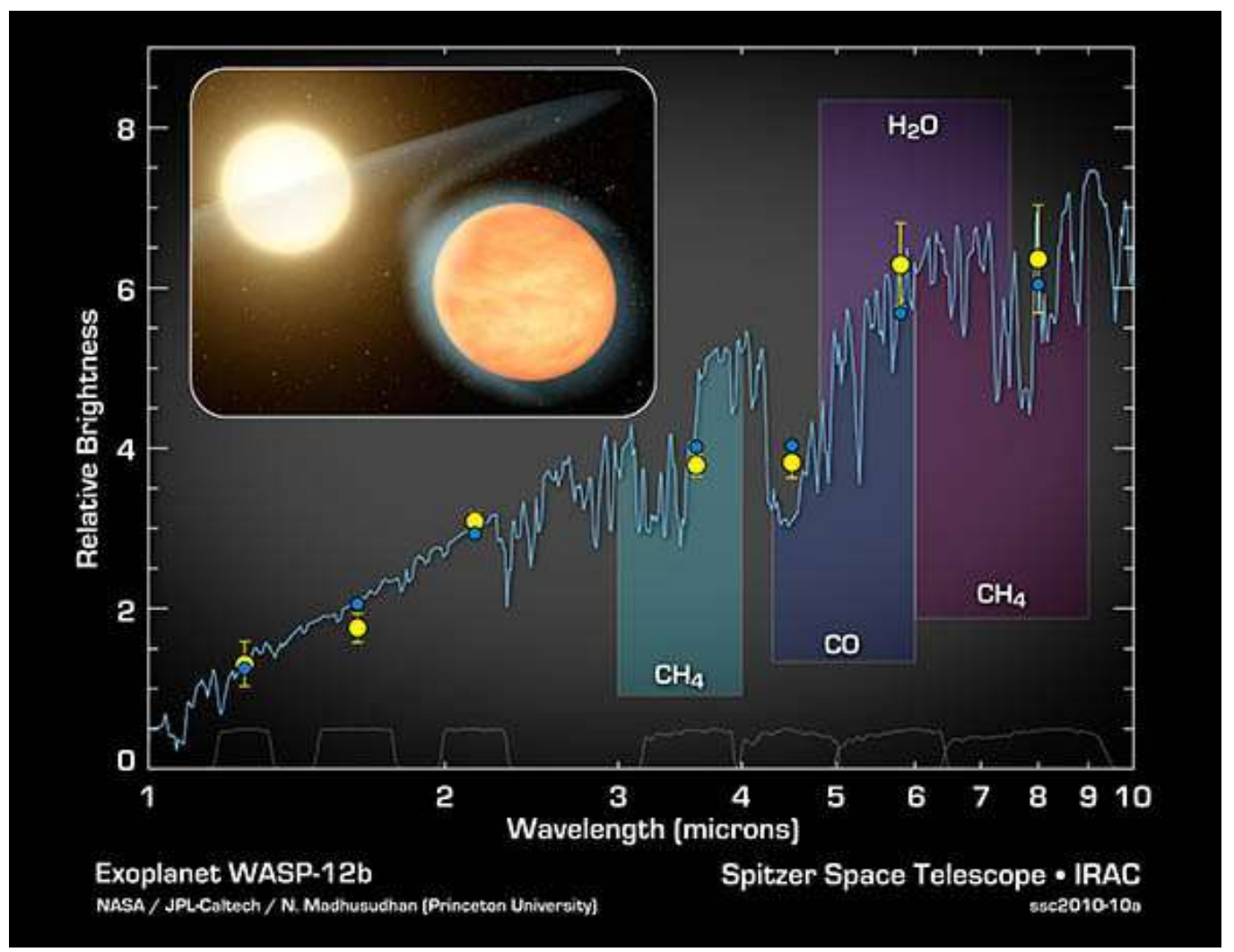

Figure 3.5 Plot of data from NASA's Spitzer Space Telescope indicating the presence of Carbon molecules in the exoplanet WASP-12b (Signature of a Carbon-Rich Planet, 2010)

\subsection{Surface data}

Surface data for all the five gases (methane, ozone, HFC134a, HCFC141b, HCFC142b) used to calculate the hydroxyl radical concentrations were obtained from Global Monitoring Laboratory (GML) of the National Oceanic and Atmospheric Administration (NOAA). GML was first established in 1972 as part of the NOAA Environmental Research Laboratories. Its mission is to record and analyse the levels of greenhouse gases, aerosols, clouds and surface radiation. Many of the sites (predominantly those in the Pacific Ocean) that were dedicated to see through the mission have been discontinued. But due to the low number of sites available for the observation of hydrocarbons, some sites were used in this research even though the data stops at some point in time.

Halocarbons and other Atmospheric Tracer Species (HATS) Flask Sampling Program has been an important part of the GML and it has been analysing air samples since 1977. It began by collecting air in stainless steel flasks at 1.5 atm by metal pumps to eliminate any decontamination. Later, the pressure was increased to $4 \mathrm{~atm}$ to facilitate the detection of gases that were too sparsely distributed to be identified. With some modifications to the instruments 
and adoption of a few different techniques, analysis of CFCs, HFCs and HCFCs began in the early 90 s. The volume of the flasks was also steadily increased from $300 \mathrm{~mL}$ in the 1970 's to $2.4 \mathrm{~L}$ by the end of the century. A decade later, glass flasks were integrated into the apparatus owing to the advantages over their stainless-steel counterparts. With a few other upgrades, HATS is still functional and contributes towards the measurement of $\mathrm{N}_{2} \mathrm{O}, \mathrm{SF}_{6}, \mathrm{CFCs}$, Halons, HFCs, HCFCs, COS, and a few other gases ("NOAA Global Monitoring Laboratory Halocarbons and other Atmospheric Trace Species", 2015).

\subsection{Box Modelling}

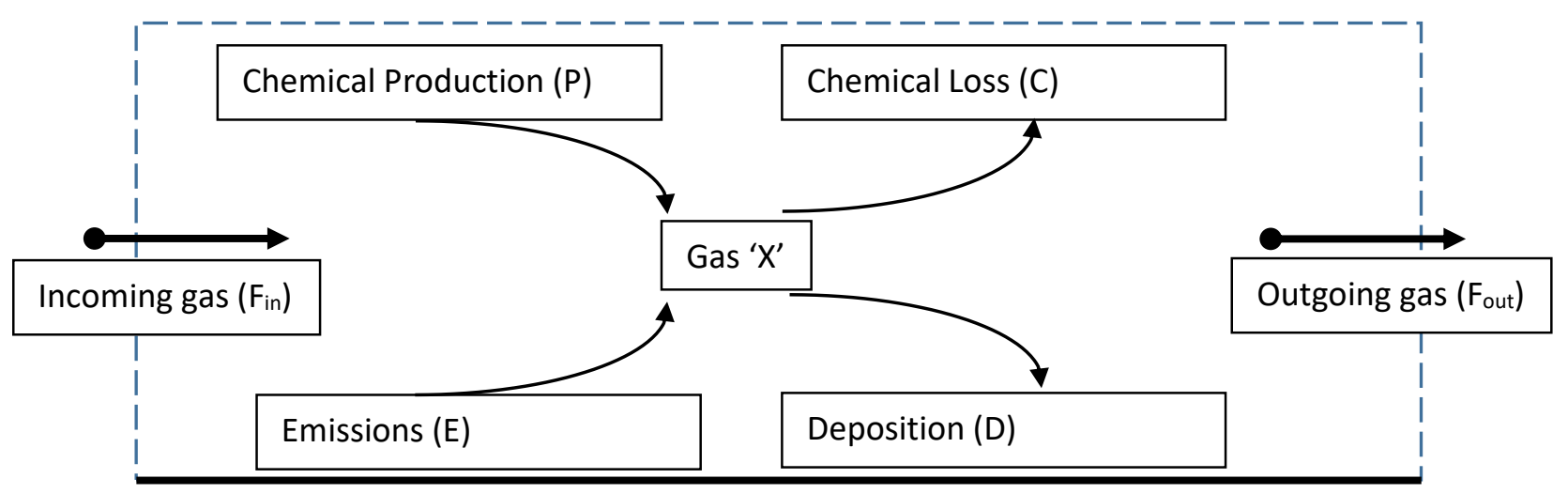

Figure 3.6 - Illustration of a part of a box model system from (Jacob, 1999)

The mass of a tracer inside of a given boundary as a function of time is described by a mass balance equation, where sources and sinks appear as forcings on the time rate of change of the tracer mass. Sources include chemical production (P), emissions (E), and any influx of the gas due to transportation $\left(F_{\text {in }}\right)$. The chemical production takes place in the atmosphere through natural processes and the emissions are usually anthropogenic. Sinks include chemical losses (L), deposition (D), and any outflux of the gas through transportation ( $\left.\mathrm{F}_{\text {out }}\right)$. Both occur naturally. For a gas $X$, at steady state conditions $(\mathrm{dm} / \mathrm{dt}=0)$, there would be no accrual of the gas or gradual decrease and the sources would be equal to sinks. This is numerically given by,

$$
\mathrm{F}_{\text {in }}+\mathrm{P}+\mathrm{E}=\mathrm{F}_{\text {out }}+\mathrm{C}+\mathrm{D}
$$

The lifetime $(\tau)$ of a gas is the ratio of the total amount of a gas (' $\mathrm{m}$ ' in $\mathrm{kg}$ ) that is removed to the removal rate $\left(\mathrm{kg} \mathrm{s}^{-1}\right)$. It is mathematically represented as

$$
\tau=\frac{\mathrm{m}}{\mathrm{F}_{\text {out }}+\mathrm{C}+\mathrm{D}}
$$

The atmosphere was divided into nine boxes on a latitude-altitude grid as shown in Figure 3.9. The surface was divided into three latitude ranges: $90^{\circ} \mathrm{S}$ to $30^{\circ} \mathrm{S}, 30^{\circ} \mathrm{S}$ to $30^{\circ} \mathrm{N}$, and 
$30^{\circ} \mathrm{N}$ to $90^{\circ} \mathrm{N}$. Each range was split into a near-surface level, a free troposphere layer, and a lower stratosphere layer. The tropopause over the tropics will extend to a higher altitude than in the other regions due to the consistent upwelling along the Intertropical Convergence Zone (ITCZ).

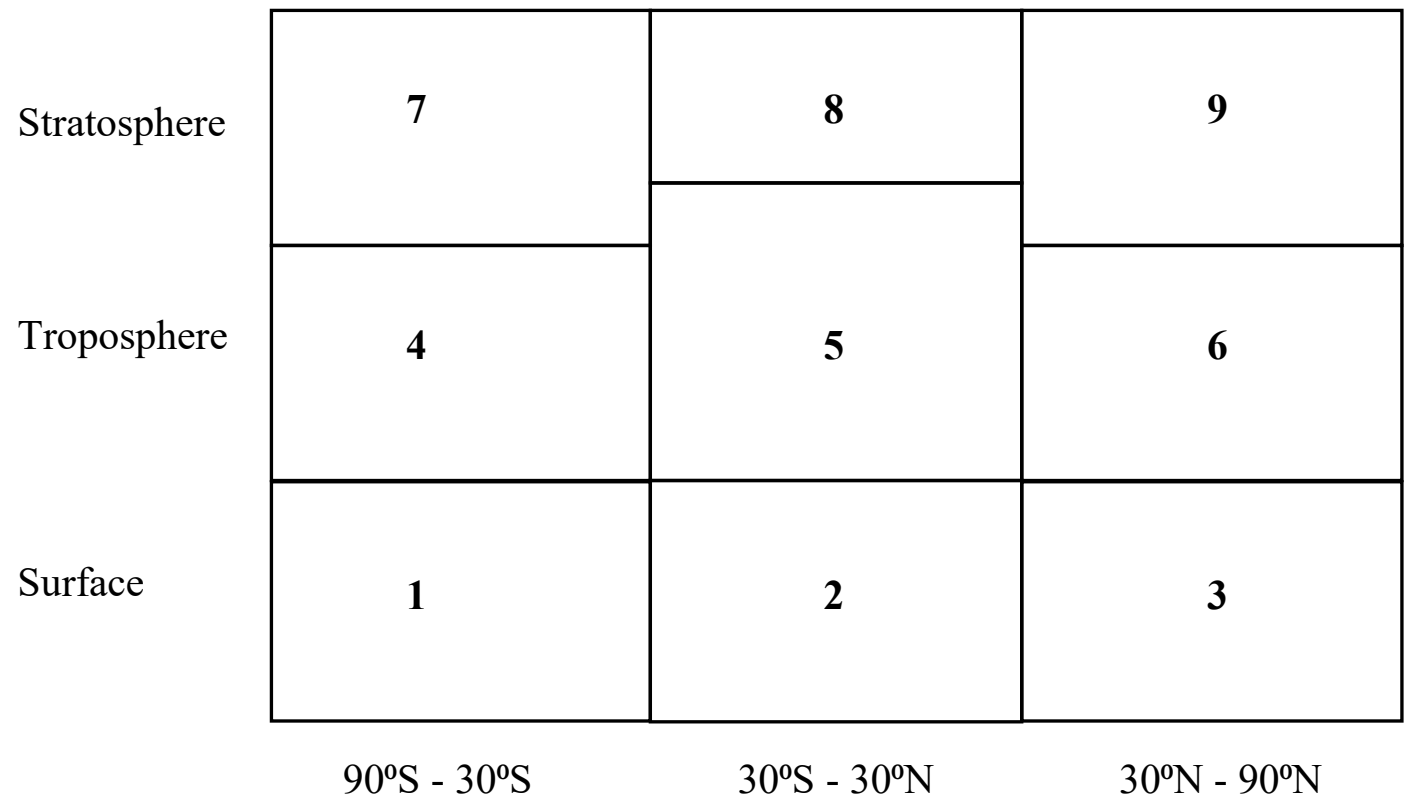

Figure 3.7 Figure illustrating the 9-box model system used in the research to calculate $\mathrm{OH}$ radical levels.

\subsection{Linkage between the use of surface and satellite datasets within the box model}

All concentration observations were averaged over their respective surface box based on their latitude. Their locations were obtained from NOAA. Each satellite measurement also contains information on its geolocation. The satellite data was categorized based on the latitude value of each measurement. The altitudes of the tropospheric regions were determined by cross-referencing the potential temperatures from the tropospheric plots to their respective altitudes, as described in section 3.6. Thus, surface and satellite datasets were compartmentalised to their respective regions based on latitude and altitude.

Since the three tracers of interest are purely anthropogenic, their emissions will take place only in the surface boxes. Once the gases are emitted into the atmosphere from the surface, they will be transported laterally and vertically. Using measurements of the concentrations on all the nine regions, it will be possible to estimate the transport rates and 
chemical losses incurred within all the boxes, especially between the surface and tropospheric regions.

\subsection{Potential biases between surface and satellite data and their impacts}

The satellite data was highly consistent with continuous measurements being made since its launch. There were no missing data for any given period of time. Multiple readings were available for each hour of each day throughout the years. However, some of the surface data obtained from NOAA were intermittent with some sites being inactive for certain periods of time halfway through, while a few others being active for only the first few years. This inconsistency was overcome by averaging the values annually and over the subset of data used in the calculation. Some of the surface sites also showed sudden and substantial spikes in the tracer levels, possibly due to being in the immediate vicinity of one or more of the tracer's sources. The spikes were so large that they could not be considered as agreeable outliers but simply be omitted. The satellite data showed no such concentration spikes.

Many validation campaigns for ACE-FTS have been conducted since its launch in 2004. The most recent work by Griffin et al., (2017) compared the measurements made by ACE-FTS with two similar instruments - Portable Atmospheric Research Interferometric Spectrometer for the InfraRed (PARIS-IR) and Bruker 125HR FTS. The measurements of eight tracers $\left(\mathrm{O}_{3}, \mathrm{HCl}, \mathrm{HNO}_{3}, \mathrm{HF}, \mathrm{CH}_{4}, \mathrm{~N}_{2} \mathrm{O}, \mathrm{CO}\right.$, and $\left.\mathrm{C}_{2} \mathrm{H}_{6}\right)$ made by all three instruments were assessed in this work. The correlation between the measurements of ACE and either of the other two for most of the species were high $(\mathrm{R} \geq 0.8)$ except for HF. The differences between ACE-FTS measurements and that of the other two were less than ACE's total retrieval uncertainty, indicating a very small potential bias. The results also showed that ACE-FTS measurements from satellite were stable between 2006 and 2013 (i.e.,) no significant increase of mean differences between said time period.

In another work by Mahieu et al., (2017) HCFC-142b vertical profiles derived from ACE-FTS were assessed against that derived from two other instruments - ground based Fourier Transform InfraRed (FTIR) and in situ surface instrument. The difference between the annual mean bias between ACE-FTS and FTIR (ACE-FTS - FTIR) was found to be $-(8 \pm 5) \%$. Similar assessments were made for ACE-FTS and surface in situ measurements where the annual mean difference (in situ measurements - ACE-FTS) was $(10 \pm 5) \%$. The annual increase

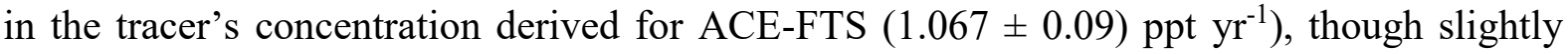

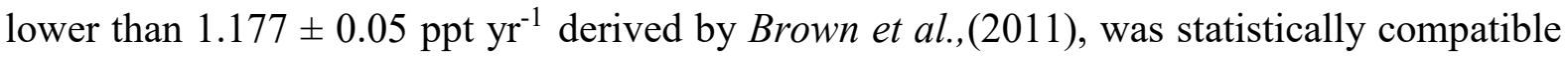


with trend obtained by FTIR. Hence, the potential biases of ACE-FTS data were found to be minimal.

\subsection{Data-driven Determination of Tropopause Height}

It is important to establish the tropopause boundary because the processing of $\mathrm{OH}$ and HCFC's in the troposphere and stratosphere are markedly different. We use a tracer correlation method to establish this boundary from the satellite data on a latitude- and season-segregated basis, resulting in enhanced accuracy in separating the two chemical regimes. This was done by plotting the $\mathrm{O}_{3}$ and HFC134a concentrations from FTS measurements for intervals of $10 \mathrm{~K}$ potential temperature readings. Ozone levels tend to be low near the surface and high above the tropopause. This is due to the fact that most of the high energy radiations from the Sun are absorbed by oxygen, ozone and other gases in the stratosphere. In the troposphere, there is significantly lower amount of UV radiation due to most of it being absorbed in the layers above it. As a result, there is a lower production and subsequently lower concentration of ozone in the troposphere. This trait of decline in ozone levels helps to mark the boundary for troposphere,

The use of HFC134a to mark the tropospheric boundary follows a rather similar principle. Since its source is from surface emissions, its concentrations would decline with increasing altitudes. So, in a concentration-altitude (x-y) plot, the values of HFC134a will be stretched out near the $\mathrm{x}$-axis at low altitudes and get closer to the $\mathrm{y}$-axis when nearing the stratosphere. On the other hand, the concentrations of ozone will be low, and its values will lie closer to the $y$-axis at low altitudes but begin to spread wider as it nears the stratosphere. So, when plotting ozone and HFC134a against each other for specific sets of altitude intervals, there will be a significant change in one interval's plots where the points plotted will appear to resemble an elbow shape. This will help to identify the boundary between the troposphere and stratosphere.

The concentrations of the gases are plotted for a set range of altitudes. The altitudes themselves are represented in terms of potential temperature.

$$
\theta=T\left(\frac{P_{0}}{P}\right)^{R / c_{p}}
$$

Where, 
$\theta$ - Potential temperature

$P_{0}-$ Standard reference pressure (taken as $1000 \mathrm{hPa}$ )

$\mathrm{P}-$ Pressure $(\mathrm{hPa})$

$\mathrm{T}$ - Temperature $(\mathrm{K})$

$\mathrm{R}$ - Gas constant of air

$c_{p}-$ Specific heat capacity

$R / c_{p}-$ value was taken as 0.286

A total of 10 plots were made (see Figure 3.7 and Appendix B), each with 10K potential temperature intervals, corresponding to certain altitudes. The $350 \mathrm{~K}-360 \mathrm{~K}$ interval had a more prominent elbow shape than the intervals just before and after. Hence, this is chosen as the altitude for tropopause. Past the 100pptv reading, the values were rounded up and hence the change in the density of the points in the plot beyond said value. The fractional values are converted to integers and hence past 100pptv, the plotted points appear in vertical lines.

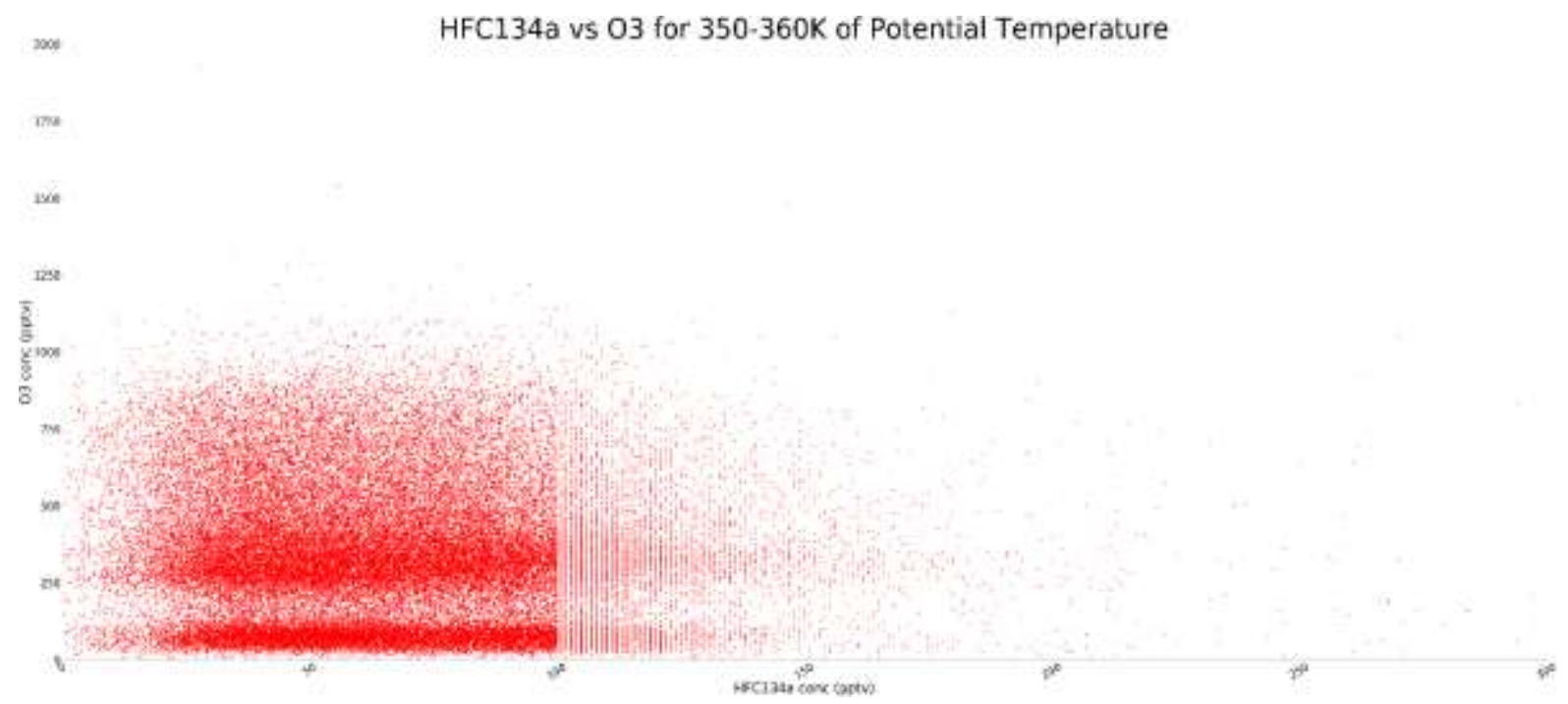

Figure $3.8 \mathrm{HFC134a}$ vs $\mathrm{O} 3$ measurements for all points measured for altitudes corresponding to potential temperatures between $350 \mathrm{~K}$ and $360 \mathrm{~K}$ from 2004 to 2020 . Plots were prepared for each $10 \mathrm{~K}$ interval of potential temperatures. Other plots obtained for different potential temperature ranges can be found in Appendix B

Another method followed a similar approach wherein the mean and standard deviation of the gases were plotted instead of the raw values. Data were categorized into bands of latitude 
and were further classified into four seasons (3 months each) in order to determine variations in the tropopause location throughout the year. Since HFC134a is synthetic, its concentrations will be greater near the surface and tend to decrease in its levels with increasing altitude. Also, it is expected to have a wider range of concentration (or higher standard deviation) along the surface and a narrowed range with corresponding increase in altitude. Ozone will have the opposite effect of HFC134a. When carefully analysing the potential temperature intervals' plots, there will be a certain range which will have a noticeable decrease in HFC134a values and a noticeable increase in ozone values. This range corresponds to the tropopause for that region and that season.

With four plots for each latitudinal band, the average of the potential temperature range was found for each band. Since the potential temperature is a function of the altitude at which the satellite measured the concentrations of the gases, the altitude that corresponds to the average of the potential temperature identified to define the tropopause is found. Generally, each $10 \mathrm{~K}$ potential temperature had not more than three altitude values in it and in all cases, the average of the altitudes was taken as the final value of the corresponding potential temperature range. The latitude bands were chosen to match the boundaries of the box model derived in Section 3.4 (see figure 3.9).

By plotting the concentrations of the two gases as such, the boundary was determined for the low, mid, and high latitudes. The altitudes corresponding to each interval were found and the average of the altitudes was taken as the final value to mark the boundary layer. For the low and high latitudes, the average stratosphere-troposphere boundary was found to be at $12.93 \mathrm{kms}$ and $12.68 \mathrm{kms}$ respectively. These values were used in the calculations. In the midlatitudes, the boundary was found to be at $16.75 \mathrm{kms}$. The corresponding plot is shown below. All plots relating to the determination of tropospheric boundary are shown in Appendix A.

Figure 3.7 shows a plot of HFC134a against ozone in the southern band for all winters from 2004 to 2020. In this plot, the mean HFC134a values drop around the $350 \mathrm{~K}-360 \mathrm{~K}$ potential temperature interval and continue to drop while the $\mathrm{O}_{3}$ mean continues to increase. This is an indicator for the tropospheric boundary or the tropopause. This potential temperature interval corresponds to an altitude of about $13.5 \mathrm{kms}( \pm 1 \mathrm{kms})$. 


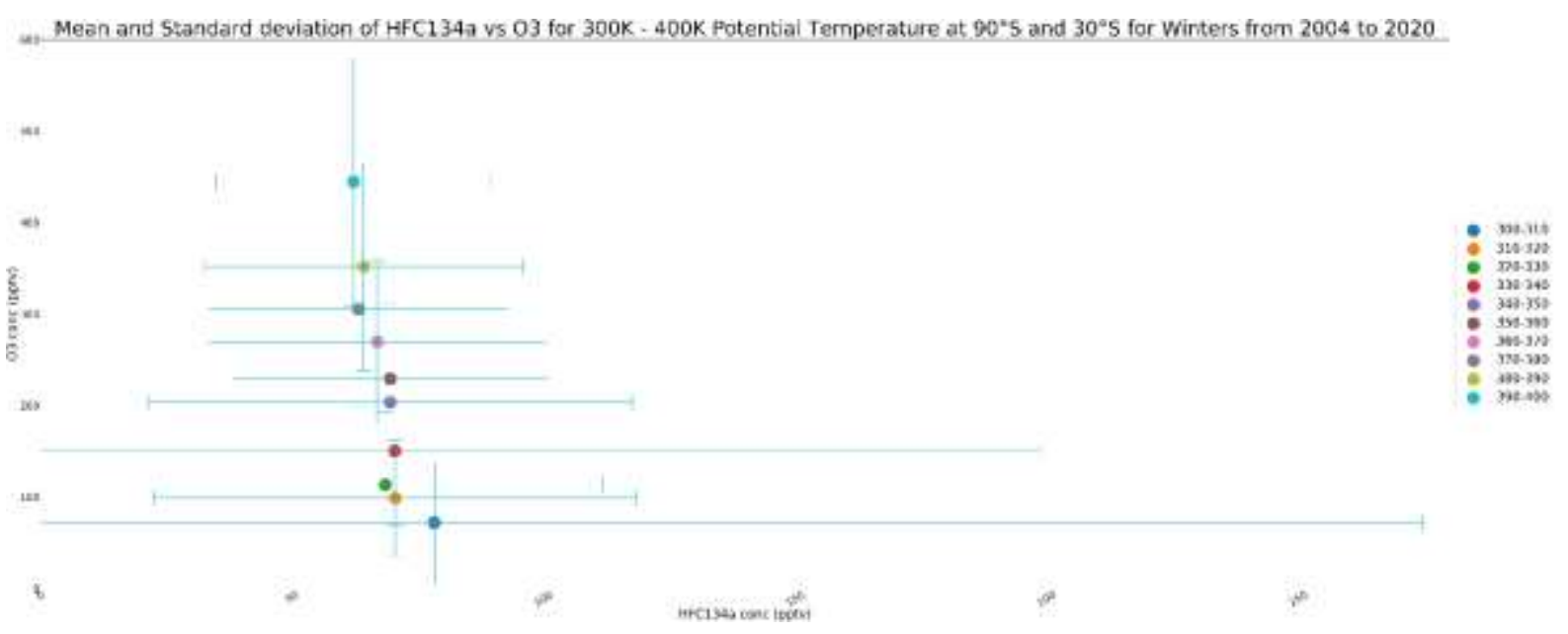

Figure 3.9 Total Means and total Standard deviations of HFC134a vs O3 concentrations as measured by ACEFTS for each $10 \mathrm{~K}$ Potential temperatures between $300 \mathrm{~K}-400 \mathrm{~K}$ Potential temperatures in the lower latitudes for all Winters from 2004 to 2020.

Similar plots were obtained by replacing HFC134a with HCFC141b and HCFC142b to prove the principle behind using these plots to define the tropospheric boundary (See Appendix B). The results obtained from all the plots were fairly similar to those obtained from HFC134a. In addition to these plots, a third type of plot was made to further check the altitude of the tropopause (see Section 4.1).

The average of the values obtained from these plots were found and are shown in Table 2. Though these values were slightly higher, they still fell within the $1 \mathrm{~km}$ altitude intervals measured by ACE-FTS.

\begin{tabular}{|c|c|c|c|}
\hline Tracer & $\mathbf{9 0}^{\mathbf{0}} \mathbf{S}-\mathbf{3 0}^{\mathbf{0}} \mathbf{S}$ & $\mathbf{3 0}^{\mathbf{0}} \mathbf{S}-\mathbf{3 0}^{\mathbf{0}} \mathbf{N}$ & $\mathbf{3 0}^{\mathbf{0}} \mathbf{N}-\mathbf{9 0}^{\mathbf{0}} \mathbf{N}$ \\
\hline HFC134a & 12 & 17 & 12 \\
\hline HCFC141b & 13 & 17 & 13 \\
\hline HCFC142b & 15 & 18 & 15 \\
\hline $\begin{array}{c}\text { Average altitude of } \\
\text { tropopause }\end{array}$ & $\mathbf{1 3 . 3 3}$ & $\mathbf{1 7 . 3 3}$ & $\mathbf{1 3 . 3 3}$ \\
\hline
\end{tabular}

Table 2 Values obtained for the plots to determine the altitude of the tropopause in $\mathrm{km}$.

\subsection{Mass Balancing}

Considering a single box model as illustrated in Figure 3.6, under non-steady state conditions, there would some residual gas of mass ' $\mathrm{m}$ ' present in it due to the difference between the sources and the sinks. The difference is given by 


$$
\frac{d m}{d t}=\mathrm{S}-\mathrm{km}
$$

Where

$\mathrm{S}$ - the sum of all sources of the gas (in $\mathrm{kg}$ )

$\mathrm{k}$ - the transport rate constant

Rearranging and integrating on both sides, we get

$$
\begin{gathered}
\int_{0}^{t} \frac{d m}{S-k m}=\int_{0}^{t} d t \\
m(t)=m(0) e^{-k t}+\frac{S}{k}\left(1-e^{-k t}\right)
\end{gathered}
$$

The function has a term describing the decaying initial value and an asymptotically decaying term representing the slow approach to steady state under the combination of a chemical sink and constant emissions source. The function is displayed graphically in Figure 3.10.

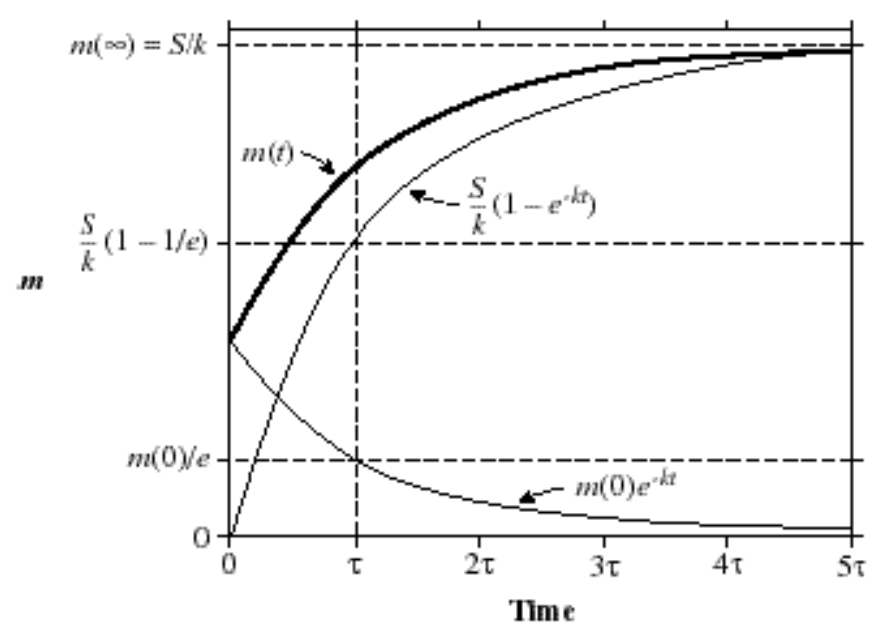

Figure 3.6 Concentration of a gas in a simple one box model with a first order loss (Jacob, 1999)

At steady state,

$$
m(\infty)=\frac{S}{k}
$$

Now, considering the two-box model system and a single tracer of mass $\mathrm{m}_{\mathrm{i}}$, where the subscript indicates the indexed box number, 


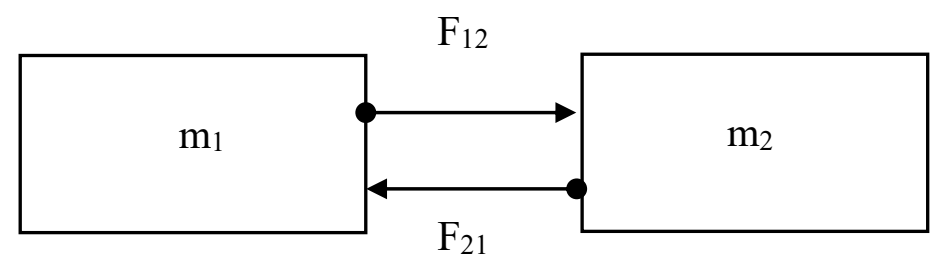

Figure 3.11 Illustration of a closed two-box model system

where $F_{i j}$ is the mass flux from box $i$ to box $j$

$$
\mathrm{F}_{\mathrm{ij}}=\mathrm{k}_{\mathrm{ij}} \cdot \mathrm{m}_{\mathrm{i}}
$$

where $\mathrm{k}_{\mathrm{ij}}$ is the mass transfer coefficient and $\mathrm{m}_{\mathrm{i}}$ is the mass box $\mathrm{i}$. For the gases under consideration, there is no chemical production within the box but there will be a chemical loss term $\left(\mathrm{C}_{\mathrm{i}}\right)$.

Eqn. (3) for box 1 becomes

$$
\frac{d m_{1}}{d t}=E_{1}-\mathrm{C}_{1}+\mathrm{F}_{21}-\mathrm{F}_{12}
$$

Replacing (9) in the above equation,

$$
\frac{d m_{1}}{d t}=E_{1}-\mathrm{C}_{1}+\mathrm{k}_{21} \mathrm{~m}_{2}-\mathrm{k}_{12} \mathrm{~m}_{1}
$$

The chemical loss is through reaction with hydroxyl radicals (See R11, R12, and R13)

$$
\mathrm{C}_{\mathrm{i}}=\mathrm{r}\left(\mathrm{T}_{\mathrm{i}}\right)\left[\mathrm{m}_{\mathrm{i}}\right] \cdot[\mathrm{moH}, \mathrm{i}]
$$

where $\mathrm{r}(\mathrm{T})$ is the temperature-dependent reaction rate constant (Burkholder et al., 2019), and the square brackets denote a number density.

Substituting $C_{i}$ in eqn (11),

$$
\begin{gathered}
\frac{d m_{1}}{d t}=E_{1}-\left(\mathrm{r}\left(\mathrm{T}_{\mathrm{i}}\right)\left[\mathrm{m}_{\mathrm{i}}\right] \cdot[\mathrm{moH}]\right)+\mathrm{k}_{21} \mathrm{~m}_{2}-\mathrm{k}_{12} \mathrm{~m}_{1} \\
\frac{d m_{1}}{d t}=E_{1}-\left[\mathrm{m}_{1}\right]\left(\mathrm{r}\left(\mathrm{T}_{\mathrm{i}}\right)\left[\mathrm{moH}_{\mathrm{OH}}\right]+\mathrm{k}_{12}\right)+\mathrm{k}_{21} \mathrm{~m}_{2}
\end{gathered}
$$

For simplicity, replace " $r\left(\mathrm{~T}_{1}\right)\left[\mathrm{m}_{\mathrm{OH}, 1}\right]+\mathrm{k}_{12}$ " by ' $\mathrm{a}_{1}$ '.

$$
\frac{d m_{1}}{d t}=E_{1}-\mathrm{a}_{1}\left[\mathrm{~m}_{1}\right]+\mathrm{k}_{21} \mathrm{~m}_{2}
$$

Rearranging and integrating on both sides, 


$$
\begin{gathered}
\int_{0}^{t} \frac{\mathrm{dm}_{1}}{\mathrm{E}-\mathrm{a}_{1}\left[m_{1}\right]+k_{21} m_{2}}=\int_{0}^{t} \mathrm{dt} \\
m_{1}(t)=m_{1}(0) e^{-a_{1} t}+\frac{\left(E_{1}+k_{21} m_{2}\right)}{\mathrm{a}_{1}}\left(1-e^{-a_{1} t}\right)
\end{gathered}
$$

Similarly, the mass balancing for box 2 will be

$$
\frac{d m_{2}}{d t}=E_{2}-\left(\mathrm{r}\left(\mathrm{T}_{2}\right) \cdot\left[\mathrm{m}_{\mathrm{HFC}} 134 \mathrm{a}\right]^{1} \cdot\left[\mathrm{moH}^{1}\right)+\mathrm{k}_{12} \mathrm{~m}_{1}-\mathrm{k}_{21} \mathrm{~m}_{2}\right.
$$

Here, $\mathrm{m}_{2}$ is simply the mass of HFC $134 \mathrm{a}$ at box 2 . So, the above equation becomes,

$$
\frac{d m_{2}}{d t}=E_{2}-\mathrm{m}_{2}\left(\mathrm{r}\left(\mathrm{T}_{2}\right)[\mathrm{moH}]+\mathrm{k}_{21}\right)+\mathrm{k}_{12} \mathrm{~m}_{1}
$$

For simplicity, replace $\left(\mathrm{r}\left(\mathrm{T}_{2}\right) .[\mathrm{moH}]+\mathrm{k}_{21}\right)$ by ' $\mathrm{a}_{2}$ '

$$
\frac{d m_{2}}{d t}=E_{2}-\mathrm{a}_{2}\left[\mathrm{~m}_{2}\right]+\mathrm{k}_{12} \mathrm{~m}_{1}
$$

Rearranging and integrating on both sides, the above equation becomes

$$
m_{2}(t)=m_{2}(0) e^{-a_{2} t}+\frac{\left(E_{2}+k_{12} m_{1}\right)}{a_{2}}\left(1-e^{-a_{2} t}\right)
$$

Now, at steady state, equations (12) and (16) become

$$
\begin{aligned}
& m_{1}(\infty)=\frac{\left(E_{1}+k_{21} m_{2}\right)}{a_{1}} \\
& m_{2}(\infty)=\frac{\left(E_{2}+k_{12} m_{1}\right)}{a_{2}}
\end{aligned}
$$

At steady state, the sources will be equal to the sinks so (dm/dt) will be equal to 0 . Equations (14) and (19) become,

$$
\begin{aligned}
& E_{1}=a_{1} m_{1}-k_{21} m_{2} \\
& E_{2}=a_{2} m_{2}-k_{12} m_{1}
\end{aligned}
$$

We can put this into matrix form:

$$
\left[\begin{array}{l}
E_{1} \\
E_{2}
\end{array}\right]=\left[\begin{array}{cc}
a_{1} & -k_{21} \\
-k_{12} & a_{2}
\end{array}\right]\left[\begin{array}{l}
m_{1} \\
m_{2}
\end{array}\right]
$$

Likewise, mass balancing for the 9-box model system can be carried out.

Let us consider multiple tracers, indicated by a subscript $\mathrm{n}$. The steady-state mass in the model will no longer be scalar and is given by 


$$
\overrightarrow{\mathrm{m}}_{\mathrm{n}}(\infty)=\frac{\left(\overrightarrow{\mathrm{E}_{\mathrm{n}}}+\overrightarrow{\mathrm{K}} \cdot \overrightarrow{\mathrm{m}_{\mathrm{n}}(\infty)}\right)}{\left(\frac{\overrightarrow{\mathrm{C}_{\mathrm{n}}}}{\mathrm{m}_{\mathrm{n}}}+\overrightarrow{\mathrm{K}^{T}}\right)}
$$

where

$\mathrm{m}_{\mathrm{n}}$ is the mass of the tracer in box $\mathrm{n}(1 \mathrm{x} 9$ matrix) (in $\mathrm{kg})$

$E_{n}$ is the emissions vector into the surface boxes (a $1 \times 9$ vector matrix)

$\mathrm{K}$ is the mass transfer coefficient matrix (a 9x9 matrix)

$\mathrm{K}^{\mathrm{T}}$ is the transpose of matrix $\mathrm{K}$

Mass of each trace gas (HFC134a, HCFC141b, and HCFC142b) (from eqn. (27)),

$$
\overrightarrow{\mathrm{m}}_{\mathrm{n}}=\frac{\left(\overrightarrow{\mathrm{E}_{\mathrm{n}}}+\overrightarrow{\mathrm{K}} \cdot \overrightarrow{\mathrm{m}_{\mathrm{n}}}\right)}{\left(\frac{\overrightarrow{\mathrm{C}_{\mathrm{n}}}}{\mathrm{m}_{\mathrm{n}}}+\overrightarrow{\mathrm{K}^{\mathrm{T}}}\right)}
$$

Solving the above equation,

$$
\begin{gathered}
\overrightarrow{\mathrm{m}}_{\mathrm{n}}\left(\overrightarrow{\frac{\mathrm{C}_{\mathrm{n}}}{\mathrm{m}_{\mathrm{n}}}}+\mathrm{K}^{\mathrm{T}}\right)=\overrightarrow{\mathrm{E}_{\mathrm{n}}}+\left(\overrightarrow{\mathrm{K}} \cdot \overrightarrow{\mathrm{m}_{\mathrm{n}}}\right) \\
\overrightarrow{\mathrm{C}_{\mathrm{n}}}+\mathrm{K}^{\mathrm{T}} \overrightarrow{\mathrm{m}}_{\mathrm{n}}=\overrightarrow{\mathrm{E}_{\mathrm{n}}}+\left(\overrightarrow{\mathrm{K}} \cdot \overrightarrow{\mathrm{m}_{\mathrm{n}}}\right) \\
\overrightarrow{\mathrm{E}_{\mathrm{n}}}=\overrightarrow{\mathrm{C}_{\mathrm{n}}}+\overrightarrow{\mathrm{m}}_{\mathrm{n}}\left[\overrightarrow{\mathrm{K}^{\mathrm{T}}}-\overrightarrow{\mathrm{K}}\right]
\end{gathered}
$$

From eqn. (12),

$$
\overrightarrow{E_{n}}=f_{n} \cdot \overrightarrow{r\left(T_{n}\right)} \cdot \overrightarrow{m_{n}} \cdot\left(\overrightarrow{m_{O H, n}}\right)+\overrightarrow{m_{n}}\left[\overrightarrow{K^{T}}-\vec{K}\right]
$$

Rearranging,

$$
\overrightarrow{E_{n}}=\left[f_{n} \cdot \overrightarrow{r\left(T_{n}\right)} \cdot\left(\overrightarrow{m_{O H, n}}\right)+\overrightarrow{K^{T}}-\vec{K}\right] \overrightarrow{m_{n}}
$$

Where $\mathrm{f}$ is a conversion factor since the unit of the reaction rate constant ' $\mathrm{r}$ ' is $\frac{\mathrm{cm}^{3}}{\text { molecule.second }}$ and that of masses of the tracer (as well as hydroxyl radical) are calculate in ' $\mathrm{kg}$ '

To solve for the conversion factor (f) for HFC134a, its unit was determined from eqn. (32)

$$
\begin{aligned}
\frac{\mathrm{kg}}{\mathrm{yr}} & =\left[f_{n} \cdot \frac{\mathrm{cm}^{3}}{\text { molecule.second }} \cdot \mathrm{kg} \cdot \mathrm{kg}\right]+\frac{\mathrm{kg}}{\mathrm{yr}} \\
1 \frac{\mathrm{cm}^{3}}{\text { molecule.second }} & =6.022 \times 10^{23} \frac{\mathrm{cm}^{3}}{\text { mol.second }}
\end{aligned}
$$




$$
\begin{aligned}
& =6.022 \times 10^{23} \frac{\mathrm{cm}^{3}}{\text { mol.second }} \times \frac{1}{102.03 \frac{\mathrm{gram}}{\mathrm{mol}}} \\
& =5.902 \times 10^{23} \frac{\mathrm{cm}^{3}}{\text { g.second }} \times \frac{60 \times 60 \times 24 \times 365.25}{1000} \frac{\text { second }}{\text { kg.year }} \\
& =1.8625 \times 10^{17} \frac{\mathrm{km}}{\mathrm{kg} \cdot y r}
\end{aligned}
$$

Substituting the above value in eqn (27),

$$
\begin{gathered}
\frac{k g}{y r}=\left[f_{n} \cdot 1.8625 \times 10^{17} \frac{\mathrm{km}^{3}}{\mathrm{~kg} \cdot \mathrm{yr}} \cdot \mathrm{kg} \cdot \mathrm{kg}\right]+\frac{\mathrm{kg}}{\mathrm{yr}} \\
\Rightarrow f_{n}=1.8625 \times 10^{17}\left(Z_{n}\right) \mathrm{km}^{-3}
\end{gathered}
$$

Where $Z_{n}$ is the inverse of the atmospheric volume of box ' $n$ '.

\section{Solving for conversion factor - surface level}

Surface area of the Earth between latitudes and longitudes is given by

$$
A=\left(\frac{\pi}{180}\right) R^{2} \mid \operatorname{Sin}(\text { lat } 1)-\operatorname{Sin}(\text { lat } 2)|| \operatorname{lon} 1-\operatorname{lon} 2 \mid
$$

Where $\mathrm{R}$ is the radius of the Earth $(\mathrm{km})$

Surface area at low-latitudes $\left(90^{\circ} \mathrm{S}-30^{\circ} \mathrm{S}\right), \mathrm{A}_{\mathrm{low}}=127.516 \times 10^{6} \mathrm{~km}^{2}$

Surface area at mid-latitudes (tropics) $\left(30^{\circ} \mathrm{S}-30^{\circ} \mathrm{N}\right), \mathrm{A}_{\text {mid }}=255.032 \times 10^{6} \mathrm{~km}^{2}$

Surface area at high-latitudes $\left(30^{\circ} \mathrm{N}-90^{\circ} \mathrm{N}\right), \mathrm{A}_{\text {high }}=127.516 \times 10^{6} \mathrm{~km}^{2}$

For the surface level, assume a height of $0.5 \mathrm{~km}$. The atmospheric volume for surface level boxes were calculated as follows.

$$
\begin{aligned}
\mathrm{V}_{\text {surface,mid }} & =\mathrm{A}_{\text {mid }} \mathrm{X} \text { height of surface level region } \\
& =\left(255.032 \times 10^{6} \mathrm{~km}^{2}\right) \times 0.5 \mathrm{~km}=127.516 \times 10^{6} \mathrm{~km}^{3} \\
\mathrm{~V}_{\text {surface,mid }}{ }^{-1} & \left.=6.846 \times 10^{-10} \mathrm{~km}^{-3} \text { (inverse of the atmospheric volume of box } 2\right)
\end{aligned}
$$

Conversion factor for box 2 ,

$$
\mathrm{f}_{\text {surface, } \operatorname{mid}}=1.8625 \times 10^{17} \times 6.846 \times 10^{-10} \mathrm{~km}^{-3}=127.506 \times 10^{6} \mathrm{~km}^{-3}
$$

Similarly,

$$
\mathrm{f}_{\text {surface, low }}=2920 \times 10^{6} \mathrm{~km}^{-3}
$$




$$
\mathrm{f}_{\text {surface,high }}=2920 \times 10^{6} \mathrm{~km}^{-3}
$$

\section{Solving for conversion factor - tropospheric regions}

With the area between the latitude bands and the height of the troposphere in the low, mid, and high latitude bands already known, the volume of the atmosphere in the troposphere and subsequently the conversion factor for these regions were calculated as follows:

$$
\begin{aligned}
& \mathrm{f}_{\text {troposphere,mid }}=44.941 \times 10^{6} \mathrm{~km}^{-3} \\
& \mathrm{f}_{\text {troposphere,low }}=117.98 \times 10^{6} \mathrm{~km}^{-3} \\
& \mathrm{f}_{\text {troposphere,high }}=120.412 \times 10^{6} \mathrm{~km}^{-3}
\end{aligned}
$$

\section{Solving for conversion factor - stratospheric regions}

The ACE-FTS measures the concentrations of gases up to altitudes of $149.5 \mathrm{~km}$. The height of the stratospheric layer was measured by simply subtracting this altitude from the known elevation of the troposphere, after which the conversion factors for each region were found through calculations similar to the above.

$$
\begin{aligned}
& \mathrm{f}_{\text {stratosphere,mid }}=6.211 \times 10^{6} \mathrm{~km}^{-3} \\
& \mathrm{f}_{\text {stratosphere,low }}=10.655 \times 10^{6} \mathrm{~km}^{-3} \\
& \mathrm{f}_{\text {stratosphere,high }}=10.636 \times 10^{6} \mathrm{~km}^{-3}
\end{aligned}
$$

Similarly, the conversion factors for each of the boxes for the gases HCFC141b and HCFC142b were calculated as follows. 
Conversion factor for all gases in each box (units: $x 10^{6} \mathrm{~km}^{-3}$ )

\begin{tabular}{|c|c|c|c|c|c|}
\hline \multirow[t]{2}{*}{ Stratosphere } & \multirow[t]{2}{*}{$\begin{array}{l}f_{H F C 134 a}=10.655 \\
f_{H C F C 141 b}=9.296 \\
f_{H C F C 142 b}=5.097\end{array}$} & \multicolumn{2}{|c|}{$\begin{aligned} f_{H F C 134 a} & =6.211 \\
f_{H C F C 141 b} & =5.419 \\
f_{H C F C 142 b} & =2.97\end{aligned}$} & \multirow[t]{2}{*}{$\begin{array}{l}f_{H F C 134 a}=10.636 \\
f_{H C F C 141 b}=9.298 \\
f_{H C F C 142 b}=5.087\end{array}$} & \multirow[b]{2}{*}{9} \\
\hline & & & & & \\
\hline Troposphere & $\begin{aligned} f_{H F C 134 a} & =117.98 \\
f_{H C F C 141 b} & =102.927 \\
f_{H C F C 142 b} & =56.436\end{aligned}$ & $\begin{array}{c}f_{H F C 134 a}=44.941 \\
f_{H C F C 141 b}=39.211 \\
f_{H C F C 142 b}=21.5\end{array}$ & 5 & $\begin{array}{l}f_{H F C 134 a}=120.412 \\
f_{H C F C 141 b}=105.05 \\
f_{H C F C 142 b}=57.603\end{array}$ & 6 \\
\hline Surface & $\begin{aligned} f_{H F C 134 a} & =2920 \\
f_{H C F C 141 b} & =2548 \\
f_{H C F C 142 b} & =2965\end{aligned}$ & $\begin{array}{c}f_{H F C 134 a}=127.516 \\
f_{H C F C 141 b}=111.247 \\
f_{H C F C 142 b}=6.01\end{array}$ & & $\begin{aligned} f_{H F C 134 a} & =2920 \\
f_{H C F C 141 b} & =2548 \\
f_{H C F C 142 b} & =2965\end{aligned}$ & 3 \\
\hline
\end{tabular}

Figure 3.7 Figure illustrating the 9 box model with conversion factors for each gas for each region.

The reaction rate constants for the three gases were taken from NASA's JPL publication (Burkholder et al., 2019). Though the rate constants for reactions (L), (M), and (N) are not pressure dependant, they are temperature dependant functions. The reaction rate constant for a tracer for a specific temperature is given by

$$
\mathrm{r}(\mathrm{T})=\mathrm{A} \times \exp (-\mathrm{E} / \mathrm{RT})
$$

where,

$\mathrm{r}(\mathrm{T})$ is the reaction rate constant for a temperature $\mathrm{T}$

$\mathrm{T}$ is the temperature of the gas at the point measured

A is the Arrhenius A-factor

$\mathrm{E} / \mathrm{R}$ is the recommended temperature dependence (or "Arrhenius activation temperature")

The values for the constants $\mathrm{A}$ and $\mathrm{E} / \mathrm{R}$ are recommended for only a certain range of temperature as shown in Table 2. Since all the points involved in the determination of $\mathrm{OH}$ levels have temperature values that fall within the ranges mentioned below, these 
recommended values are used in the calculation of temperature dependant rate constants for each point for each tracer. The values so obtained are averaged annually for each tracer and used in the calculations further below.

\begin{tabular}{|c|c|c|c|c|}
\hline Tracer & $\begin{array}{c}\text { Temperature Range of } \\
\text { Experimental Data (K) }\end{array}$ & A - Factor & E/R & $\mathbf{r ( 2 9 8 K )}$ \\
\hline HFC134a & $220-473$ & $1.03 \times 10^{-12}$ & 1620 & $4.5 \times 10^{-15}$ \\
\hline HCFC141b & $220-479$ & $1.25 \times 10^{-12}$ & 1600 & $5.8 \times 10^{-15}$ \\
\hline HCFC142b & $220-808$ & $1.3 \times 10^{-12}$ & 1770 & $3.4 \times 10^{-15}$ \\
\hline
\end{tabular}

Table 3 Values used to calculate the temperature dependant reaction rate constants for each tracer (Burkholder et al., 2019).

\section{Parameters being estimated}

Mass balance for the nine-box model system for a single tracer is given in matrix form as shown in Equation (39). The indices of the variables $\mathrm{E}$ and $\mathrm{m}$ denote the emissions (kg/year) and masses $(\mathrm{kg})$ of their respective boxes. Note that the emission values for boxes 4 to 9 are taken as zero because there are no upper air sources for these gases.

The equation so obtained will be of a linear equation form $\vec{y}=\vec{X} . \vec{m}$

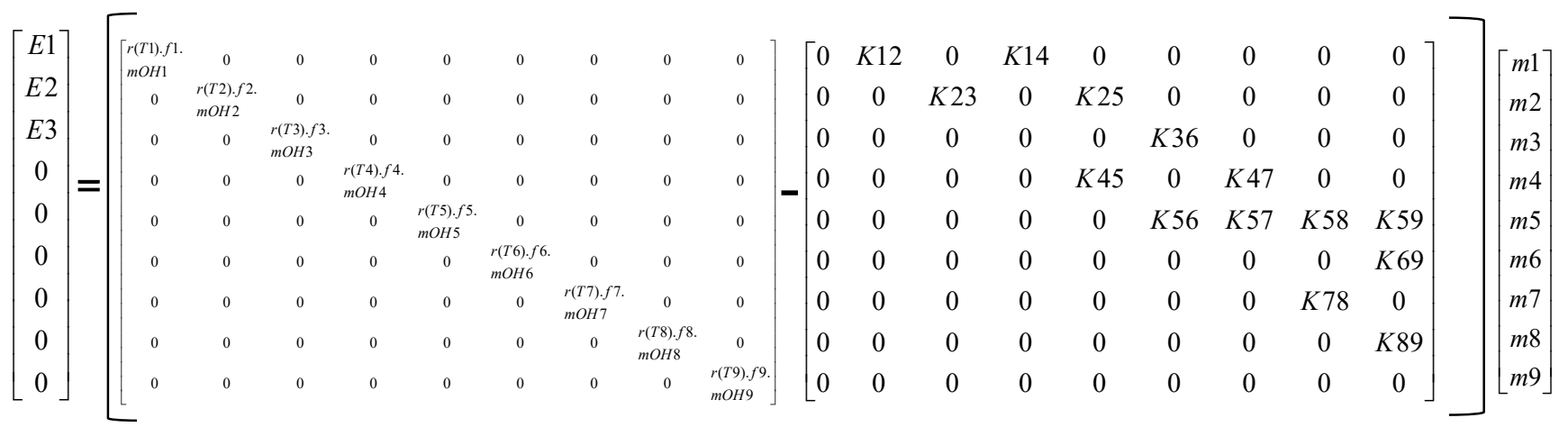

Where Kij is the net mass transfer coefficient between boxes $\mathrm{i}$ and $\mathrm{j}$. 
But since the mass of $\mathrm{OH}$ is the value to be calculated, the $\mathrm{X}$ matrix was rewritten as products of known masses. The $\mathrm{OH}$ levels, along with the net mass transfer coefficients, were placed in the predicted vector. The $\mathrm{X}$ matrix for one tracer was written as

\begin{tabular}{|c|c|c|c|c|c|c|c|c|c|c|c|c|c|c|c|c|c|c|c|c|c|c|}
\hline$r 1 . f 1 . m 1$ & 0 & 0 & 0 & 0 & 0 & 0 & 0 & 0 & $m 2$ & $m 4$ & 0 & 0 & 0 & 0 & 0 & 0 & 0 & & 0 & 0 & 0 & 0 \\
\hline 0 & $r 2 . f 2 . m 2$ & 0 & 0 & 0 & 0 & 0 & 0 & 0 & 0 & 0 & $m 3$ & $m 5$ & 0 & 0 & 0 & 0 & 0 & 0 & 0 & 0 & 0 & 0 \\
\hline 0 & 0 & $r 3 . f 3 . m 3$ & 0 & 0 & 0 & 0 & 0 & 0 & 0 & 0 & 0 & 0 & $m 6$ & 0 & 0 & 0 & 0 & 0 & 0 & 0 & 0 & 0 \\
\hline 0 & 0 & 0 & $r 4 . f 4 . m 4$ & 0 & 0 & 0 & 0 & 0 & 0 & 0 & 0 & 0 & 0 & $m 5$ & $m 7$ & 0 & 0 & 0 & 0 & 0 & 0 & 0 \\
\hline 0 & 0 & 0 & 0 & $r 5 . f 5 . m 5$ & 0 & 0 & 0 & 0 & 0 & 0 & 0 & 0 & 0 & 0 & 0 & $m 6$ & $m 7 m$ & & $m 9$ & 0 & 0 & 0 \\
\hline 0 & 0 & 0 & 0 & 0 & $r 6 . f 6 . m 6$ & 0 & 0 & 0 & 0 & 0 & 0 & 0 & 0 & 0 & 0 & 0 & 0 & 0 & 0 & $m 9$ & 0 & 0 \\
\hline 0 & 0 & 0 & 0 & 0 & 0 & $r 7 . f 7 . m 7$ & 0 & 0 & 0 & 0 & 0 & 0 & 0 & 0 & 0 & 0 & 0 & 0 & 0 & 0 & $m 8$ & 0 \\
\hline 0 & 0 & 0 & 0 & 0 & 0 & 0 & $r 8 . f 8 . m 8$ & 0 & 0 & 0 & 0 & 0 & 0 & 0 & 0 & 0 & 0 & 0 & 0 & 0 & 0 & $m 9$ \\
\hline 0 & 0 & 0 & 0 & 0 & 0 & 0 & 0 & $r 9 . f 9 . m 9$ & 0 & 0 & 0 & 0 & 0 & 0 & 0 & 0 & 0 & 0 & 0 & 0 & 0 & 0 \\
\hline
\end{tabular}

and the predictor was given as

$\left[\begin{array}{c}P 1 \\ P 2 \\ P 3 \\ \cdot \\ \cdot \\ \cdot \\ P 22 \\ P 23\end{array}\right]$

so that there were individual predictors for $\mathrm{OH}$ concentrations and net mass transport coefficients in each box in each latitudinal bands. The values P1 to P9 are estimators of $\mathrm{OH}$ levels in boxes 1 to 9 respectively while the values P10 to P23 are the estimators of the net transport coefficients between the respective boxes. The equation now is of the form $\vec{y}=\overrightarrow{X_{2}} \cdot \vec{P}$, where $\vec{P}$ is the predictor vector.

\section{Choosing the data subset}

But the rate of change of mass of the tracers $(\mathrm{dm} / \mathrm{dt})$ used in the model, $y$, is not equal to zero. The slope value $(\vec{y})$ for each box in the surface level was calculated for the time interval 2004 to 2016 where the annual increase in HFC134a (as well as HCFC141b and HCFC142b) levels were fairly linear. This was important because all three tracers showed varying rates of emissions where the concentrations of HFC134a continued to increase through 2020 whereas the concentrations of the other two tracers plateaued in the early to mid-2010s. However, all three tracers maintained a linear growth their levels from 2004 to 2016 and hence, the data for this period was chosen for $\mathrm{OH}$ estimations. Emission values of a box were calculated as the difference between 2016 levels and 2004 levels divided by the total number of years (13). The 
underlying assumption here was that the transportation and chemical losses were minimal due to their higher lifetimes.

Note that the rate of change of mass of the tracers $(\mathrm{dm} / \mathrm{dt})$ used in the model, $y$, is not equal to zero. The slope value $(\vec{y})$ for each box in the surface level was calculated for the time interval 2004 to 2016 where the annual increase in HFC134a (as well as HCFC141b and HCFC142b) levels were fairly linear. Emission value of a box was the difference between 2016 levels and 2004 levels divided by the total number of years (13). The underlying assumption here was that the transportation and chemical losses were minimal.

There were nine equations obtained for each gas making the total number of equations twenty-seven. All twenty-seven equations were stacked vertically and rearranged such that the first three rows of the matrix were made of the first three rows of HFC 134a, HCFC141b, and HCFC142b respectively, the next three rows of the matrix were made of the second rows of the tracers in the same order, and so on. With the $\mathrm{X}$ matrix finally built, the $\vec{P}$ could be calculated from the equation

$$
P=\operatorname{inv}\left(X^{\mathrm{T}} \cdot X\right) X^{\mathrm{T}}(\mathbf{y}-\mathrm{E})
$$

This is effectively a least-squares estimation of the predictor vector $\mathrm{P}$ constrained by the observed concentrations embodied in the matrix $\mathrm{X}$ and the rates of change of the concentrations.

\section{Results}

\subsection{Defining the Tropopause}

The mean annual values of each tracer just above the tropopause $(\sim 1 \mathrm{~km})$ was plotted against that of the mean annual values of the same tracer just below it $(\sim 1 \mathrm{~km})$. All plots showed very strong correlation when the proper altitude of the tropopause was used. Plotting the mean annual values of the tracers for any two altitudes below the tropopause or showed very poor correlation. However, as the altitudes near the tropopause, a strong correlation seemed to appear where the mean annual values above the tropopause were consistently higher than that below it. By looking at the altitudes where this change began to appear prominent, it was possible to discern the altitude of the tropopause. 
It was found that altitude of the tropopause obtained by all three tracers were very similar in the tropics but showed slight variations in the northern and southern bands (see Table 2). The plot for the northern band showed a substantial difference between the immediately above $(\sim 1 \mathrm{~km})$ and immediately below $(\sim 1 \mathrm{~km})$ tropopause concentrations. This could possibly be due to the fact that a majority of the sources of the gas are present in the Northern hemisphere. The same plots for the tropics and the Southern latitude bands show similar correlation. The Southern band also showed a notable difference between the concentration levels of the gases below and above the Tropopause as well (Figure 4.13) while the tropical bands showed the least difference (Figure 4.14).

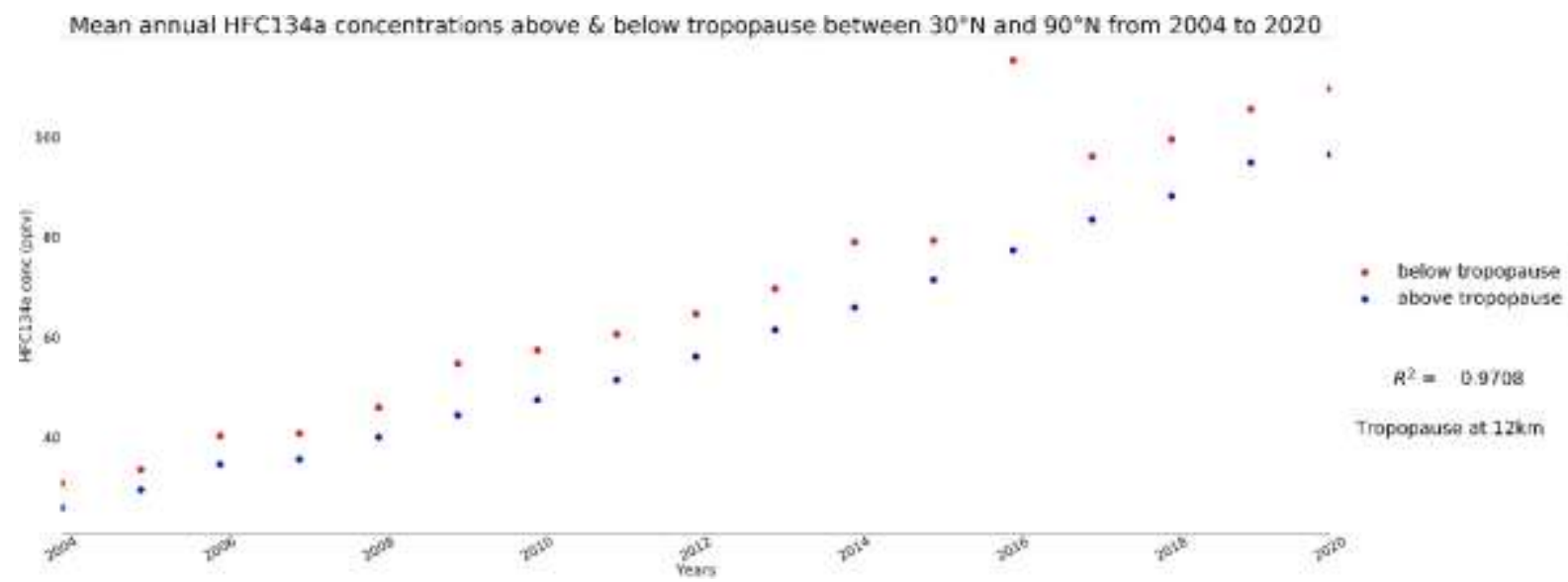

Figure 4.8 Figure showing the positive correlation between the mean annual HFC134a concentrations immediately above and below the established tropopause from 2004 to 2020 between $90^{\circ} \mathrm{N}$ and $30^{\circ} \mathrm{N}$ with an outlier at 2016

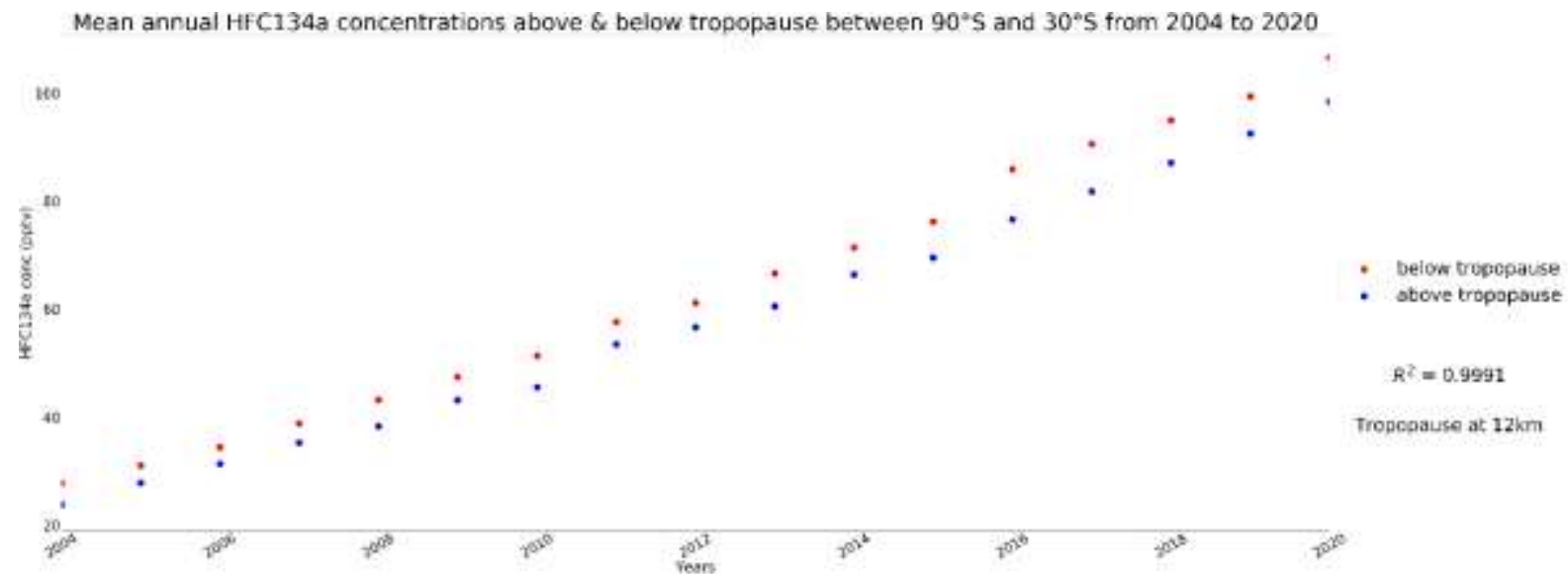

Figure 4.9 Figure showing the positive correlation between the mean annual HFC134a concentrations immediately above and below the established tropopause from 2004 to 2020 between $90^{\circ} \mathrm{S}$ and $30^{\circ} \mathrm{S}$ 


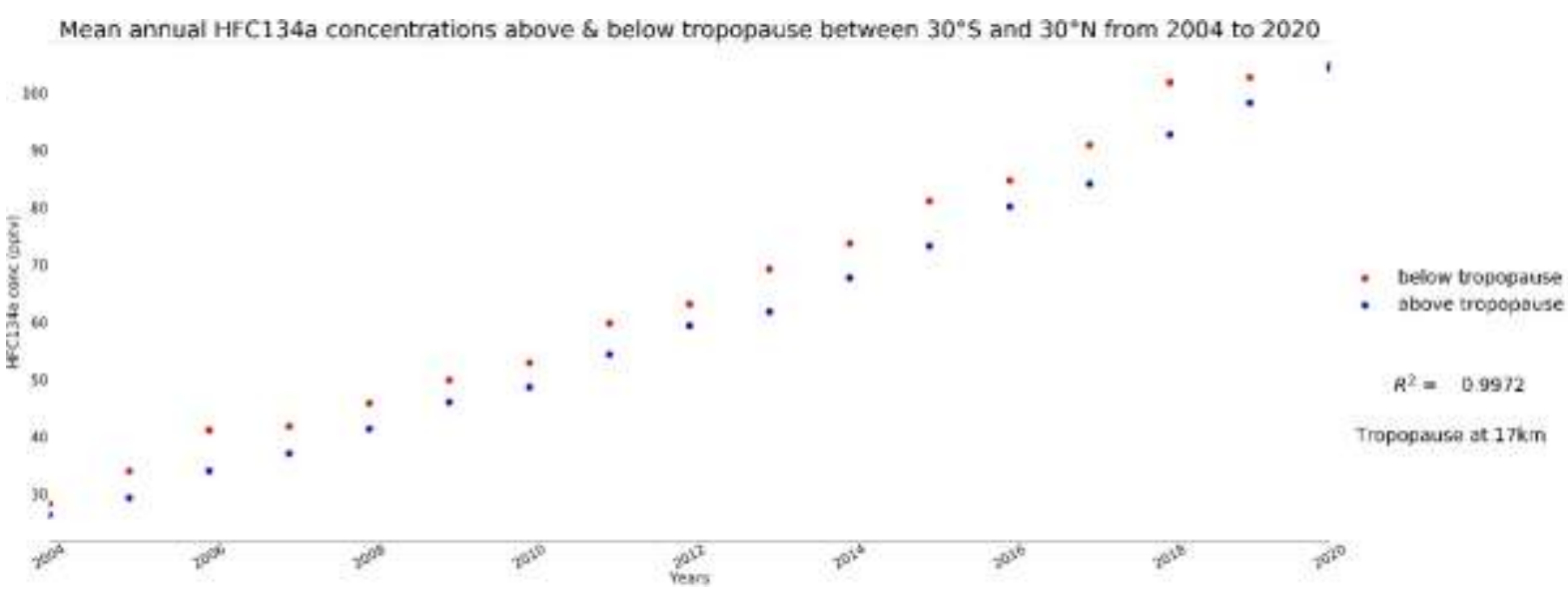

Figure 4.10 Figure showing the positive correlation between the mean annual HFC134a concentrations immediately above and below the established tropopause from 2004 to 2020 between $90^{\circ} \mathrm{N}$ and $30^{\circ} \mathrm{N}$

Similar plots were obtained for HCFC141b and HCFC142b (See Appendix C) and the average of the values was taken as the tropospheric boundary (See Table 2).

\section{Comparison of obtained values against other works}

Fueglistaler et al., (2009) showed that the tropopause over the tropics extended from $14 \mathrm{~km}$ to $18 \mathrm{kms}$ from the mean sea level. Their work suggested that the troposphere to stratosphere transition occurred in layers rather than an acute transition at a certain altitude. The results obtained from our research's tropospheric plots fall within this limit. For the purpose of the box model, the tropopause is taken as a sharp tropopause instead of a layer of atmosphere in itself.

In another work by Liu et al., (2021) the conventionally used lapse rate method was analyzed against radio occultation bending angle method. Both methods showed fairly similar results averaged over $60^{\circ}$ latitudes. The tropopause over the tropics was calculated at about $18 \mathrm{kms}$ and $17 \mathrm{kms}$ by bending angle method and lapse rate method respectively. The values for the northern and southern bands also appeared to be in line with that obtained by this research with the tracer vs $\mathrm{O}_{3}$ plots.

\subsection{Time series of the long-lived greenhouse gases used in the literature}

All data collected for this research was analysed using Python. Firstly, time series plots for all five gases involved were created to check on the general trends of the gases. Some of the sites had sporadic data either due to being inactive or due to being discontinued. Regardless, 
all data that was available was used to observe the annual trends of the gases. Some of the inferences made from these plots are as follows:

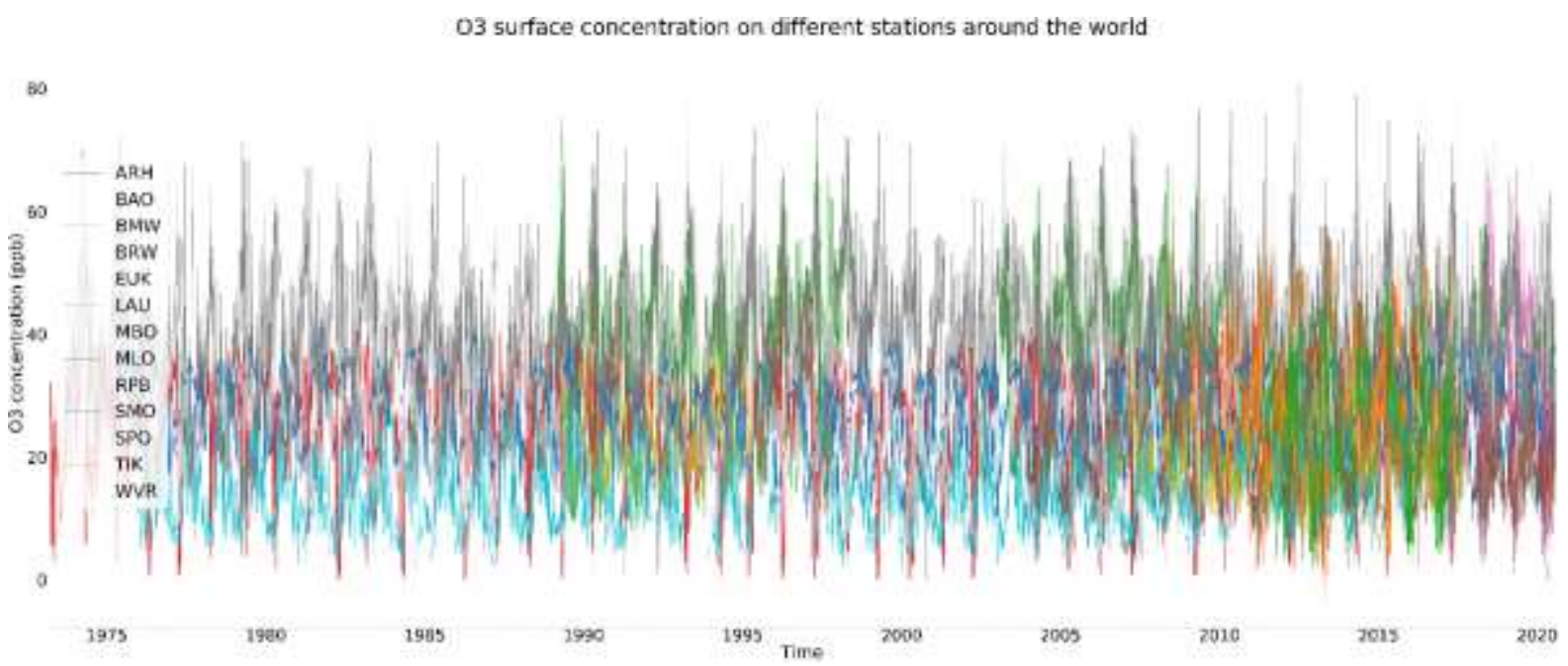

Figure 4.11 Time series plot of surface level Ozone concentrations from different sites around the world between 1975 and 2020

1. In the time series plots of surface ozone levels obtained across the world, the seasonal variations of the gas are apparent. All sites show peak concentrations in late Spring and Summer as indicated by several studies.

2. Average ozone levels in the tropics were higher than those in the southern and the northern bands (See Appendix - D). Surface ozone levels are predominantly determined by NOx levels, VOCs, temperature, and sunlight. The tropics are generally warmer, and the urban environments facilitate relatively higher levels of NOx and VOCs. A combination of all the factors may explain the higher ozone levels between $30^{\circ} \mathrm{N}$ and $30^{\circ} \mathrm{S}$. In addition, the difference in tropopause altitudes between the tropics and the northern/southern latitudes as calculated earlier shows that the atmosphere is more voluminous in the tropics and tends to decrease in volume closer to the poles. Larger atmospheric volumes do not necessarily signify higher concentrations, but this is also a small factor. Lower ozone levels in the southern band can also be attributed to lower land area compared to the northern band. Lower land area corresponds to lower urban areas as well as reduced natural and anthropogenic VOC emissions. Such circumstances inhibit ozone formation. 
3. The concentrations, however, do not follow a linear pattern and are difficult to predict with an acceptable degree of certainty. The seasonal variations were in 1987 and highest in 2012.

HFC134a surface concentration on different stations around the world

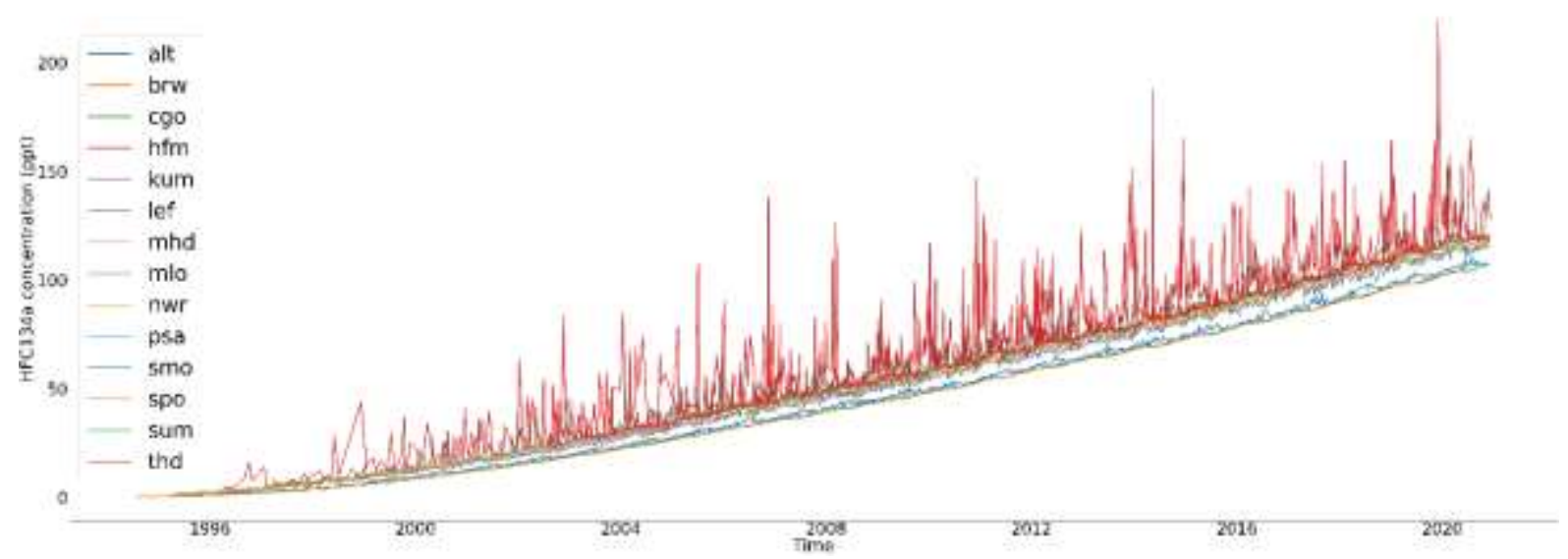

Figure 4.12 Time series plot of surface level HFC134a concentrations (in ppt) from different sites around the world from 1996 to 2020

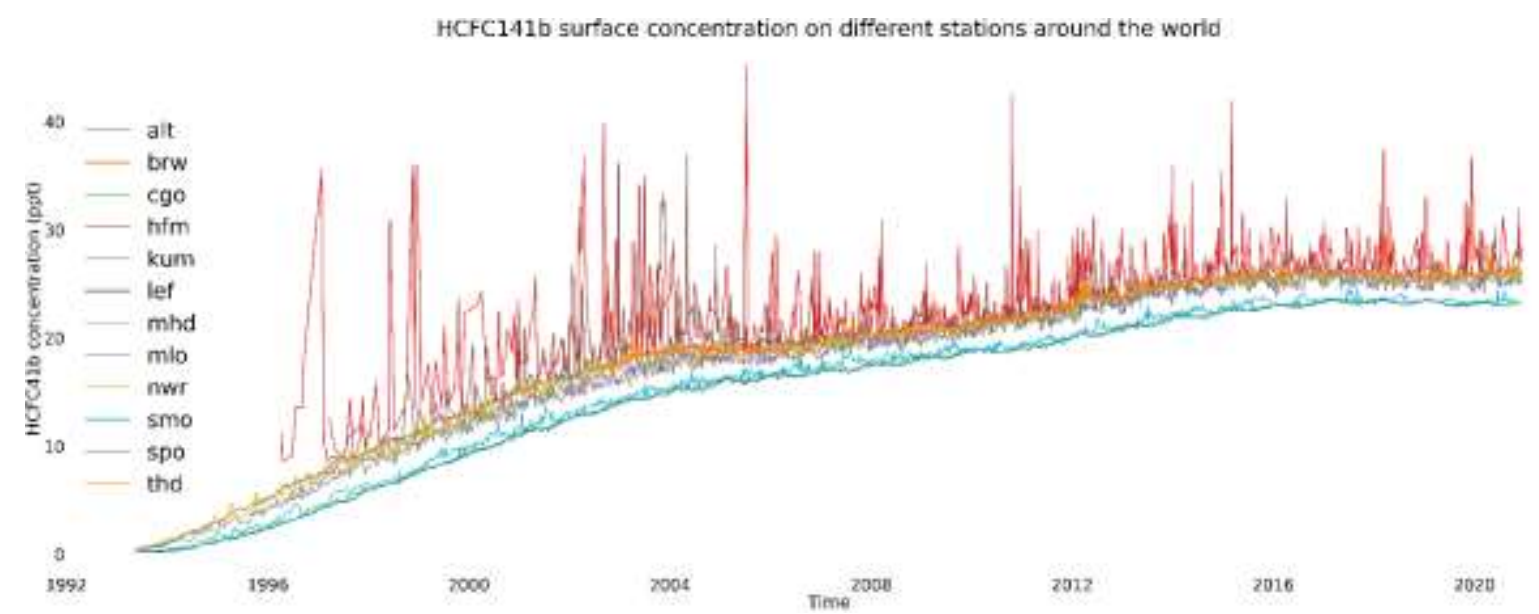

Figure 4.13 Time series plot of surface level HCFC141b concentrations (in ppt) from different sites around the world between 1992 and 2020 


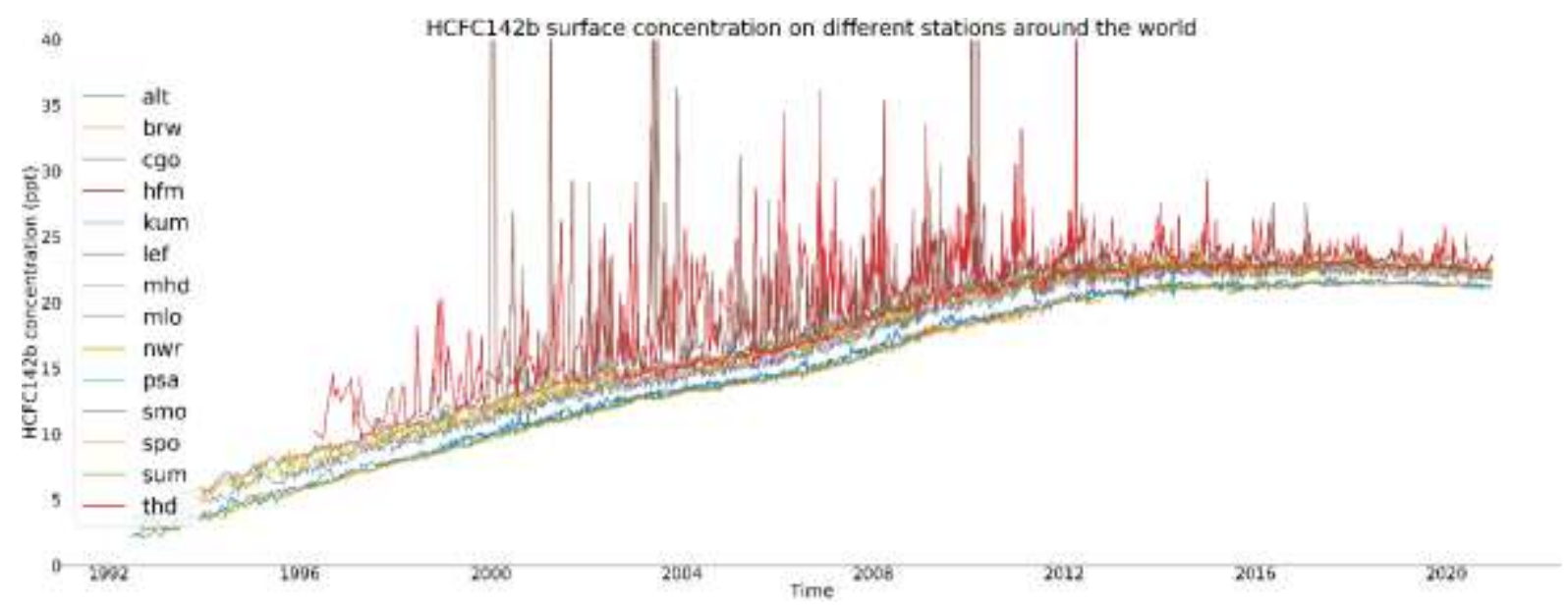

Figure 4.14 Time series plot of surface level HCFC142b concentrations (in ppt) from different sites around the world between 1992 and 2020

4. It was observed that the concentrations of all the synthetic gases increased over the years and either kept increasing or stabilised in recent years. HFC134a and HCFC141b have seen a significant increase despite the implementation of the Montreal Protocol. This could be vital in future policies and regulations for air quality and emission regulations. HFC142b, on the other hand, seemed to have stabilised emissions since 2010. It is an indicator that the regulations on this gas has had a significant effect. These time series data can not only help in understanding the efficiency of the gas regulations but also be used for atmospheric budget for scientific researches.

5. There were many extreme spikes in concentrations of HFC134a, HCFC141b, and HCFC142b gases for certain stations throughout the years. One possible explanation is the presence of one or more source of the tracers located in such way that the sites were in the immediate downwind of said source. Though peaks are normally used as outliers, these erratic and substantial concentration levels were omitted during the calculations.

6. For all the three synthetic gases, the stations in the northern hemisphere consistently showed a higher concentration compared to their counterparts in the southern hemisphere. This could be due to the fact that a majority of the gases have their sources in the northern hemisphere. Due to the slower horizontal atmospheric transport times, the southern hemisphere takes a proportionate amount of time to receive the gases from the north. In other words, it takes a certain amount of time for the southern part of the globe to reach concentrations similar to that of the northern part. This lag is consistent throughout the years for which the data was available. 


\subsection{Hydroxyl level estimations from box model}

The results were calculated for each region of the atmosphere defined by the model. The following is a summary of the obtained values and a comparison against other literature values:

1. The 9-box model was successfully created with boundaries clearly defined for each box using methods stated earlier. The horizontal extent of each of the box is $60^{\circ}$ latitude each. The vertical extent of the surface boxes was taken as $0.5 \mathrm{~km}$ while the tropospheric boundary for each of the bin was determined on a case-by-case basis. The troposphere over the tropics is relatively larger than that over the northern and southern bands because of the higher temperature closer to the equator. This high temperature pushes the Brewer-Dobson circulation cells to higher altitudes to cool down.

2. Surface levels show the most agreeable results among the other two domains when compared to previous studies and simulations. The atmosphere over the tropics has a higher $\mathrm{OH}$ concentration due to higher temperatures and higher water vapour levels compared to the northern and southern regions. Both high temperature and high water vapour concentrations are essential for the production of hydroxyl radicals and both get lower with increasing distance from the equator. This model clearly predicts the higher decadal average levels, especially in the tropics. The northern latitude band obtained a surface concentration of $1 \times 10^{5}$ molecules $/ \mathrm{cm}^{3}$ but the observed value over that region was $3.4 \times 10^{5}$ molecules $/ \mathrm{cm}^{3}$ (Holland et al., 1995). Similarly, the southern surface region showed a lower value of $1.2 \times 10^{5}$ molecules $/ \mathrm{cm}^{3}$ while it was expected to have around $3.5 \times 10^{5}$ molecules $/ \mathrm{cm}^{3}$ (Creasey, 2003). All three regions showed values much lower than that observed by other literature.

3. The tropospheric region shows the most discrepancy. The $\mathrm{OH}$ level obtained for tropical troposphere is much lower, at $0.56 \times 10^{5}$ molecules $/ \mathrm{cm}^{3}$ when it is supposed to have values around $14.6 \times 10^{5}$ molecules $/ \mathrm{cm}^{3}$ (Lelieveld et al., 2016). The $\mathrm{OH}$ levels obtained for the northern and the southern troposphere were $2.55 \times 10^{5}$ molecules $/ \mathrm{cm}^{3}$ and $1.47 \times 10^{5}$ molecules $/ \mathrm{cm}^{3}$ respectively, lower than the expected levels of $9.1 \times 10^{5}$ molecules $/ \mathrm{cm}^{3}$ and $6.6 \times 10^{5}$ molecules $/ \mathrm{cm}^{3}$ respectively (Lelieveld et al., 2016). The significantly lower value for box 5 is a clear indication that the 9-box model misrepresented one or more of the net transport coefficients. Box 5 has a total of 6 net transport coefficients (from eqn. (39)), the highest among all other boxes. It is possible that the uncertainty in each of the variables added up to such an extent that the obtained 
value was much lower than that obtained by several other models and approaches. Observing boxes 1,2 , and 3 , it is plausible that lower numbers of net transport coefficients would provide better results.

4. Though there is an abundance of high energy radiation from the Sun at higher altitudes, there is also a limited supply of water vapour. Consequently, $\mathrm{OH}$ concentrations in the defined stratospheric region (and above) will be lower than the tropospheric $\mathrm{OH}$ levels. Conventional values are around $1 \times 10^{5}$ molecules $/ \mathrm{cm}^{3}$ (Li et al., 2018) but since the vertical extent of the three regions used in the box model is approximately $135 \mathrm{kms}$, the average values obtained from this model could be closer to observed values. In addition, there were lower net transport coefficients in the upper boxes and hence it is possible that the obtained average $\mathrm{OH}$ values for those regions are close to the observed values.

\subsection{Limitation of the model}

As mentioned earlier, the estimates obtained from this model are lower than those obtained from other works by varying magnitudes. It is evident that the model misrepresented one or more of the variables (chemical losses and/or net transport coefficients). There is a certain degree of uncertainty associated with each of the net transport coefficients as well as the chemical losses. These uncertainties get compounded with a greater number of variables and can have a notable effect on the final estimates. But the decadal average approach used in this research does not include these uncertainties in the calculations. Hence the final estimates are not close to those obtained in other works. This research did not calculate the uncertainties of any of the variables.

\section{Conclusion}

Data on gas measurements of all tracers obtained from NOAA and ACE-FTS were analysed to check for the annual trends. This gave a comprehensive understanding on the implications of regulations imposed on HFC134a, HCFC141b, and HCFC142b from Montreal Protocol. The data was also used to determine the tropospheric boundary. The synthetic gases were plotted against ozone and all three gases indicated similar altitudes for the tropopause. With the tropopause defined, the gas levels were used in a 9-box model to calculate hydroxyl radical concentrations. To summarise: 
- The satellite profile observations obtained from ACE-FTS were separated into points and categorized into troposphere and stratosphere based on their chemical characteristics. The tropospheric boundary so obtained by the observation-based method for the lower, mid, and high latitudes were $12.93 \mathrm{~km}, 16.75 \mathrm{~km}$, and $12.68 \mathrm{~km}$ respectively from the mean sea level. The values correlate well with the traditional methods used to define the same. Tropopause over the tropics has a higher altitude compared to its northern and southern counterparts as confirmed by several works.

- Mean hydroxyl radical concentrations were estimated for each of the boxes by estimating the chemical losses and the losses through transportation. The box model made fairly good estimates in the lower and upper boxes. The tropospheric regions had poor estimates, with $2.55 \times 10^{5}$ molecules $/ \mathrm{cm}^{3}, 0.56 \times 10^{5}$ molecules $/ \mathrm{cm}^{3}$, and $1.47 \mathrm{x}$ $10^{5}$ molecules $/ \mathrm{cm}^{3}$ for the northern, tropical, and southern regions respectively. All values were lower than the conventionally observed values with the tropics lower by a factor of 40-50. The lower domain of the atmosphere as defined by the box model showed the closest estimate of surface global average of the regions around $2.5 \times 10^{5}$ molecules $/ \mathrm{cm}^{3}$ with the observed values being around $3.5 \times 10^{5}$ molecules $/ \mathrm{cm}^{3}$. Obtained stratospheric $\mathrm{OH}$ levels had a global average of $0.08 \times 10^{5}$ molecules $/ \mathrm{cm}^{3}$. Conventional values for these regions are 12 times higher, in the order of $1 \times 10^{5}$ molecules $/ \mathrm{cm}^{3}$. Future works will be undertaken to get estimates closer to the observed values.

\section{Future works:}

Future works involving a time evolving model could help to calculate the uncertainties in the variables in the system. In said model, the selected subset of years will be divided further into smaller time periods and estimates will be made for each of the variables for each time period in the system. The values so obtained will be analysed to see how they evolve over time. This would give a better understanding of the uncertainty involved in each of the variable and eventually aid in providing estimates closer to the observed values. 


\section{REFERENCES}

About Canada's SCISAT satellite. (2003, July 1). Retrieved from https://www.asccsa.gc.ca/eng/satellites/scisat/about.asp.

Amedro, D., Miyazaki, K., Parker, A., Schoemaecker, C., \& Fittschen, C. (2012). Atmospheric and kinetic studies of $\mathrm{OH}$ and $\mathrm{HO} 2$ by the FAGE technique. Journal of Environmental Sciences, 24(1), 78-86. https://doi.org/10.1016/S1001-0742(11)60723-7

Ananthaswamy, H. N. (1997). Mechanisms of induction of skin cancer by UV radiation. Frontiers in Bioscience, 2(4), d538-551. https://doi.org/10.2741/A211

Aprea, C., Greco, A., \& Maiorino, A. (2018). HFOs and their binary mixtures with HFC134a working as drop-in refrigerant in a household refrigerator: Energy analysis and environmental impact assessment. Applied Thermal Engineering, 141, 226-233. https://doi.org/10.1016/j.applthermaleng.2018.02.072

Bernath, P. F. (2005). Atmospheric Chemistry Experiment (ACE): Mission overview. Geophysical Research Letters, 32(15), L15S01. https://doi.org/10.1029/2005GL022386

Berntsen, T. K., Fuglestvedt, J. S., Joshi, M. M., Shine, K. P., Stuber, N., Ponater, M., Sausen, R., Hauglustaine, D. A., \& Li, L. (2005). Response of climate to regional emissions of ozone precursors: Sensitivities and warming potentials. Tellus B: Chemical and Physical Meteorology, 57(4), 283-304. https://doi.org/10.3402/tellusb.v57i4.16549

Bischoff, S. A., Canziani, P. O., \& Yuchechen, A. E. (2007). The tropopause at southern extratropical latitudes: Argentine operational rawinsonde climatology. International Journal of Climatology, 27(2), 189-209. https://doi.org/10.1002/joc.1385

Bloss, W. J., Gravestock, T. J., Heard, D. E., Ingham, T., Johnson, G. P., \& Lee, J. D. (2003). Application of a compact all solid-state laser system to the in situ detection of atmospheric $\mathrm{OH}, \mathrm{HO} 2, \mathrm{NO}$ and IO by laser-induced fluorescence. Journal of Environmental Monitoring, 5(1), 21-28. https://doi.org/10.1039/b208714f 
Brown, A. T., Chipperfield, M. P., Boone, C., Wilson, C., Walker, K. A., \& Bernath, P. F. (2011). Trends in atmospheric halogen containing gases since 2004. Journal of Quantitative Spectroscopy and Radiative Transfer, 112(16), 2552-2566. https://doi.org/10.1016/j.jqsrt.2011.07.005

Chadyšiene, R., Girgždiene, R., \& Girgždys, A. (2005). ULTRAVIOLET RADIATION AND GROUND-LEVEL OZONE VARIATION IN LITHUANIA. JOURNAL OF ENVIRONMENTAL ENGINEERING AND LANDSCAPE MANAGEMENT, 13(1), 31-36. https://doi.org/10.3846/16486897.2005.9636843

Creasey, D. J. (2003). Measurements of $\mathrm{OH}$ and $\mathrm{HO}_{2}$ concentrations in the Southern Ocean marine boundary layer. Journal of Geophysical Research, 108(D15), 4475. https://doi.org/10.1029/2002JD003206

Dalsøren, S. B., Myhre, C. L., Myhre, G., Gomez-Pelaez, A. J., Søvde, O. A., Isaksen, I. S. A., Weiss, R. F., \& Harth, C. M. (2016). Atmospheric methane evolution the last 40 years. Atmospheric Chemistry and Physics, 16(5), 3099-3126. https://doi.org/10.5194/acp-16-3099-2016

El-Nouby Adam, M. (2011). Effect of The Atmosphere on UVB Radiation Reaching the Earth's Surface: Dependence on Solar Zenith Angle. Atmospheric and Oceanic Science Letters, 4(3), 139-145. https://doi.org/10.1080/16742834.2011.11446918

Emmerson, K. M., Carslaw, N., Carslaw, D. C., Lee, J. D., McFiggans, G., Bloss, W. J., Gravestock, T., Heard, D. E., Hopkins, J., Ingham, T., Pilling, M. J., Smith, S. C., Jacob, M., \& Monks, P. S. (2007). Free radical modelling studies during the UK TORCH Campaign in Summer 2003. Atmospheric Chemistry and Physics, 7(1), 167-181. https://doi.org/10.5194/acp-7-167-2007 Fernando, A. M., Bernath, P. F., \& Boone, C. D. (2019). Trends in atmospheric HFC-23 (CHF3) and HFC-134a abundances. Journal of Quantitative Spectroscopy and Radiative Transfer, 238, 106540. https://doi.org/10.1016/j.jqsrt.2019.06.019

Fiore, A. M., Jacob, D. J., Field, B. D., Streets, D. G., Fernandes, S. D., \& Jang, C. (2002). Linking ozone pollution and climate change: The case for controlling methane: LINKING OZONE POLLUTION AND CLIMATE CHANGE. Geophysical Research Letters, 29(19), 25-1-25-4.

https://doi.org/10.1029/2002GL015601 
Fuchs, H., Holland, F., \& Hofzumahaus, A. (2008). Measurement of tropospheric RO2 and HO2 radicals by a laser-induced fluorescence instrument. Review of Scientific Instruments, 79(8), 084104. https://doi.org/10.1063/1.2968712

Fueglistaler, S., Dessler, A. E., Dunkerton, T. J., Folkins, I., Fu, Q., \& Mote, P. W. (2009). Tropical tropopause layer. Reviews of Geophysics, 47(1), RG1004.

https://doi.org/10.1029/2008RG000267

Fuglestvedt, J. (1999). Climatic forcing of nitrogen oxides through changes in tropospheric ozone and methane; global 3D model studies. Atmospheric Environment, 33(6), 961-977. https://doi.org/10.1016/S1352-2310(98)00217-9

Griffin, D., Walker, K. A., Conway, S., Kolonjari, F., Strong, K., Batchelor, R., Boone, C. D., Dan, L., Drummond, J. R., Fogal, P. F., Fu, D., Lindenmaier, R., Manney, G. L., \& Weaver, D. (2017). Multi-year comparisons of ground-based and space-borne Fourier transform spectrometers in the high Arctic between 2006 and 2013. Atmospheric Measurement Techniques, 10(9), 3273-3294. https://doi.org/10.5194/amt-10-3273-2017

Hard, T. M., O’Brien, R. J., Chan, C. Y., \& Mehrabzadeh, A. A. (1984). Tropospheric free radical determination by fluorescence assay with gas expansion. Environmental Science \& Technology, 18(10), 768-777. https://doi.org/10.1021/es00128a009

Hoell, J. M., Gregory, G. L., Carroll, M. A., McFarland, M., Ridley, B. A., Davis, D. D., Bradshaw, J., Rodgers, M. O., Torres, A. L., Sachse, G. W., Hill, G. F., Condon, E. P., Rasmussen, R. A., Campbell, M. C., Farmer, J. C., Sheppard, J. C., Wang, C. C., \& Davis, L. I. (1984). An intercomparison of carbon monoxide, nitric oxide, and hydroxyl measurement techniques: Overview of results. Journal of Geophysical Research, 89(D7), 11819. https://doi.org/10.1029/JD089iD07p11819

Hoesly, R. M., Smith, S. J., Feng, L., Klimont, Z., Janssens-Maenhout, G., Pitkanen, T., Seibert, J. J., Vu, L., Andres, R. J., Bolt, R. M., Bond, T. C., Dawidowski, L., Kholod, N., Kurokawa, J., Li, M., Liu, L., Lu, Z., Moura, M. C. P., O’Rourke, P. R., \& Zhang, Q. (2018). Historical (1750-2014) 
anthropogenic emissions of reactive gases and aerosols from the Community Emissions Data System (CEDS). Geoscientific Model Development, 11(1), 369-408.

https://doi.org/10.5194/gmd-11-369-2018

Jackson, L. S., Carslaw, N., Carslaw, D. C., \& Emmerson, K. M. (2009). Modelling trends in OH radical concentrations using generalized additive models. Atmospheric Chemistry and Physics, 9(6), 2021-2033. https://doi.org/10.5194/acp-9-2021-2009

Jacob, D. J. (1999). Introduction to atmospheric chemistry. Princeton University Press.

Johnson, F. S., Mo, T., \& Green, A. E. S. (1976). AVERAGE LATITUDINAL VARIATION IN ULTRAVIOLET RADIATION AT THE EARTH'S SURFACE. Photochemistry and Photobiology, 23(3), 179-188. https://doi.org/10.1111/j.1751-1097.1976.tb07239.x

Kirschke, S., Bousquet, P., Ciais, P., Saunois, M., Canadell, J. G., Dlugokencky, E. J., Bergamaschi, P., Bergmann, D., Blake, D. R., Bruhwiler, L., Cameron-Smith, P., Castaldi, S., Chevallier, F., Feng, L., Fraser, A., Heimann, M., Hodson, E. L., Houweling, S., Josse, B., ... Zeng, G. (2013). Three decades of global methane sources and sinks. Nature Geoscience, 6(10), 813-823. https://doi.org/10.1038/ngeo1955

Krol, M. C., Lelieveld, J., Oram, D. E., Sturrock, G. A., Penkett, S. A., Brenninkmeijer, C. A. M., Gros, V., Williams, J., \& Scheeren, H. A. (2003). Continuing emissions of methyl chloroform from Europe. Nature, 421(6919), 131-135. https://doi.org/10.1038/nature01311

Kurtenbach, R., Becker, K. H., Gomes, J. A. G., Kleffmann, J., Lörzer, J. C., Spittler, M., Wiesen, P., Ackermann, R., Geyer, A., \& Platt, U. (2001). Investigations of emissions and heterogeneous formation of HONO in a road traffic tunnel. Atmospheric Environment, 35(20), 3385-3394. https://doi.org/10.1016/\$1352-2310(01)00138-8

Lelieveld, J., Dentener, F. J., Peters, W., \& Krol, M. C. (2004). On the role of hydroxyl radicals in the self-cleansing capacity of the troposphere. Atmospheric Chemistry and Physics, 4(9/10), 2337-2344. https://doi.org/10.5194/acp-4-2337-2004 
Lelieveld, J., Gromov, S., Pozzer, A., \& Taraborrelli, D. (2016). Global tropospheric hydroxyl distribution, budget and reactivity. Atmospheric Chemistry and Physics, 16(19), 1247712493. https://doi.org/10.5194/acp-16-12477-2016

Levy, H. (1971). Normal atmosphere: Large radical and formaldehyde concentrations predicted. Science (New York, N.Y.), 173(3992), 141-143. https://doi.org/10.1126/science.173.3992.141

Li, M., Karu, E., Brenninkmeijer, C., Fischer, H., Lelieveld, J., \& Williams, J. (2018). Tropospheric OH and stratospheric $\mathrm{OH}$ and $\mathrm{Cl}$ concentrations determined from $\mathrm{CH} 4, \mathrm{CH} 3 \mathrm{Cl}$, and $\mathrm{SF} 6$ measurements. Npj Climate and Atmospheric Science, 1(1), 29. https://doi.org/10.1038/s41612-018-0041-9

Liang, Q., Chipperfield, M. P., Fleming, E. L., Abraham, N. L., Braesicke, P., Burkholder, J. B., Daniel, J. S., Dhomse, S., Fraser, P. J., Hardiman, S. C., Jackman, C. H., Kinnison, D. E., Krummel, P. B., Montzka, S. A., Morgenstern, O., McCulloch, A., Mühle, J., Newman, P. A., Orkin, V. L., ... Weiss, R. F. (2017). Deriving Global OH Abundance and Atmospheric Lifetimes for Long-Lived Gases: A Search for $\mathrm{CH}_{3} \mathrm{CCl}_{3}$ Alternatives: $\mathrm{CH}_{3} \mathrm{CCl}_{3}$ Alternatives for $\mathrm{OH}$ Estimate. Journal of Geophysical Research: Atmospheres, 122(21), 11,914-11,933. https://doi.org/10.1002/2017JD026926

Liu, Z., Sun, Y., Bai, W., Xia, J., Tan, G., Cheng, C., Du, Q., Wang, X., Zhao, D., Tian, Y., Meng, X., Liu, C., Cai, Y., \& Wang, D. (2021). Comparison of RO tropopause height based on different tropopause determination methods. Advances in Space Research, 67(2), 845-857. https://doi.org/10.1016/j.asr.2020.10.023

Mahieu, E., Lejeune, B., Bovy, B., Servais, C., Toon, G. C., Bernath, P. F., Boone, C. D., Walker, K. A., Reimann, S., Vollmer, M. K., \& O’Doherty, S. (2017). Retrieval of HCFC-142b (CH 3 CCIF 2 ) from ground-based high-resolution infrared solar spectra: Atmospheric increase since 1989 and comparison with surface and satellite measurements. Journal of Quantitative 
Spectroscopy and Radiative Transfer, 186, 96-105.

https://doi.org/10.1016/j.jqsrt.2016.03.017

Mather, J. H., Stevens, P. S., \& Brune, W. H. (1997). OH and $\mathrm{HO}_{2}$ measurements using laser-induced fluorescence. Journal of Geophysical Research: Atmospheres, 102(D5), 6427-6436. https://doi.org/10.1029/96JD01702

Matsumoto, J., Imai, H., Kosugi, N., \& Kajii, Y. (2005). In situ measurement of N2O5 in the urban atmosphere by thermal decomposition/laser-induced fluorescence technique. Atmospheric Environment, 39(36), 6802-6811. https://doi.org/10.1016/j.atmosenv.2005.07.055

McCONNELL, J. C., \& Schiff, H. I. (1978). Methyl Chloroform: Impact on Stratospheric Ozone. Science, 199(4325), 174-177. https://doi.org/10.1126/science.199.4325.174

Midgley, P., \& Mcculloch, A. (1995). The production and global distribution of emissions to the atmosphere of 1,1,1-trichloroethane (methyl chloroform). Atmospheric Environment, 29(14), 1601-1608. https://doi.org/10.1016/1352-2310(95)00078-D

Montzka, S. A., Krol, M., Dlugokencky, E., Hall, B., Jockel, P., \& Lelieveld, J. (2011). Small Interannual Variability of Global Atmospheric Hydroxyl. Science, 331(6013), 67-69. https://doi.org/10.1126/science.1197640

Murray, L. T., Mickley, L. J., Kaplan, J. O., Sofen, E. D., Pfeiffer, M., \& Alexander, B. (2014). Factors controlling variability in the oxidative capacity of the troposphere since the Last Glacial Maximum. Atmospheric Chemistry and Physics, 14(7), 3589-3622. https://doi.org/10.5194/acp-14-3589-2014

Myhre, G., Shindell, D., Bréon, F.-M., Collins, W., Fuglestvedt, J., Huang, J., Koch, D., Lamarque, J.-F., Lee, D., Mendoza, B., Nakajima, T., Robock, A., Stephens, G., Zhang, H., Aamaas, B., Boucher, O., Dalsøren, S. B., Daniel, J. S., Forster, P., ... Shine, K. (2013). 8 Anthropogenic and Natural Radiative Forcing. Cambridge University Press, Cambridge, United Kingdom and New York, NY, USA, 82. 
Naik, V., Voulgarakis, A., Fiore, A. M., Horowitz, L. W., Lamarque, J.-F., Lin, M., Prather, M. J., Young, P. J., Bergmann, D., Cameron-Smith, P. J., Cionni, I., Collins, W. J., Dalsøren, S. B., Doherty, R., Eyring, V., Faluvegi, G., Folberth, G. A., Josse, B., Lee, Y. H., ... Zeng, G. (2013). Preindustrial to present-day changes in tropospheric hydroxyl radical and methane lifetime from the Atmospheric Chemistry and Climate Model Intercomparison Project (ACCMIP). Atmospheric Chemistry and Physics, 13(10), 5277-5298. https://doi.org/10.5194/acp-13-5277-2013

Nisbet, E. G., Manning, M. R., Dlugokencky, E. J., Fisher, R. E., Lowry, D., Michel, S. E., Myhre, C. L., Platt, S. M., Allen, G., Bousquet, P., Brownlow, R., Cain, M., France, J. L., Hermansen, O., Hossaini, R., Jones, A. E., Levin, I., Manning, A. C., Myhre, G., ... White, J. W. C. (2019). Very Strong Atmospheric Methane Growth in the 4 Years 2014-2017: Implications for the Paris Agreement. Global Biogeochemical Cycles, 33(3), 318-342.

https://doi.org/10.1029/2018GB006009

Park, M., Randel, W. J., Kinnison, D. E., Garcia, R. R., \& Choi, W. (2004). Seasonal variation of methane, water vapor, and nitrogen oxides near the tropopause: Satellite observations and model simulations: SEASONAL CONSTITUENT VARIABILITY NEAR THE TROPOPAUSE. Journal of Geophysical Research: Atmospheres, 109(D3), n/a-n/a. https://doi.org/10.1029/2003JD003706

Rigby, M., Montzka, S. A., Prinn, R. G., White, J. W. C., Young, D., O’Doherty, S., Lunt, M. F., Ganesan, A. L., Manning, A. J., Simmonds, P. G., Salameh, P. K., Harth, C. M., Mühle, J., Weiss, R. F., Fraser, P. J., Steele, L. P., Krummel, P. B., McCulloch, A., \& Park, S. (2017). Role of atmospheric oxidation in recent methane growth. Proceedings of the National Academy of Sciences, 114(21), 5373-5377. https://doi.org/10.1073/pnas.1616426114

Saunois, M., Stavert, A. R., Poulter, B., Bousquet, P., Canadell, J. G., Jackson, R. B., Raymond, P. A., Dlugokencky, E. J., Houweling, S., Patra, P. K., Ciais, P., Arora, V. K., Bastviken, D., Bergamaschi, P., Blake, D. R., Brailsford, G., Bruhwiler, L., Carlson, K. M., Carrol, M., ... 
Zhuang, Q. (2020). The Global Methane Budget 2000-2017. Earth System Science Data, 12(3), 1561-1623. https://doi.org/10.5194/essd-12-1561-2020

Schmidt, T., Beyerle, G., Heise, S., Wickert, J., \& Rothacher, M. (2006). A climatology of multiple tropopauses derived from GPS radio occultations with CHAMP and SAC-C. Geophysical Research Letters, 33(4), L04808. https://doi.org/10.1029/2005GL024600

Seidel, D. J., \& Randel, W. J. (2006). Variability and trends in the global tropopause estimated from radiosonde data. Journal of Geophysical Research, 111(D21), D21101. https://doi.org/10.1029/2006JD007363

Shindell, D. T., Faluvegi, G., Bell, N., \& Schmidt, G. A. (2005). An emissions-based view of climate forcing by methane and tropospheric ozone: EMISSIONS-BASED CLIMATE FORCING. Geophysical Research Letters, 32(4), n/a-n/a. https://doi.org/10.1029/2004GL021900

Simmonds, P. G., Rigby, M., McCulloch, A., O’Doherty, S., Young, D., Mühle, J., Krummel, P. B., Steele, P., Fraser, P. J., Manning, A. J., Weiss, R. F., Salameh, P. K., Harth, C. M., Wang, R. H. J., \& Prinn, R. G. (2017). Changing trends and emissions of hydrochlorofluorocarbons (HCFCs) and their hydrofluorocarbon (HFCs) replacements. Atmospheric Chemistry and Physics, 17(7), 4641-4655. https://doi.org/10.5194/acp-17-4641-2017

Toon, G. C., Liebe, C. C., Nemati, B., Harris, I., Kleinböhl, A., Allen, M., Hipkin, V., Drummond, J., Soucy, M., Yung, Y. L., Zeng, Z., Wunch, D., \& Wennberg, P. O. (2019). Solar Occultation FTIR Spectrometry at Mars for Trace Gas Detection: A Sensitivity Study. Earth and Space Science, 6(5), 836-860. https://doi.org/10.1029/2018EA000469

Velders, G. J. M., Andersen, S. O., Daniel, J. S., Fahey, D. W., \& McFarland, M. (2007). The importance of the Montreal Protocol in protecting climate. Proceedings of the National Academy of Sciences, 104(12), 4814-4819. https://doi.org/10.1073/pnas.0610328104

Wild, O., Prather, M. J., \& Akimoto, H. (2001). Indirect long-term global radiative cooling from NO $x$ Emissions. Geophysical Research Letters, 28(9), 1719-1722.

https://doi.org/10.1029/2000GL012573 
Zhou, M., Langerock, B., Vigouroux, C., Sha, M. K., Ramonet, M., Delmotte, M., Mahieu, E., Bader, W., Hermans, C., Kumps, N., Metzger, J.-M., Duflot, V., Wang, Z., Palm, M., \& De Mazière, M. (2018). Atmospheric $\mathrm{CO}$ and $\mathrm{CH} 4$ time series and seasonal variations on Reunion Island from ground-based in situ and FTIR (NDACC and TCCON) measurements. Atmospheric Chemistry and Physics, 18(19), 13881-13901. https://doi.org/10.5194/acp-18-13881-2018 


\section{APPENDIX - A}

Mean apd Standard deviation of HFC134a vs 03 for 300K - 400K Potential Temperatures between $30^{\circ} \mathrm{S}$ and $30^{\circ} \mathrm{N}$ for Winters from 2004 to 2020

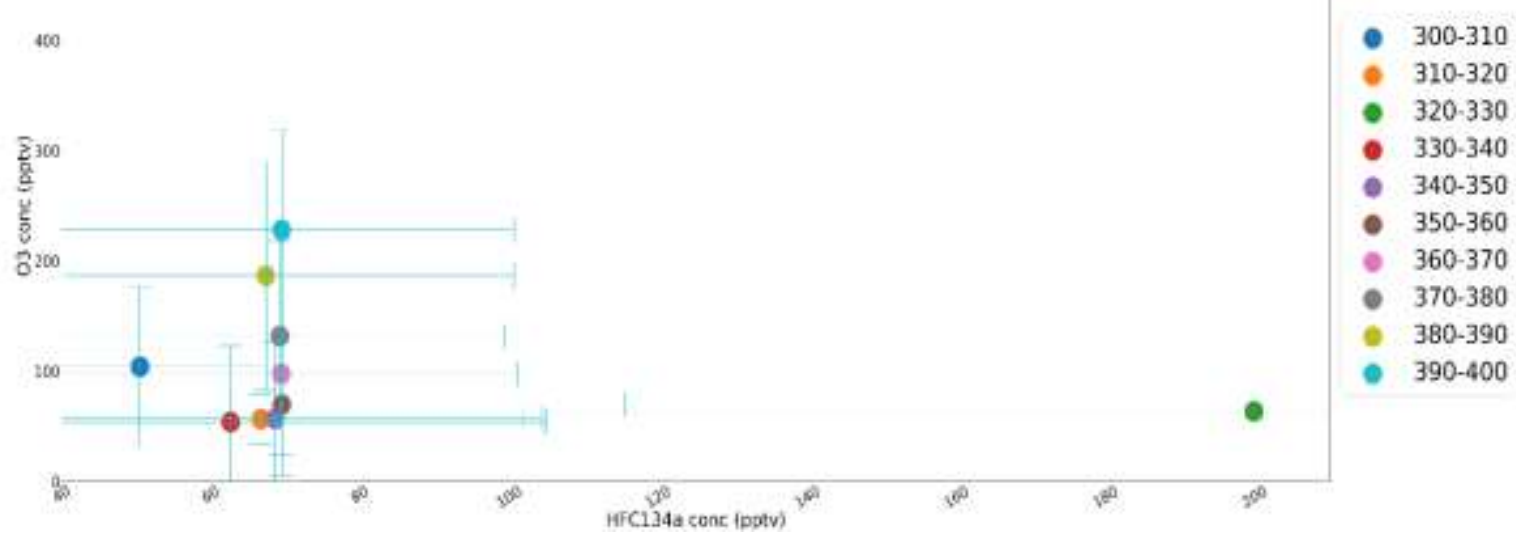

Figure A1 Total Means and total Standard deviations of HFC134a vs O3 for each 10K Potential temperatures between 300K-400K Potential temperatures in the Tropics for all Winters from 2004 to 2020

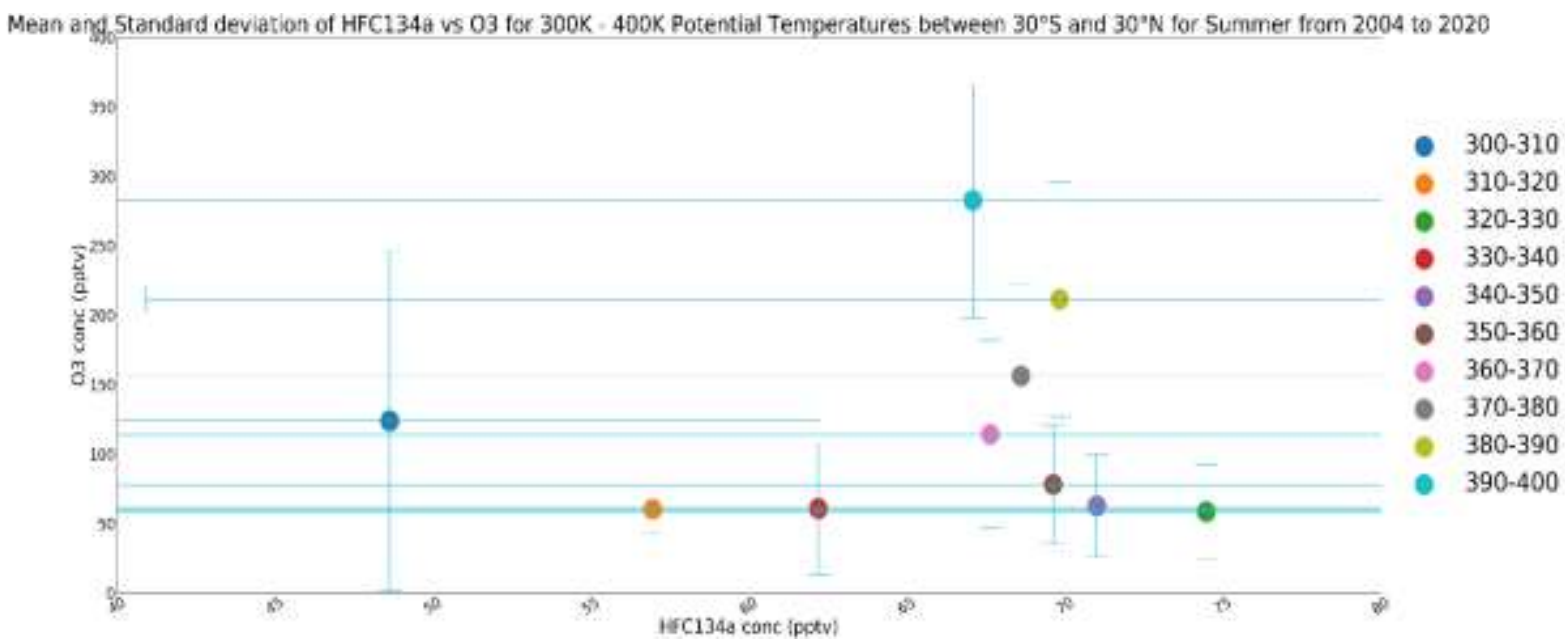

Figure A2 Total Means and total Standard deviations of HFC134a vs O3 for each 10K Potential temperatures between 300K-400K Potential temperatures in the Tropics for all Summers from 2004 to 2020 


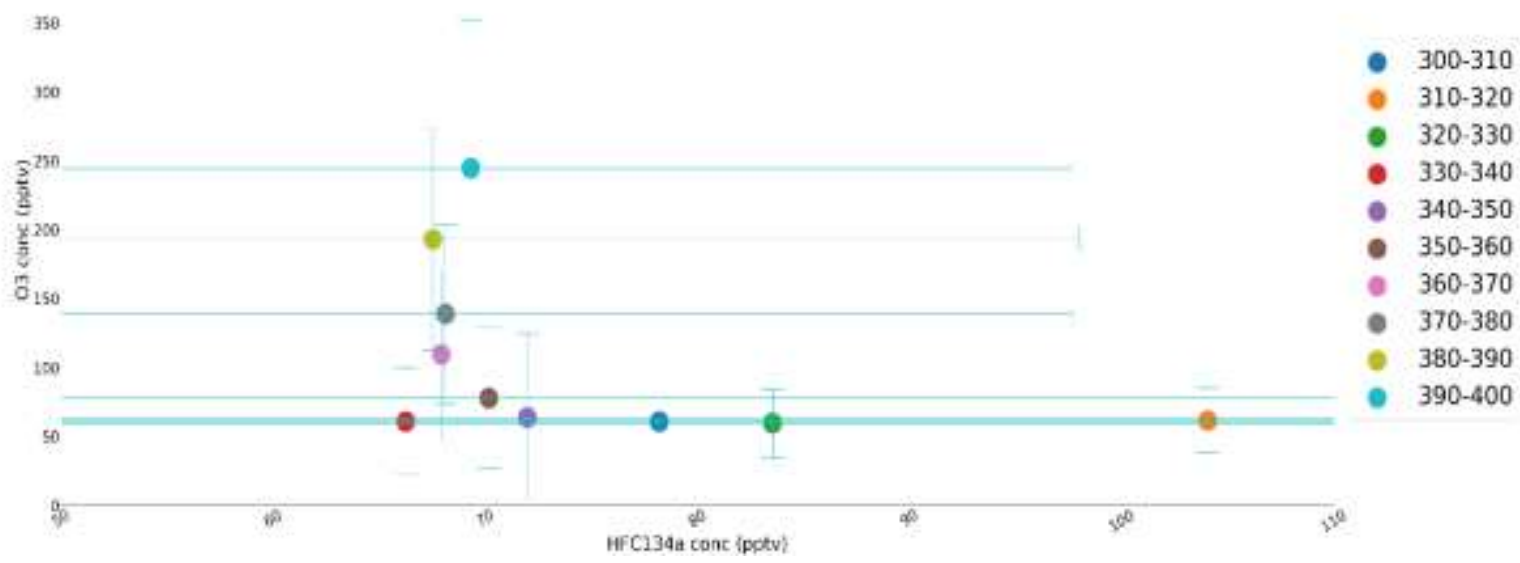

Figure A3 Total Means and total Standard deviations of HFC134a vs O3 for each 10K Potential temperatures between 300K-400K Potential temperatures in the Tropics for all Springs from 2004 to 2020

Mean and Standard deviation of HFC134a vs 03 for 300K - 400K Potential Temperatures between $30^{\prime} \$$ and $30^{\circ} \mathrm{N}$ for Fall from 2004 to 2020

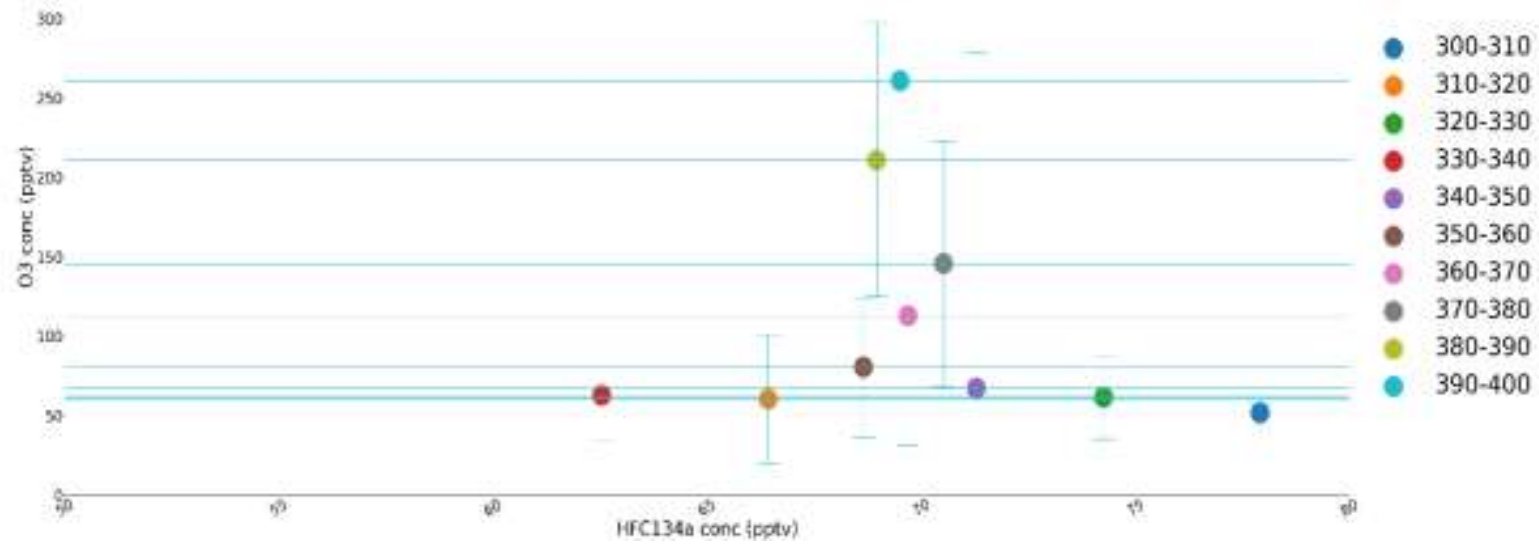

Figure A4 Total Means and total Standard deviations of HFC134a vs O3 for each 10K Potential temperatures between 300K-400K Potential temperatures in the Tropics for all Fall seasons from 2004 to 2020 


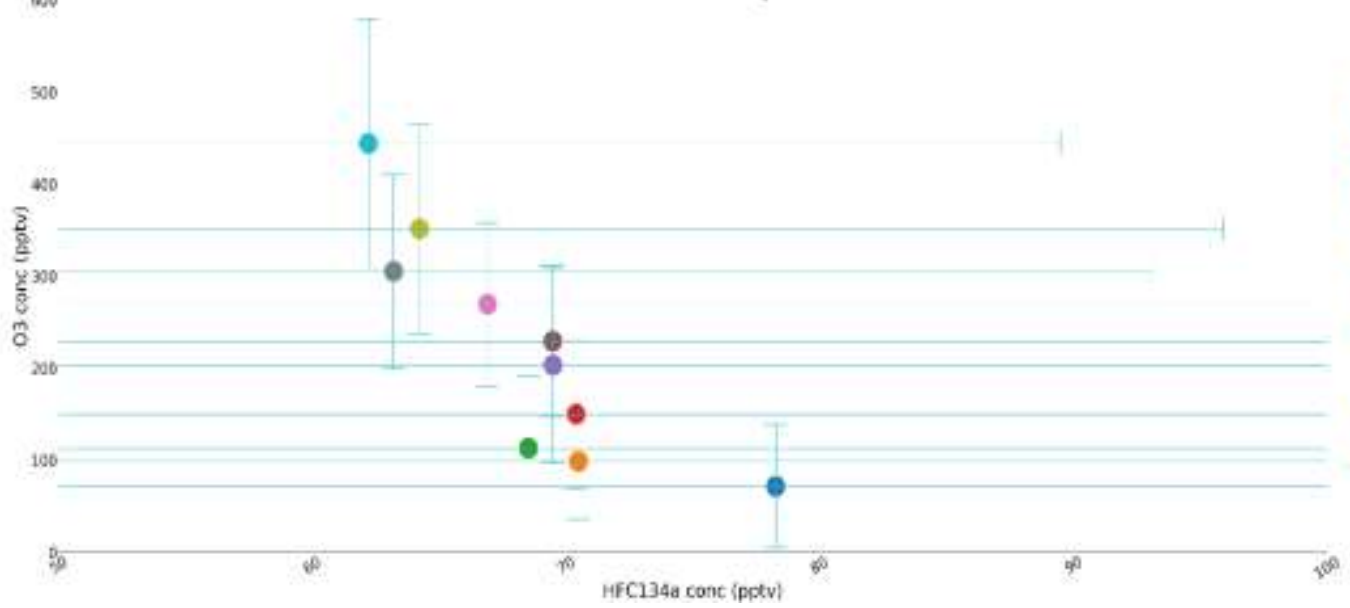

Figure A5 Total Means and total Standard deviations of HFC134a vs O3 for each 10K Potential temperatures between $300 \mathrm{~K}-400 \mathrm{~K}$ Potential temperatures in the lower latitudes for all Winters from 2004 to 2020

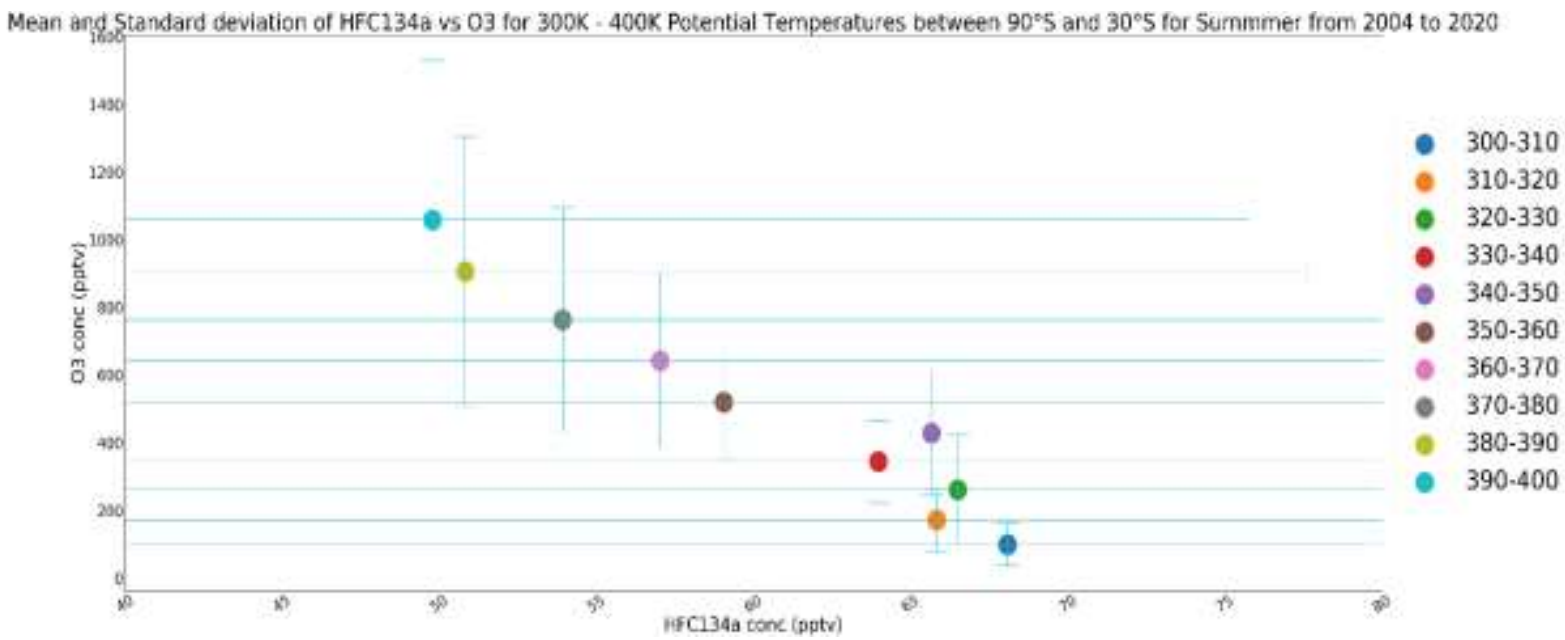

Figure A6 Total Means and total Standard deviations of HFC134a vs O3 for each 10K Potential temperatures between $300 \mathrm{~K}-400 \mathrm{~K}$ Potential temperatures in the lower latitudes for all Summers from 2004 to 2020 


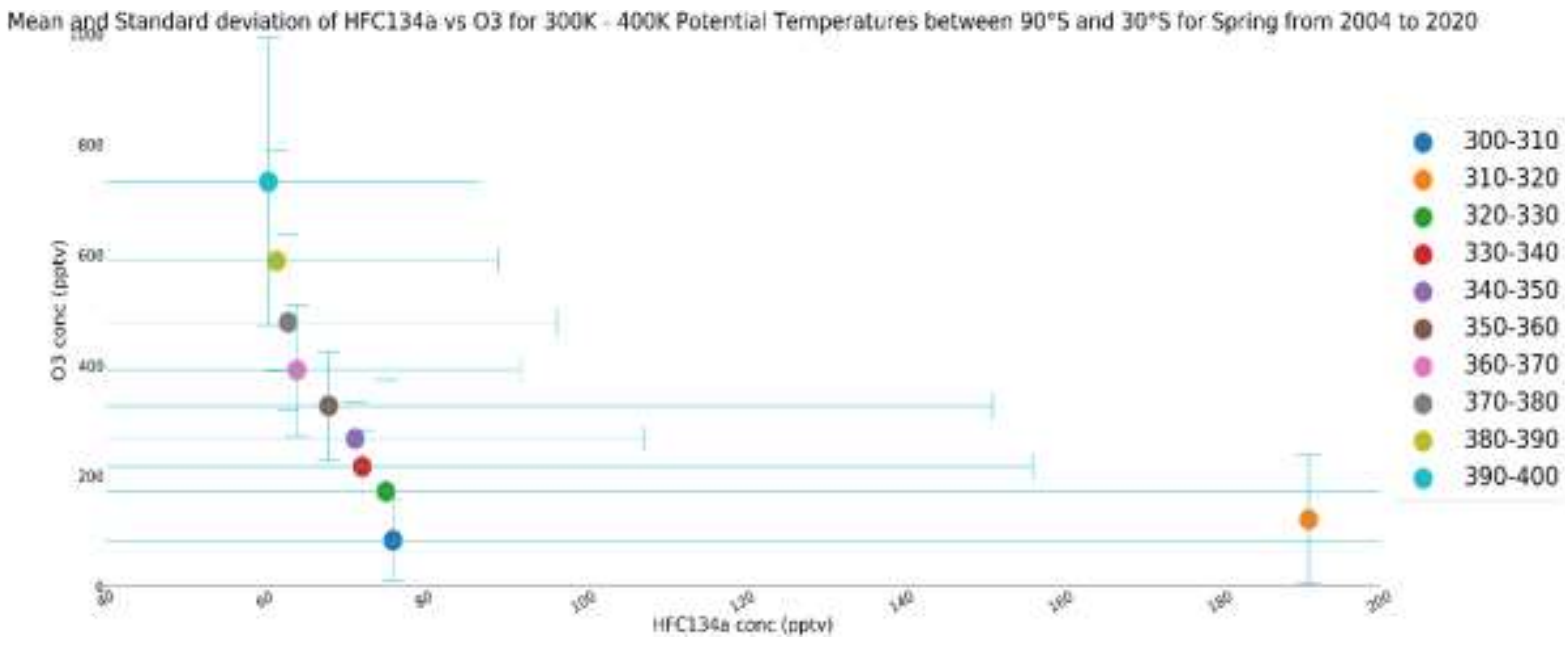

Figure A7 Total Means and total Standard deviations of HFC134a vs O3 for each 10K Potential temperatures between $300 \mathrm{~K}-400 \mathrm{~K}$ Potential temperatures in the lower latitudes for all Springs from 2004 to 2020

Mean and Standard deviation of HFC134a vs 03 for 300K - 400K. Potential Temperatures between $90^{\circ} 5$ and $30^{\circ} 5$ for Fall from 2004 to 2020

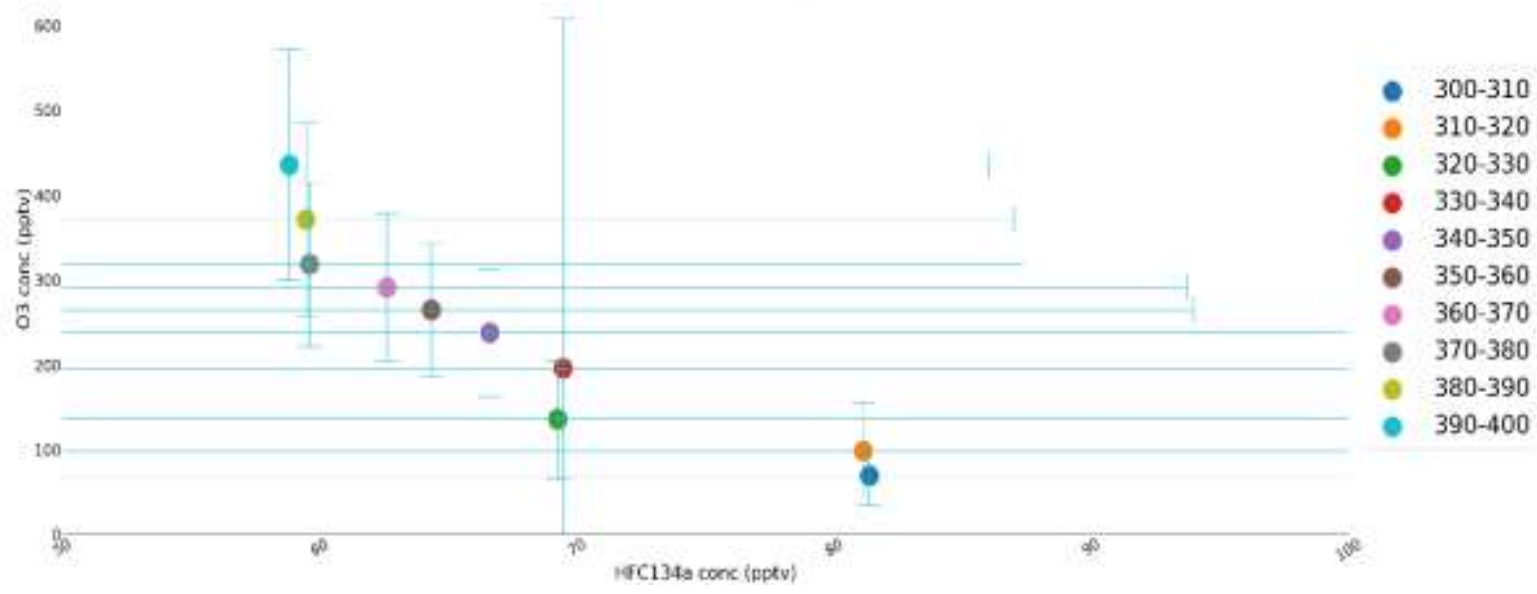

Figure A8 Total Means and total Standard deviations of HFC134a vs O3 for each 10K Potential temperatures between $300 \mathrm{~K}-400 \mathrm{~K}$ Potential temperatures in the lower latitudes for all Fall seasons from 2004 to 2020 


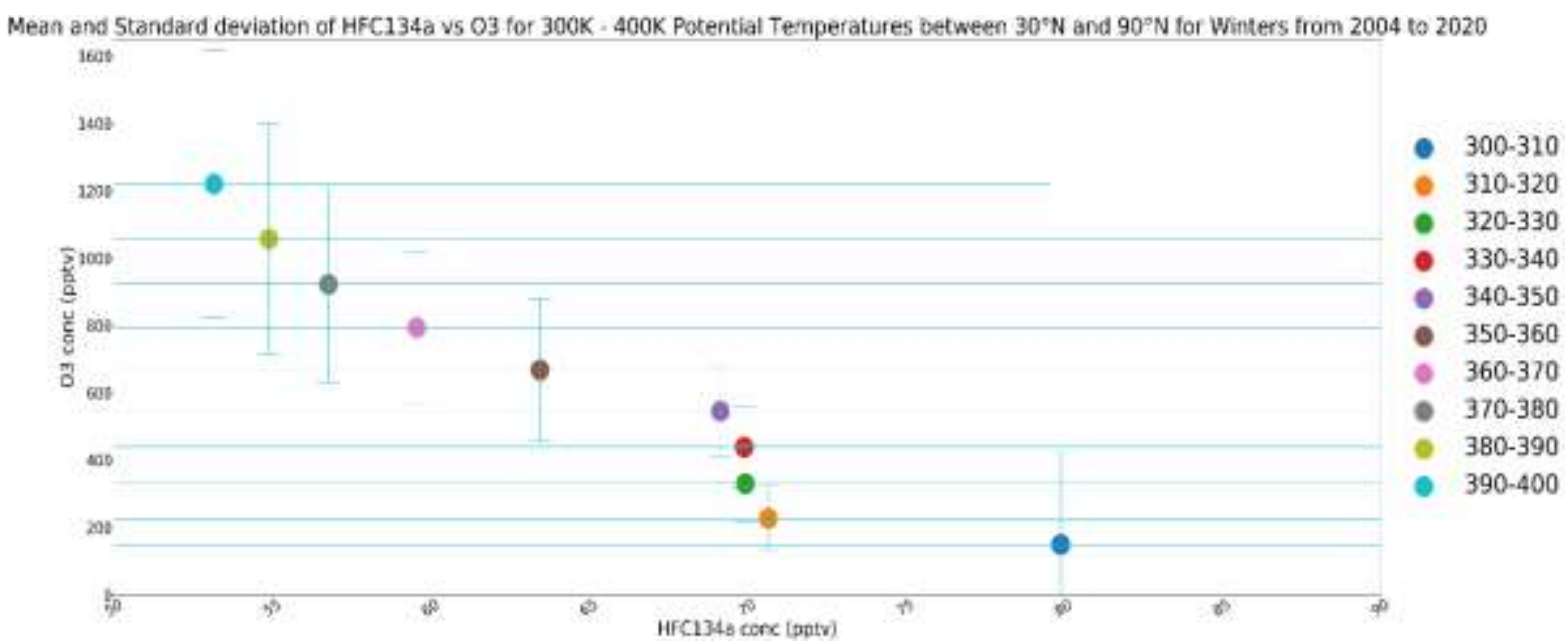

Figure A9 Total Means and total Standard deviations of HFC134a vs O3 for each 10K Potential temperatures between $300 \mathrm{~K}-400 \mathrm{~K}$ Potential temperatures in the higher latitudes for all Winters from 2004 to 2020

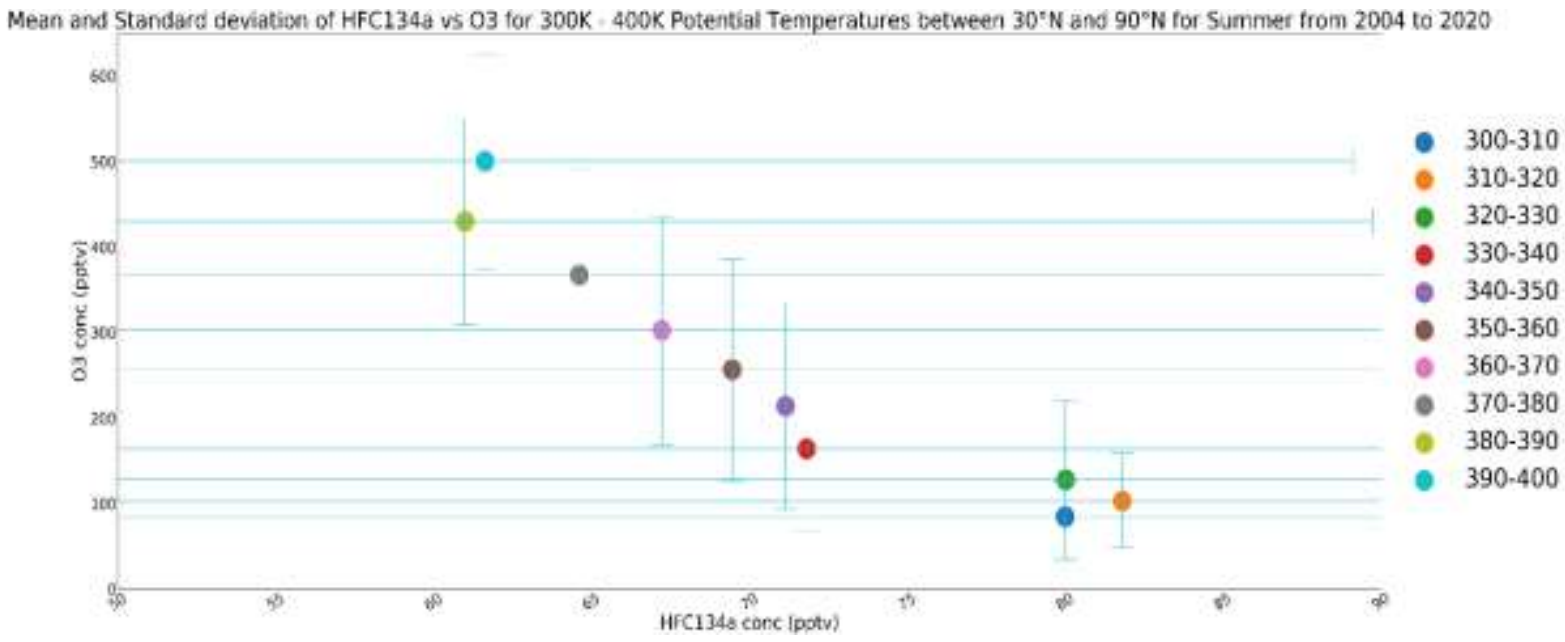

Figure A10 Total Means and total Standard deviations of HFC134a vs O3 for each 10K Potential temperatures between $300 \mathrm{~K}-400 \mathrm{~K}$ Potential temperatures in the higher latitudes for all Summers from 2004 to 2020 


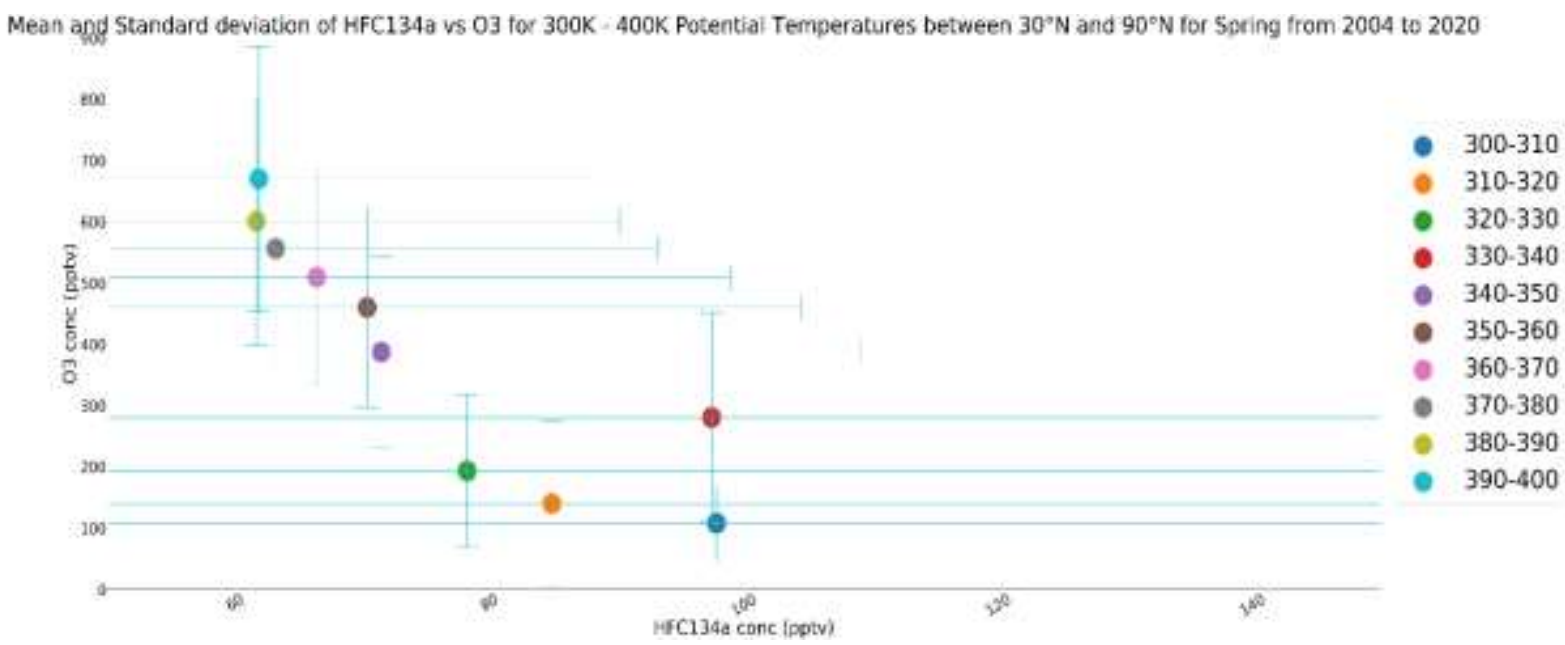

Figure A11 Total Means and total Standard deviations of HFC134a vs O3 for each 10K Potential temperatures between $300 \mathrm{~K}-400 \mathrm{~K}$ Potential temperatures in the higher latitudes for all Springs from 2004 to 2020

Mean agd Standard deviation of HFC134a vs 03 for 300K .400K Potential Temperatures between $30^{\circ} \mathrm{N}$ and $90^{\circ} \mathrm{N}$ for Fall from 2004 to 2020

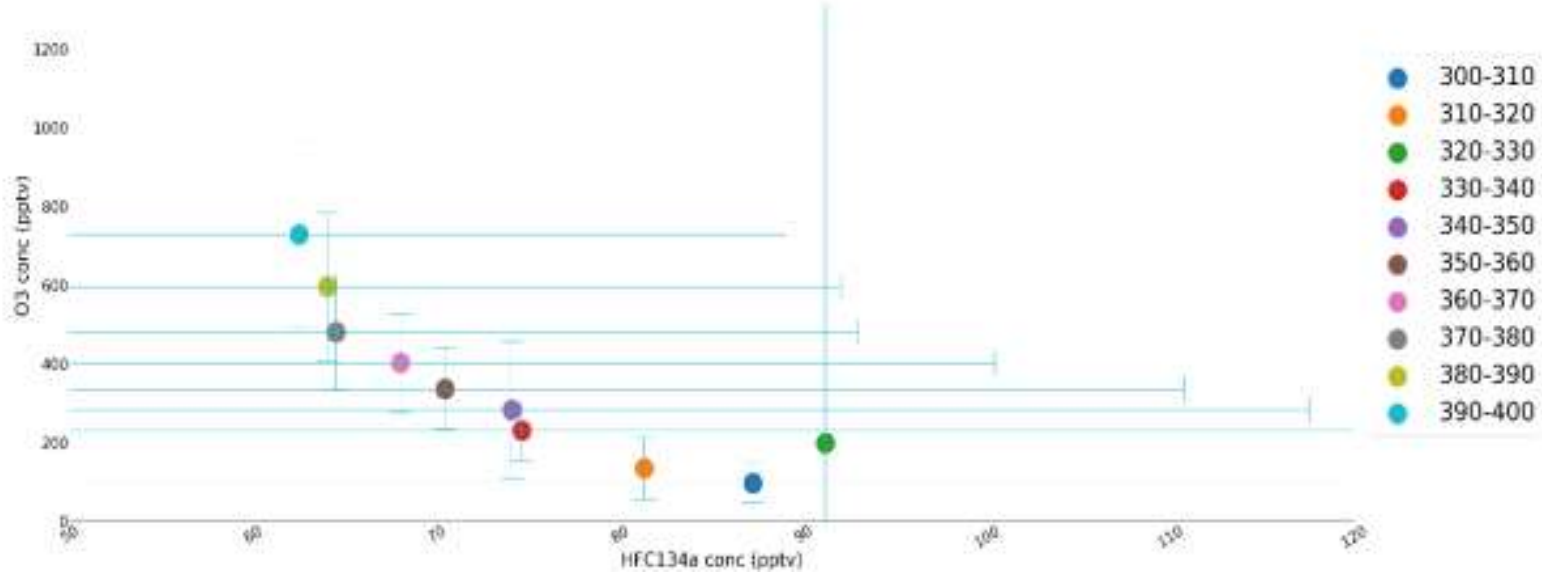

Figure A12 Total Means and total Standard deviations of HFC134a vs O3 for each 10K Potential temperatures between 300K-400K Potential temperatures in the higher latitudes for all Fall seasons from 2004 to 2020 


\section{APPENDIX - B}

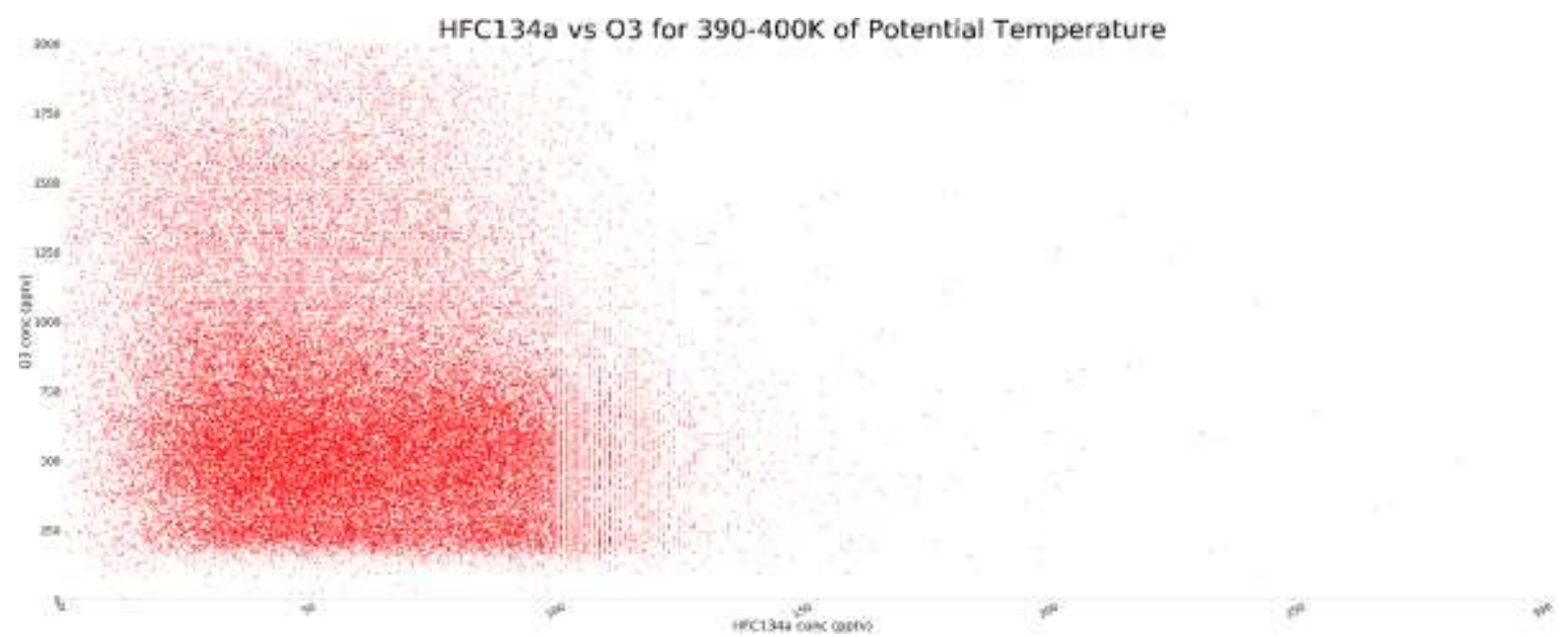

Figure B1 HFC134a vs O3 measurements for all points measured by ACE-FTS for altitudes corresponding to potential temperatures between $390 \mathrm{~K}$ and $400 \mathrm{~K}$.

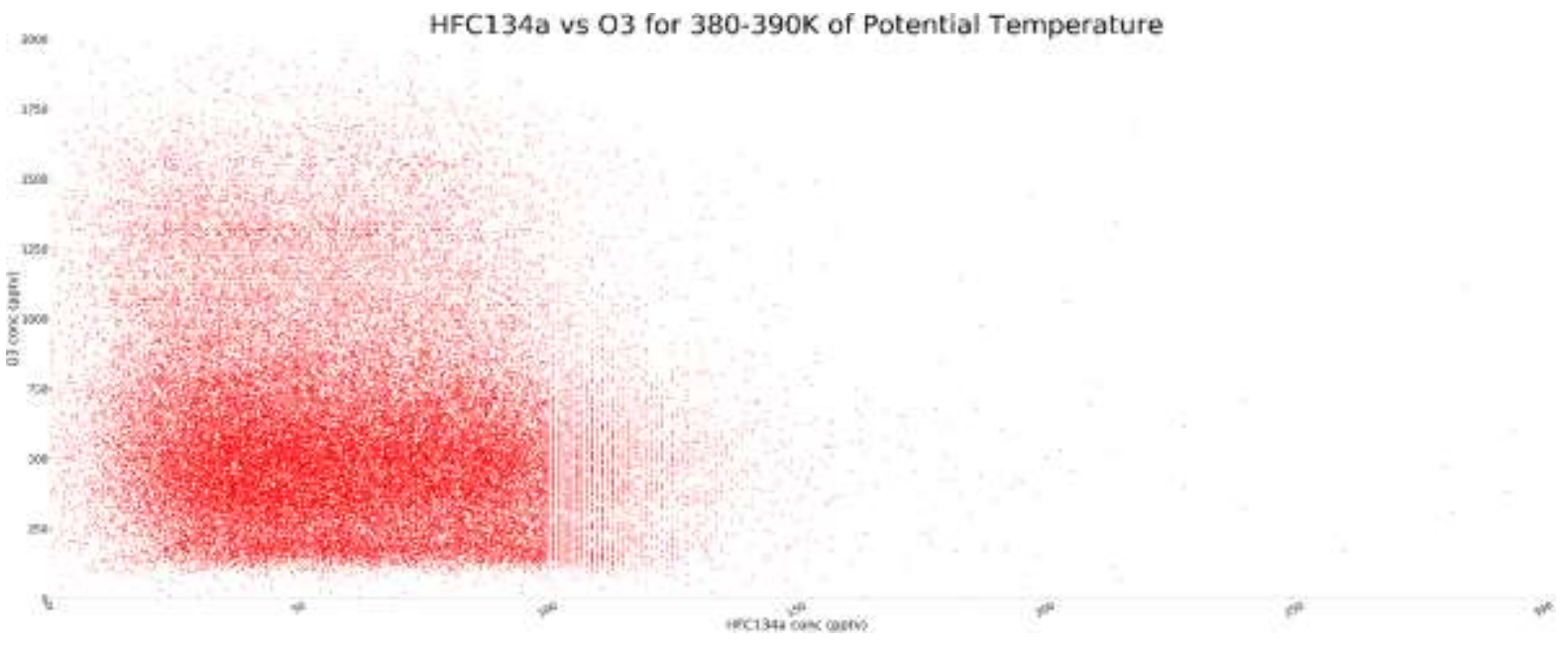

Figure B2 HFC134a vs O3 measurements for all points measured by ACE-FTS for altitudes corresponding to potential temperatures between $380 \mathrm{~K}$ and $390 \mathrm{~K}$. 


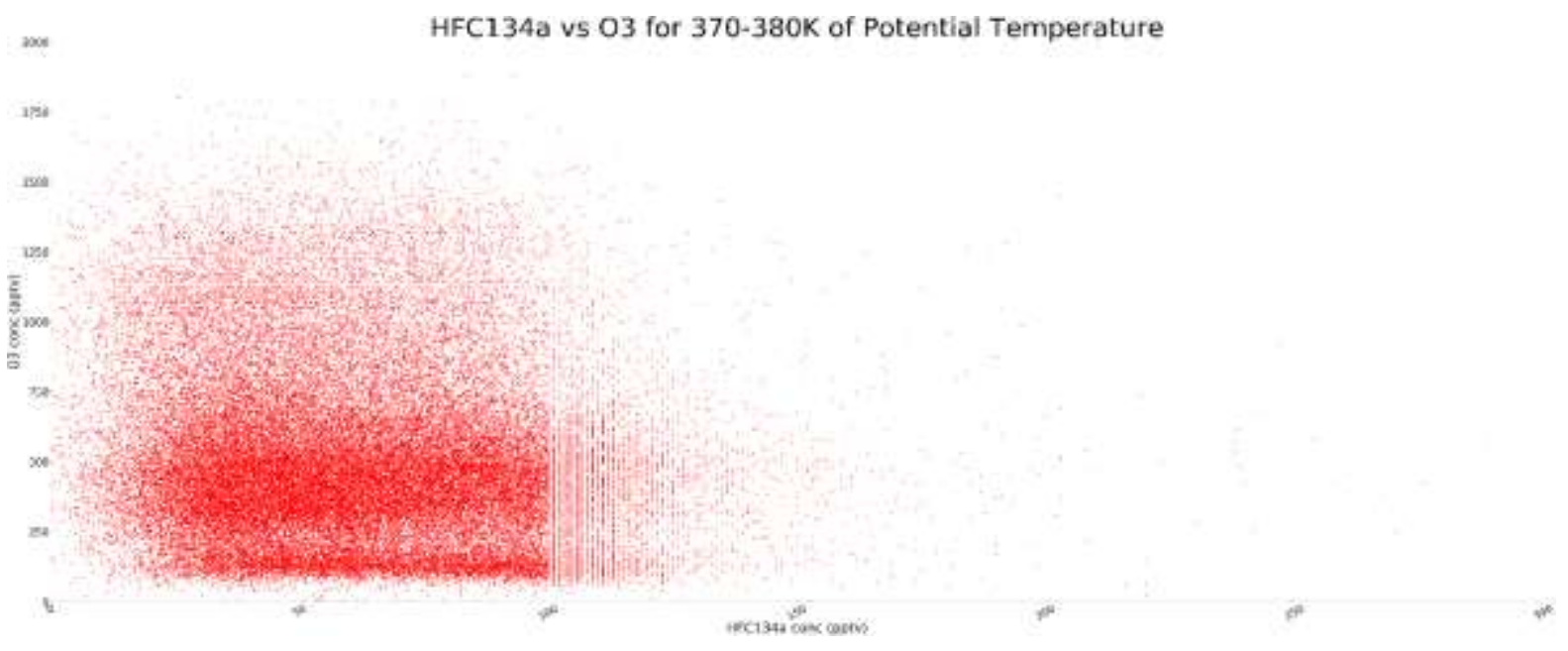

Figure B3 HFC134a vs O3 measurements for all points measured by ACE-FTS for altitudes corresponding to potential temperatures between $370 \mathrm{~K}$ and $380 \mathrm{~K}$.

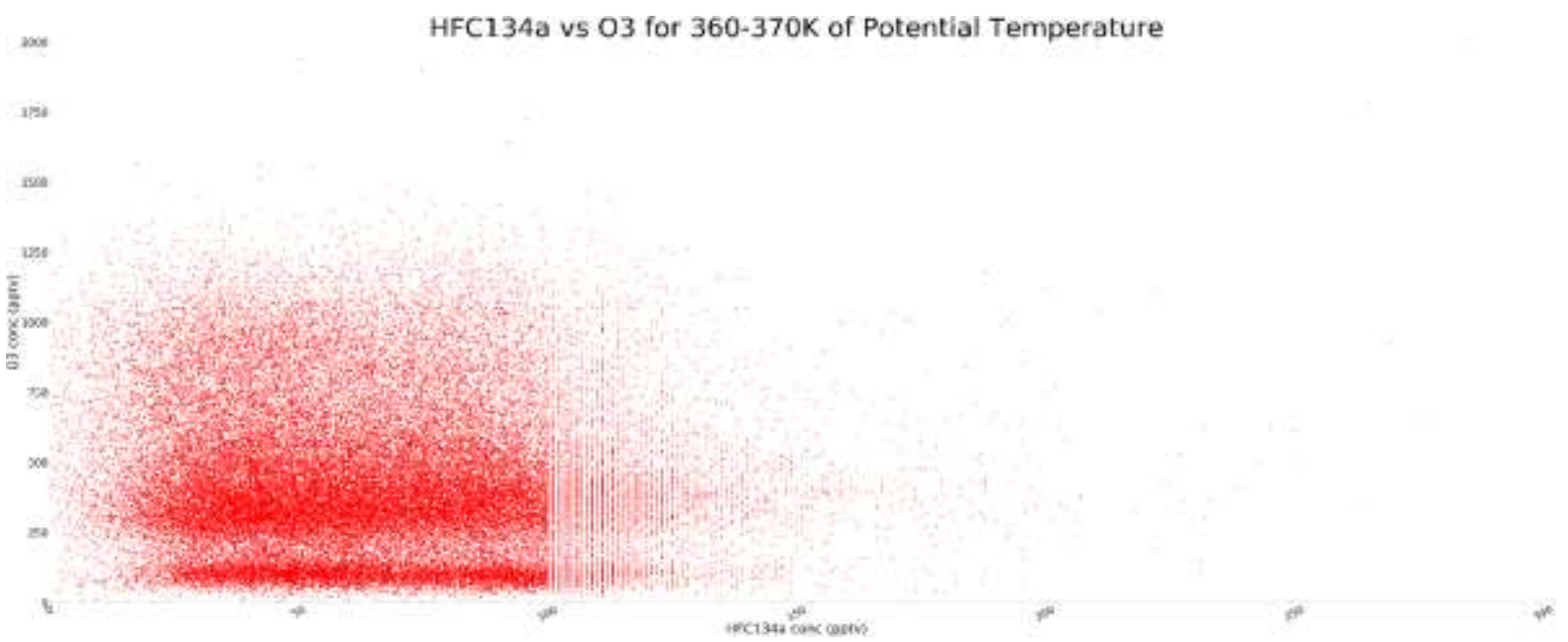

Figure B4 HFC134a vs O3 measurements for all points measured by ACE-FTS for altitudes corresponding to potential temperatures between $360 \mathrm{~K}$ and $370 \mathrm{~K}$. 


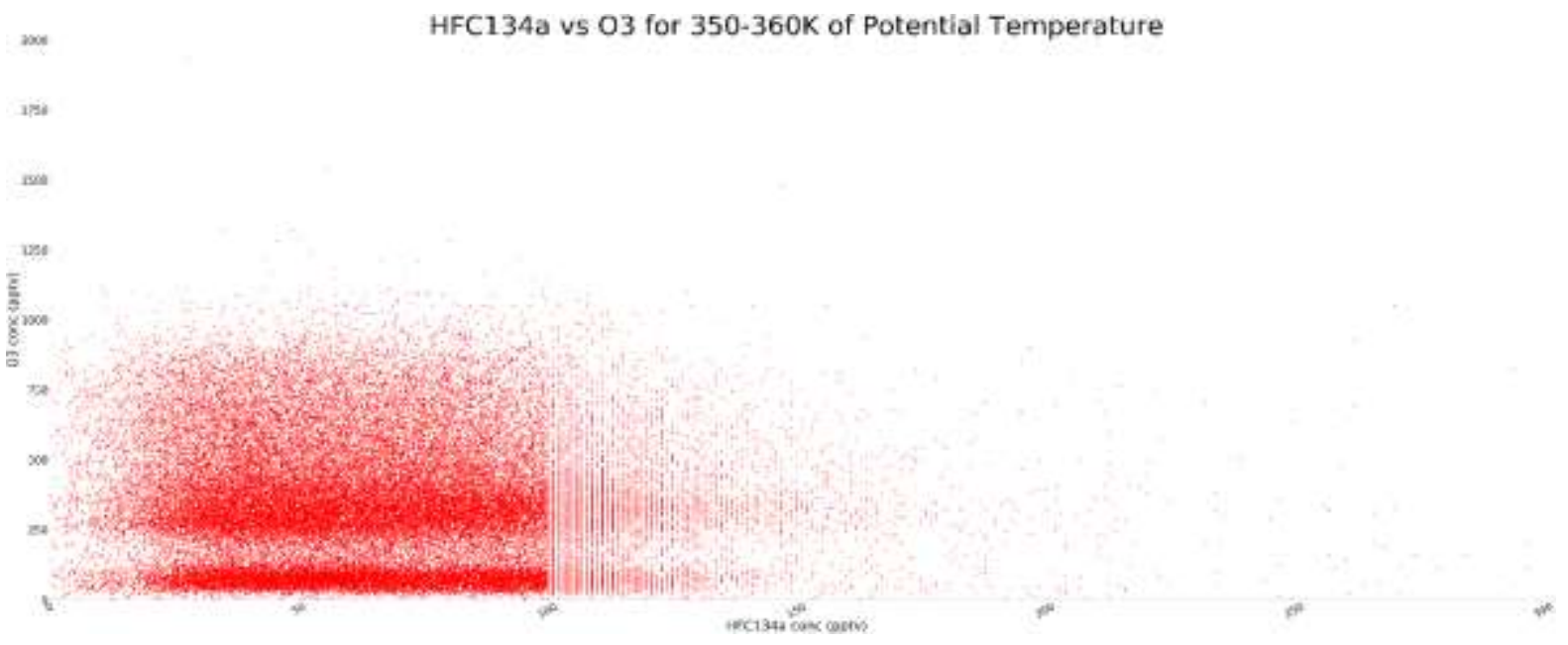

Figure B5 HFC134a vs O3 measurements for all points measured by ACE-FTS for altitudes corresponding to potential temperatures between $350 \mathrm{~K}$ and $360 \mathrm{~K}$.

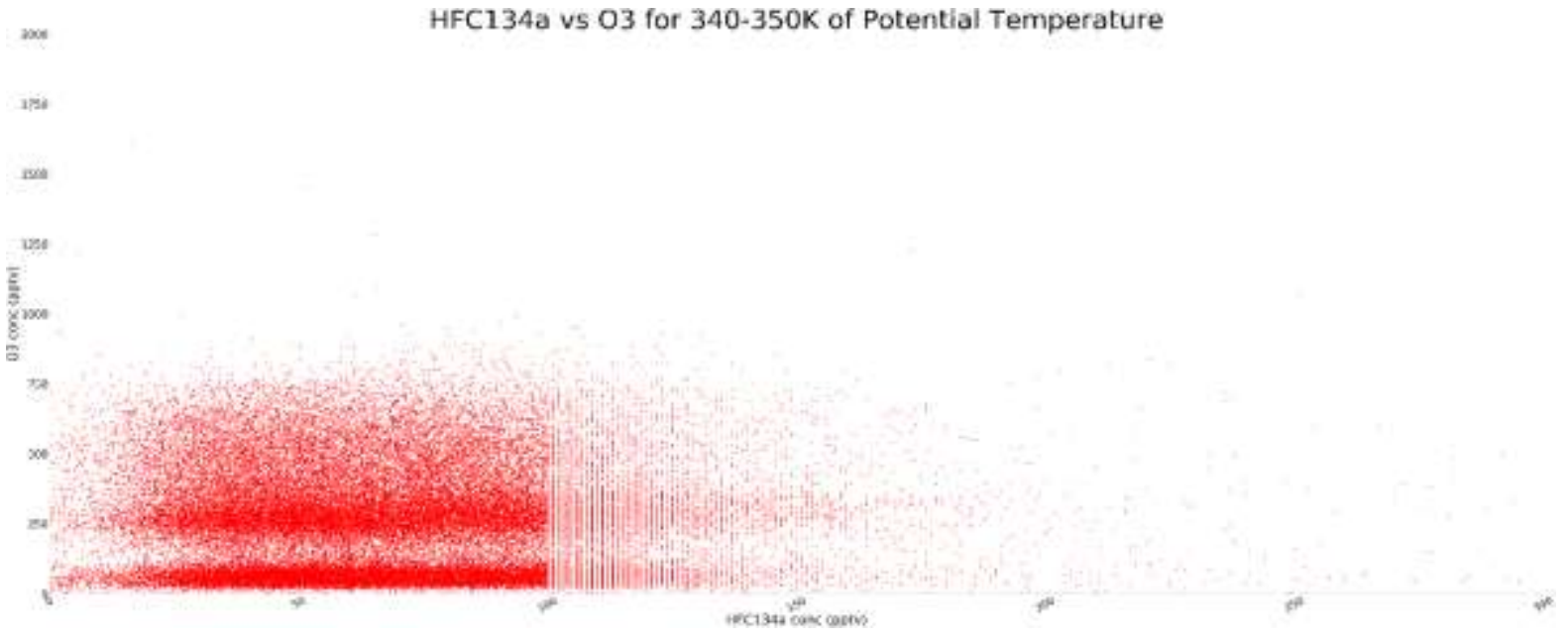

Figure B6 HFC134a vs O3 measurements for all points measured by ACE-FTS for altitudes corresponding to potential temperatures between $380 \mathrm{~K}$ and $390 \mathrm{~K}$. 


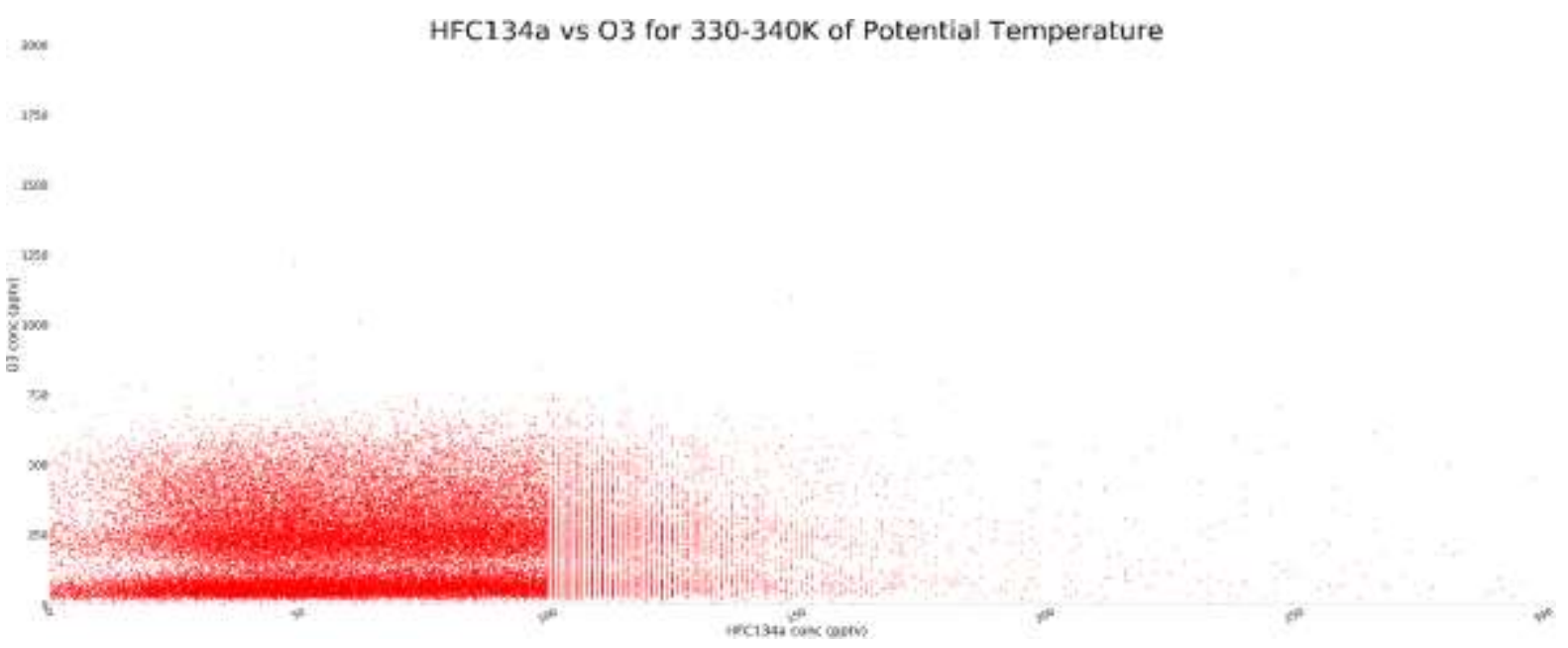

Figure B7 HFC134a vs O3 measurements for all points measured by ACE-FTS for altitudes corresponding to potential temperatures between $330 \mathrm{~K}$ and $340 \mathrm{~K}$.

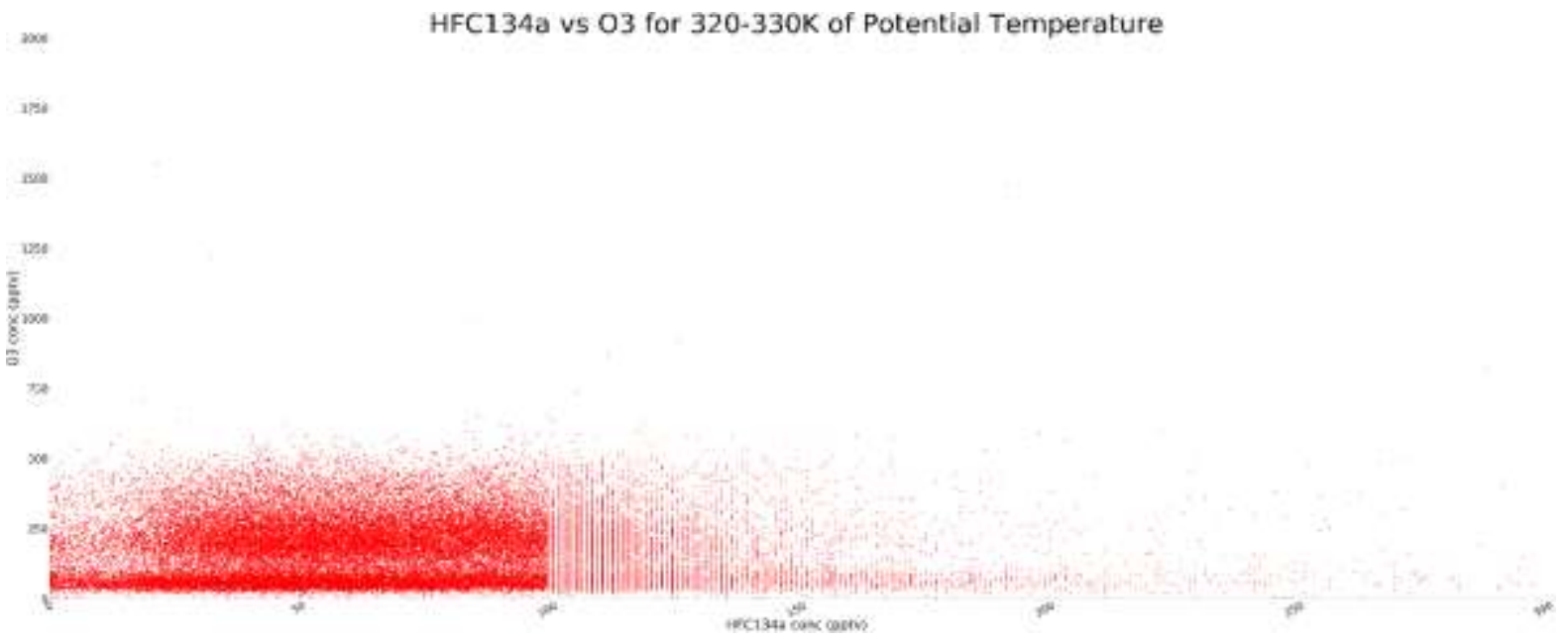

Figure B8 HFC134a vs O3 measurements for all points measured by ACE-FTS for altitudes corresponding to potential temperatures between $320 \mathrm{~K}$ and $330 \mathrm{~K}$. 


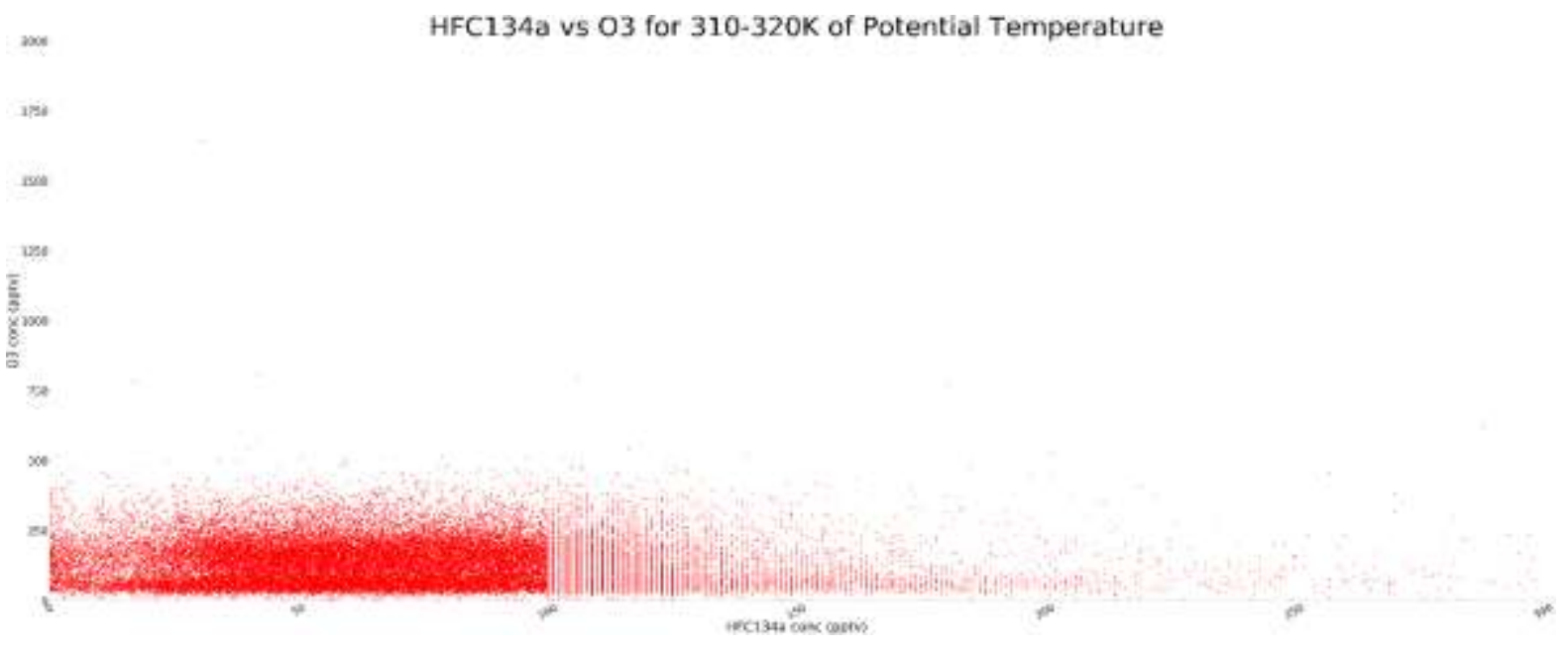

Figure B9 HFC134a vs O3 measurements for all points measured by ACE-FTS for altitudes corresponding to potential temperatures between $310 \mathrm{~K}$ and $320 \mathrm{~K}$.

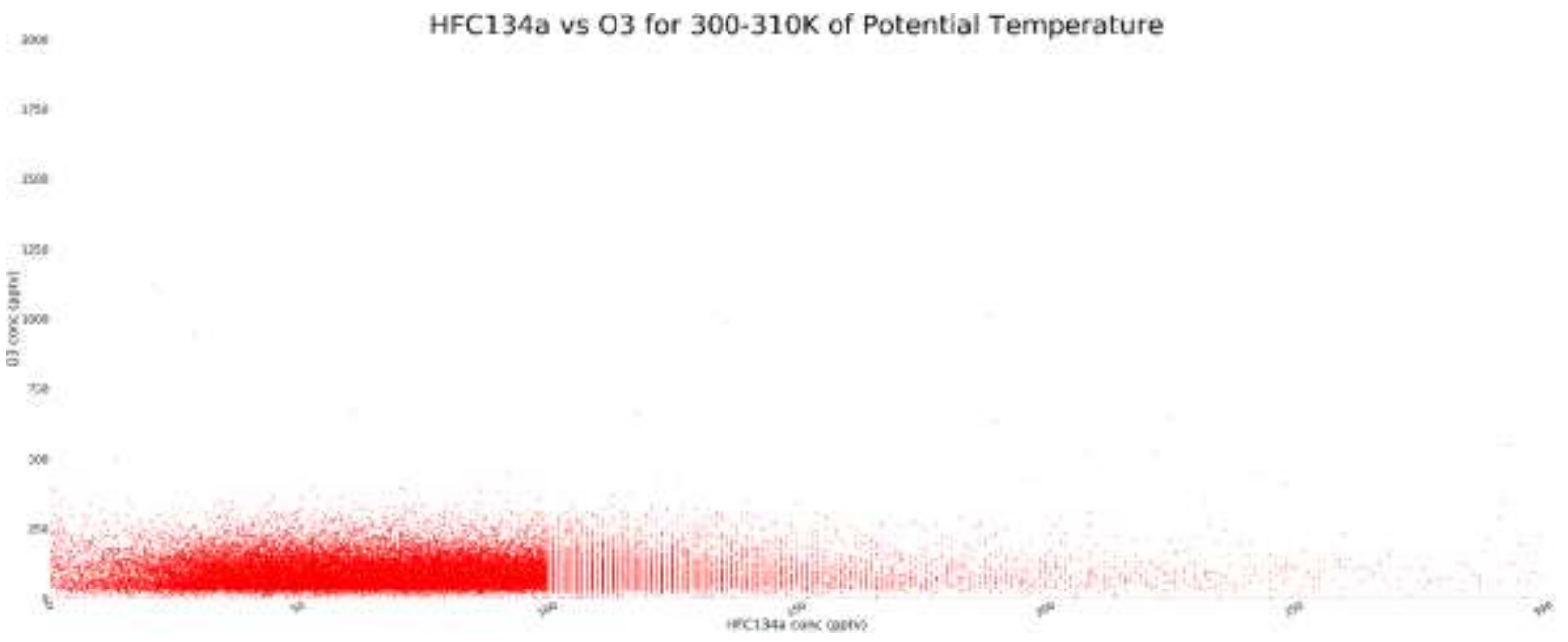

Figure B10 HFC134a vs O3 measurements for all points measured by ACE-FTS for altitudes corresponding to potential temperatures between $380 \mathrm{~K}$ and $390 \mathrm{~K}$. 


\section{APPENDIX - C}

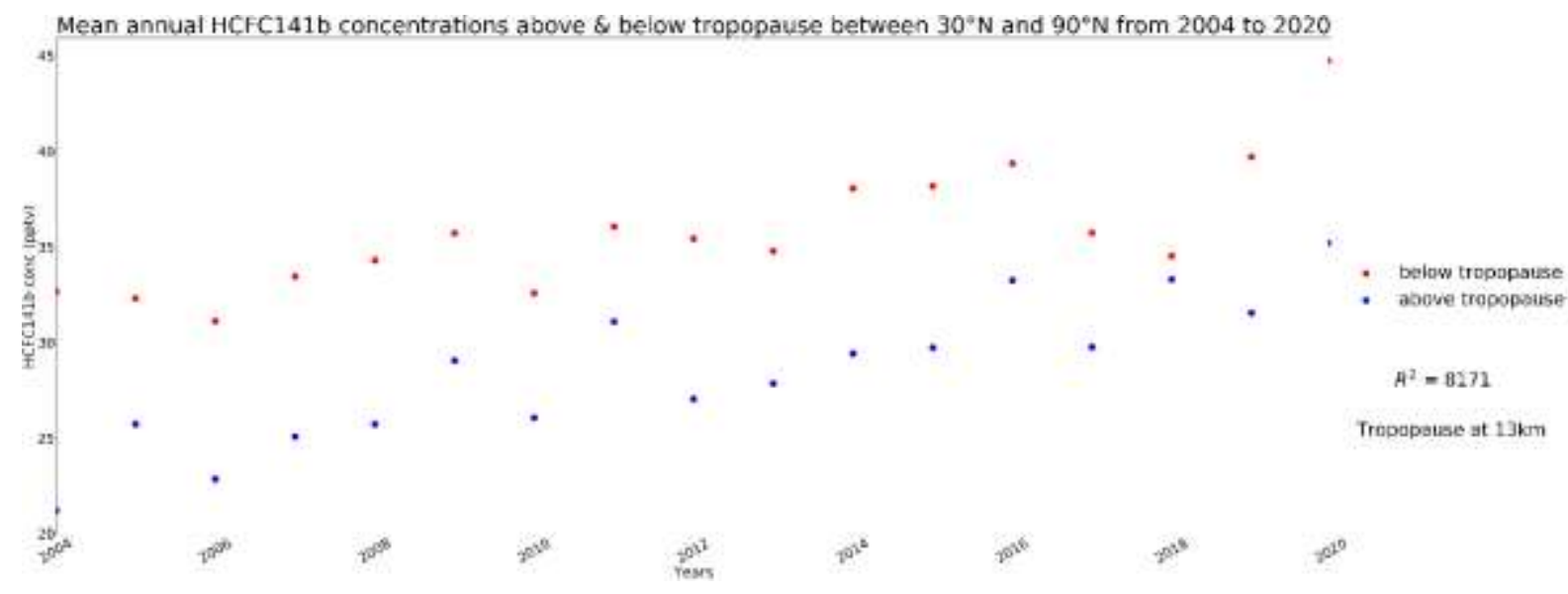

Figure C1 Figure showing the positive correlation between the mean annual HCFC141b concentrations immediately above and below the established tropopause from 2004 to 2020 between $90^{\circ} \mathrm{N}$ and $30^{\circ} \mathrm{N}$

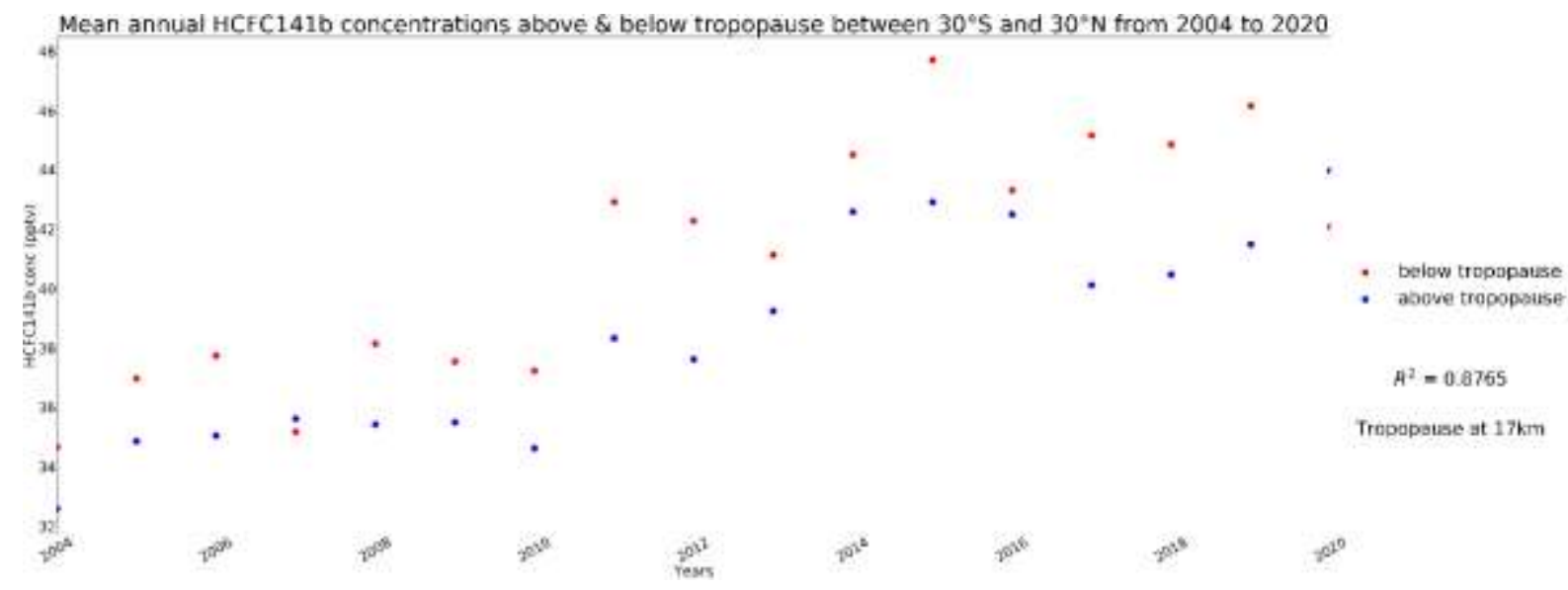

Figure C2 Figure showing the positive correlation between the mean annual HCFC141b concentrations immediately above and below the established tropopause from 2004 to 2020 between $30^{\circ} \mathrm{N}$ and $30^{\circ} \mathrm{S}$ 


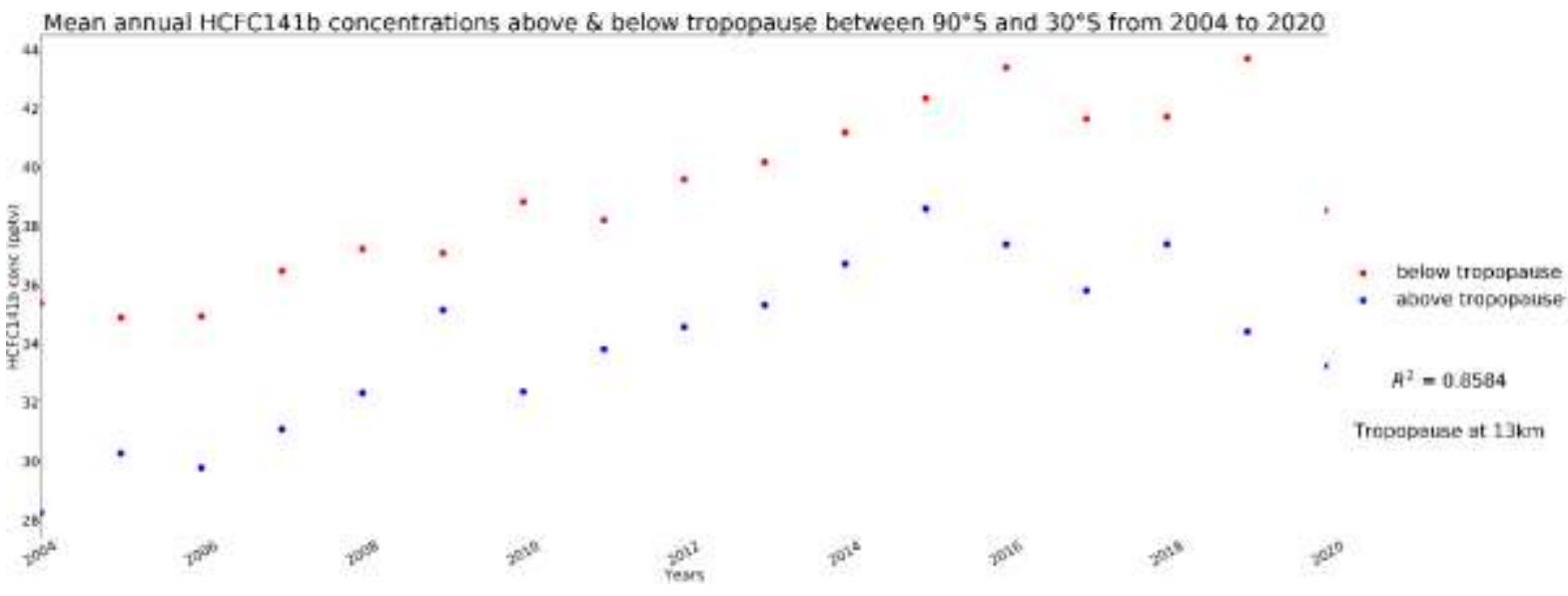

Figure C3 Figure showing the positive correlation between the mean annual HCFC141b concentrations immediately above and below the established tropopause from 2004 to 2020 between $30^{\circ} \mathrm{S}$ and $90^{\circ} \mathrm{S}$

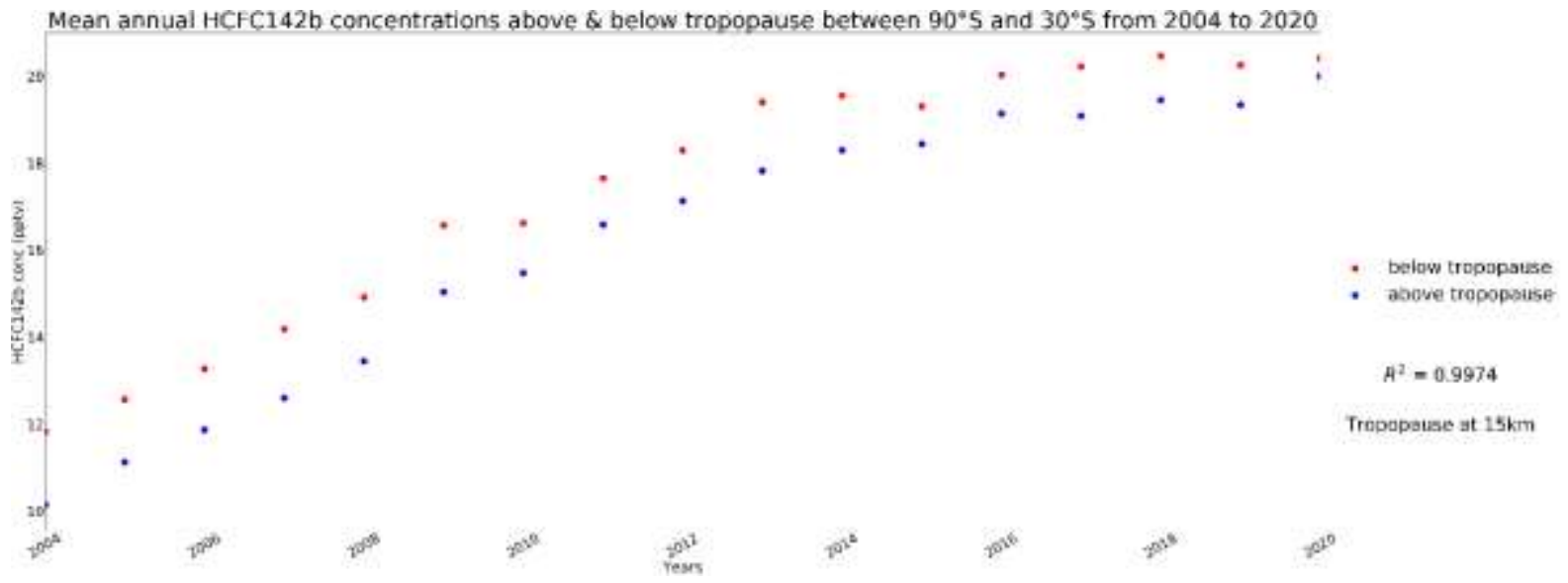

Figure C4 Figure showing the positive correlation between the mean annual HCFC142b concentrations immediately above and below the established tropopause from 2004 to 2020 between $30^{\circ} \mathrm{S}$ and $90^{\circ} \mathrm{S}$ 


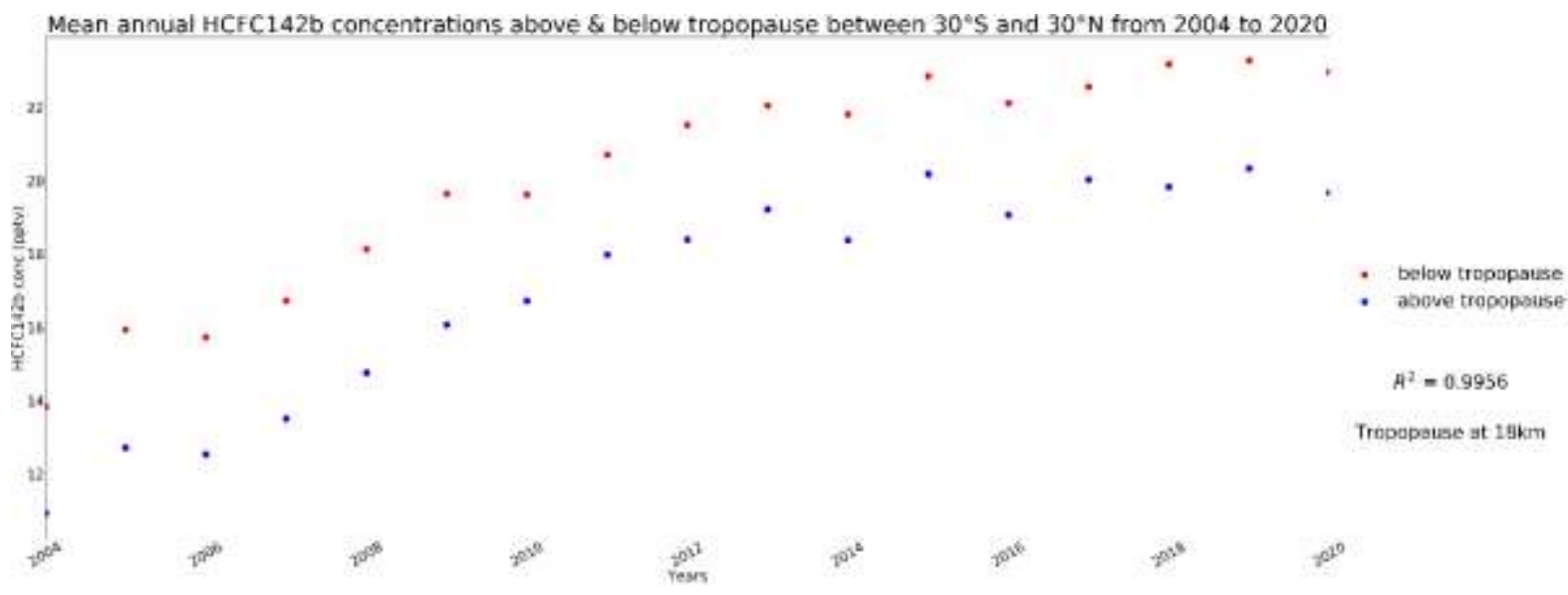

Figure C5 Figure showing the positive correlation between the mean annual HCFC142b concentrations immediately above and below the established tropopause from 2004 to 2020 between $30^{\circ} \mathrm{N}$ and $30^{\circ} \mathrm{S}$

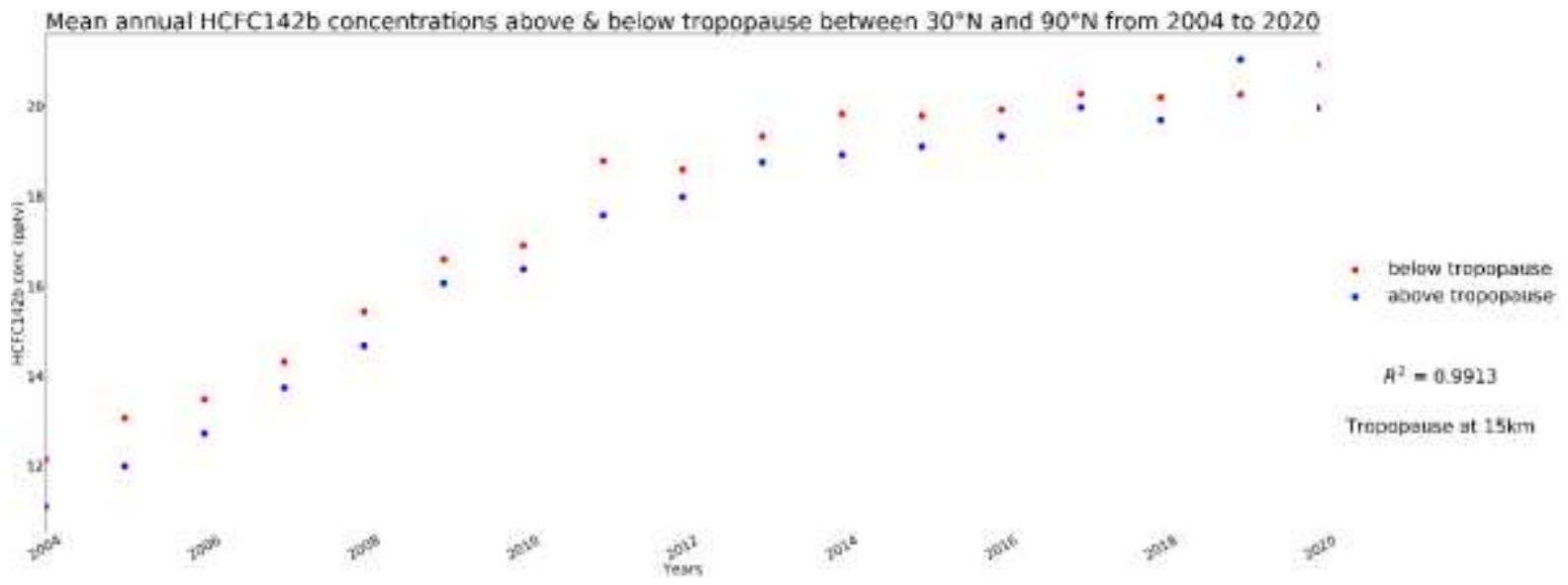

Figure C6 Figure showing the positive correlation between the mean annual HCFC142b concentrations immediately above and below the established tropopause from 2004 to 2020 between $30^{\circ} \mathrm{N}$ and $90^{\circ} \mathrm{N}$ 


\section{APPENDIX - D}

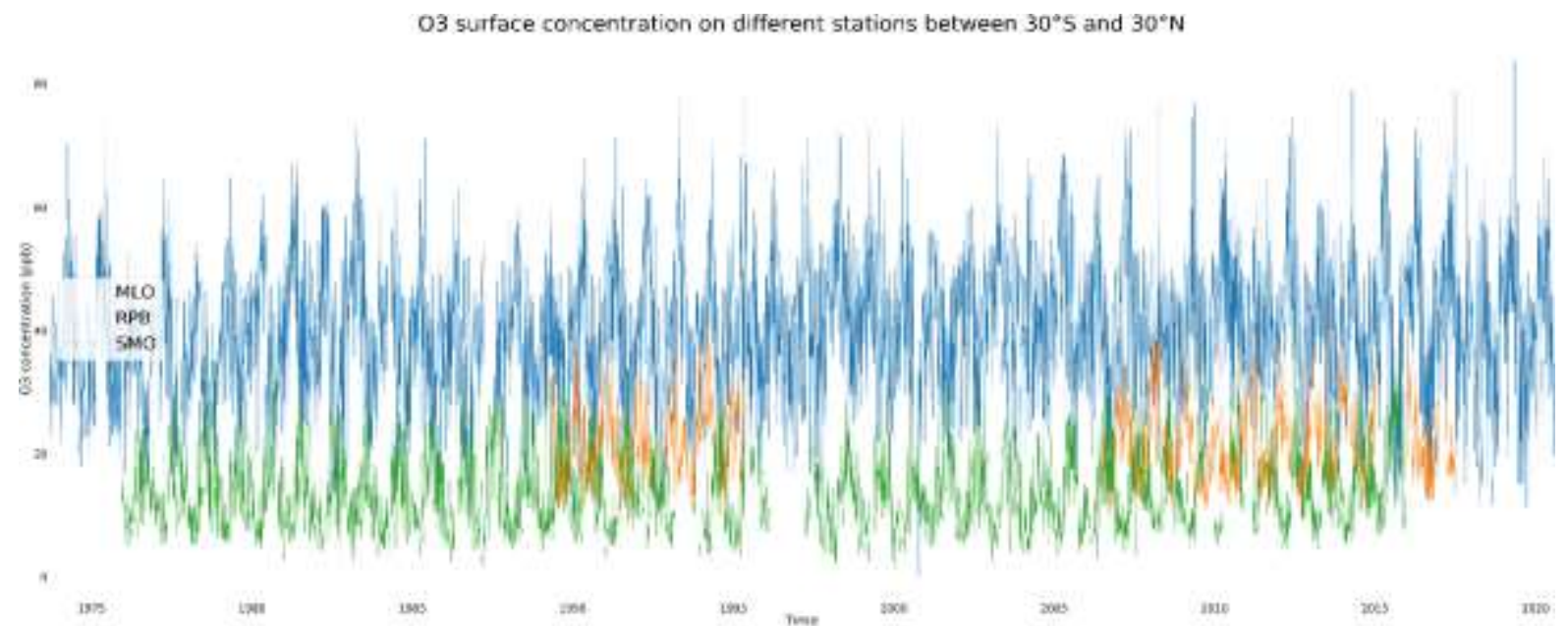

Figure D1 Time series plot of surface level Ozone concentrations from different sites around the world between $30^{\circ} \mathrm{S}$ and $30^{\circ} \mathrm{N}$ from 1975 to 2020

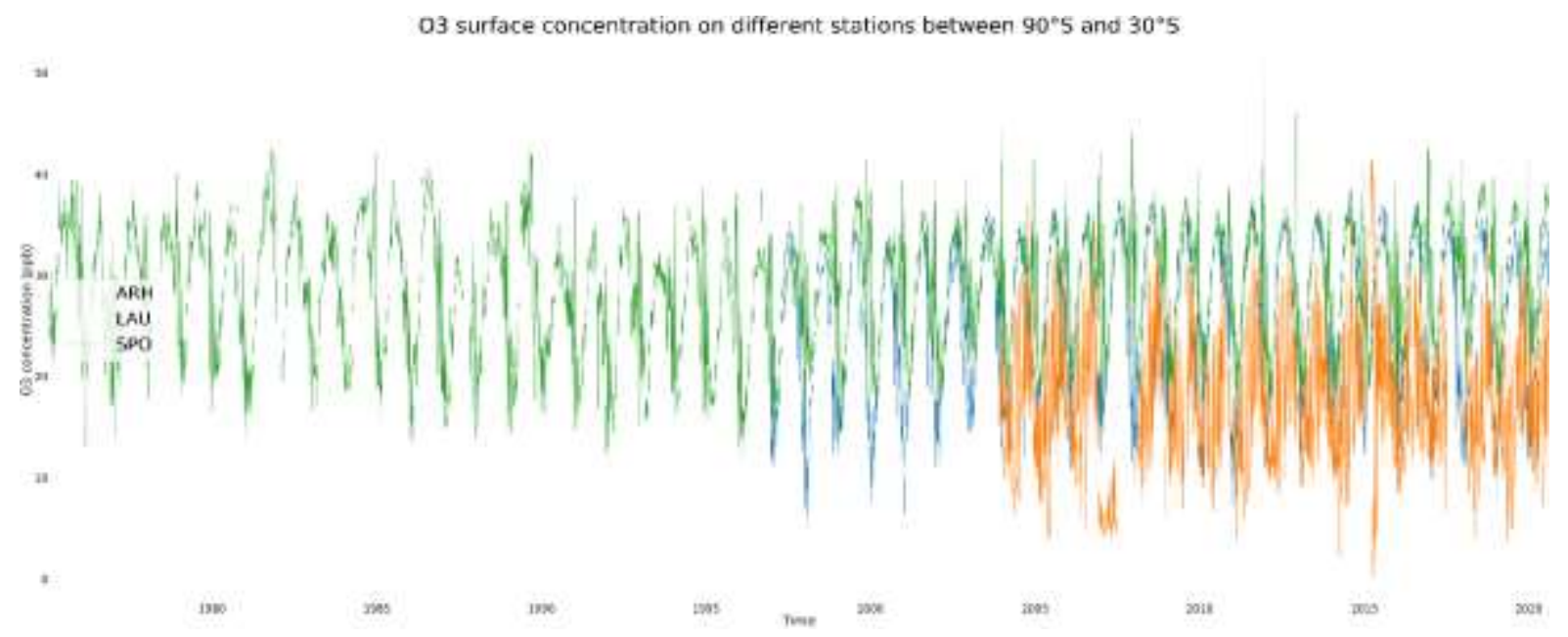

Figure D2 Time series plot of surface level Ozone concentrations from different sites around the world between $90^{\circ} \mathrm{S}$ and $30^{\circ} \mathrm{S}$ from 1975 to 2020 


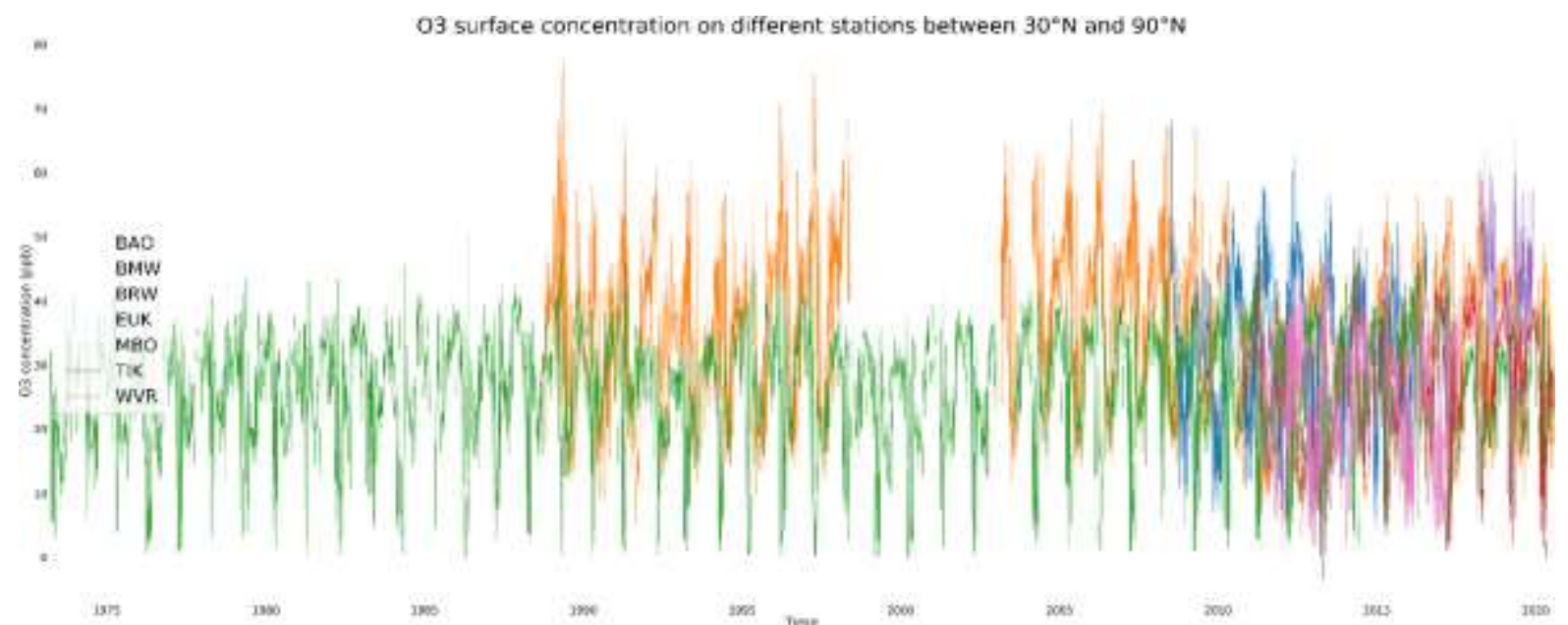

Figure D3 Time series plot of surface level Ozone concentrations from different sites around the world between $30^{\circ} \mathrm{N}$ and $90^{\circ} \mathrm{N}$ from 1975 to 2020

$\mathrm{HFCl} 34 \mathrm{a}$ surface concentration on different stations between $90^{\circ} \mathrm{S}$ and $30^{\circ} \mathrm{S}$

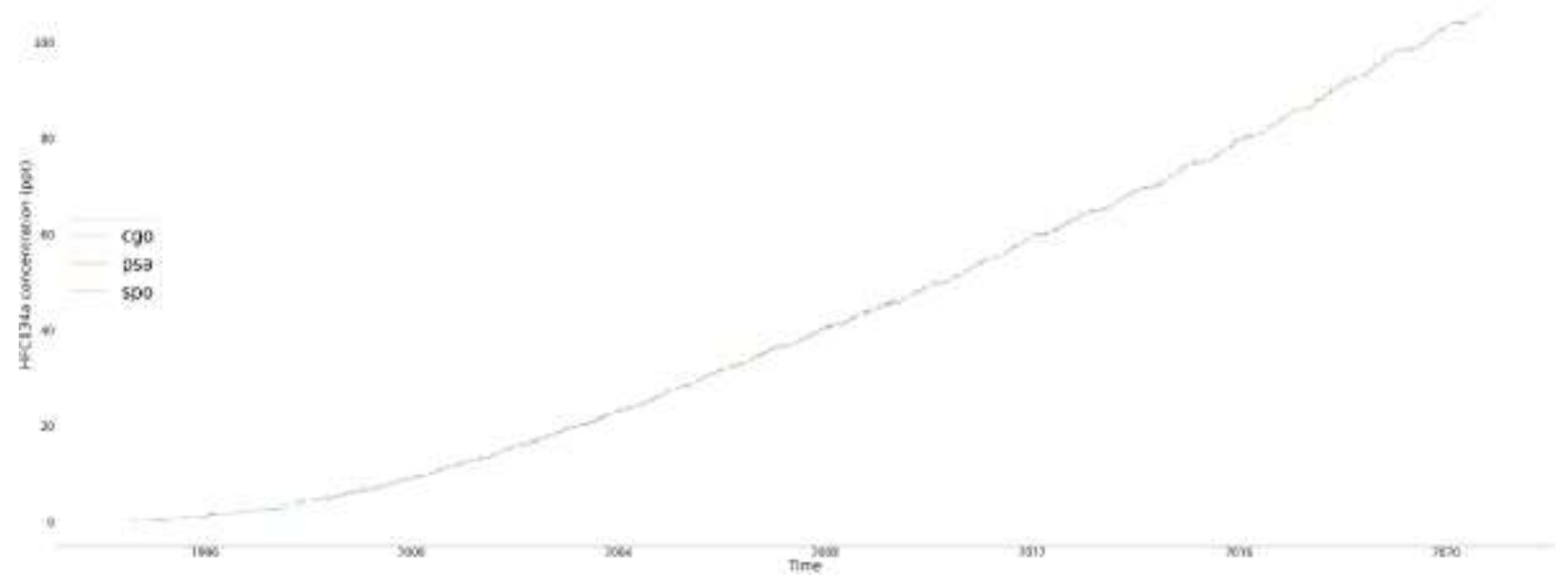

Figure D4 Time series plot of surface level HFC134a concentrations from different sites around the world between $90^{\circ} \mathrm{S}$ and $30^{\circ} \mathrm{S}$ from 1996 to 2020 


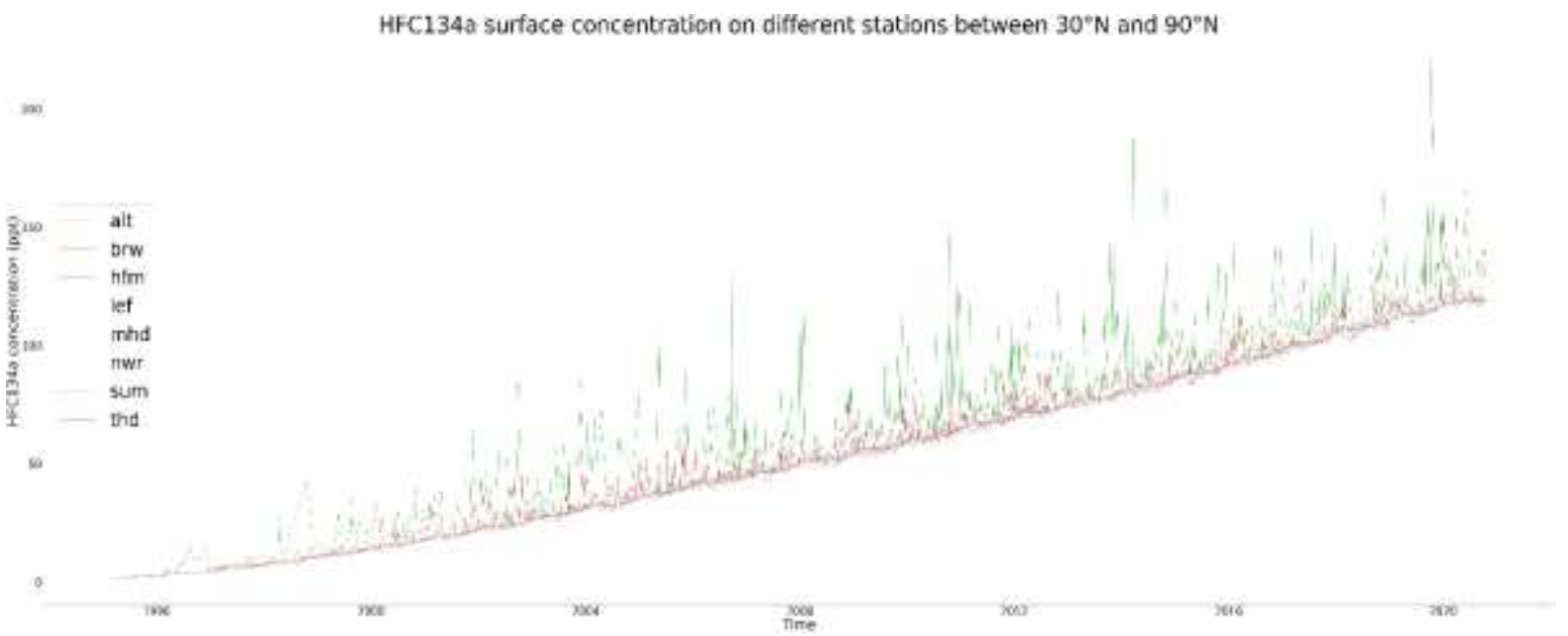

Figure D5 Time series plot of surface level HFC134a concentrations from different sites around the world between $30^{\circ} \mathrm{N}$ and $90^{\circ} \mathrm{N}$ from 1996 to 2020

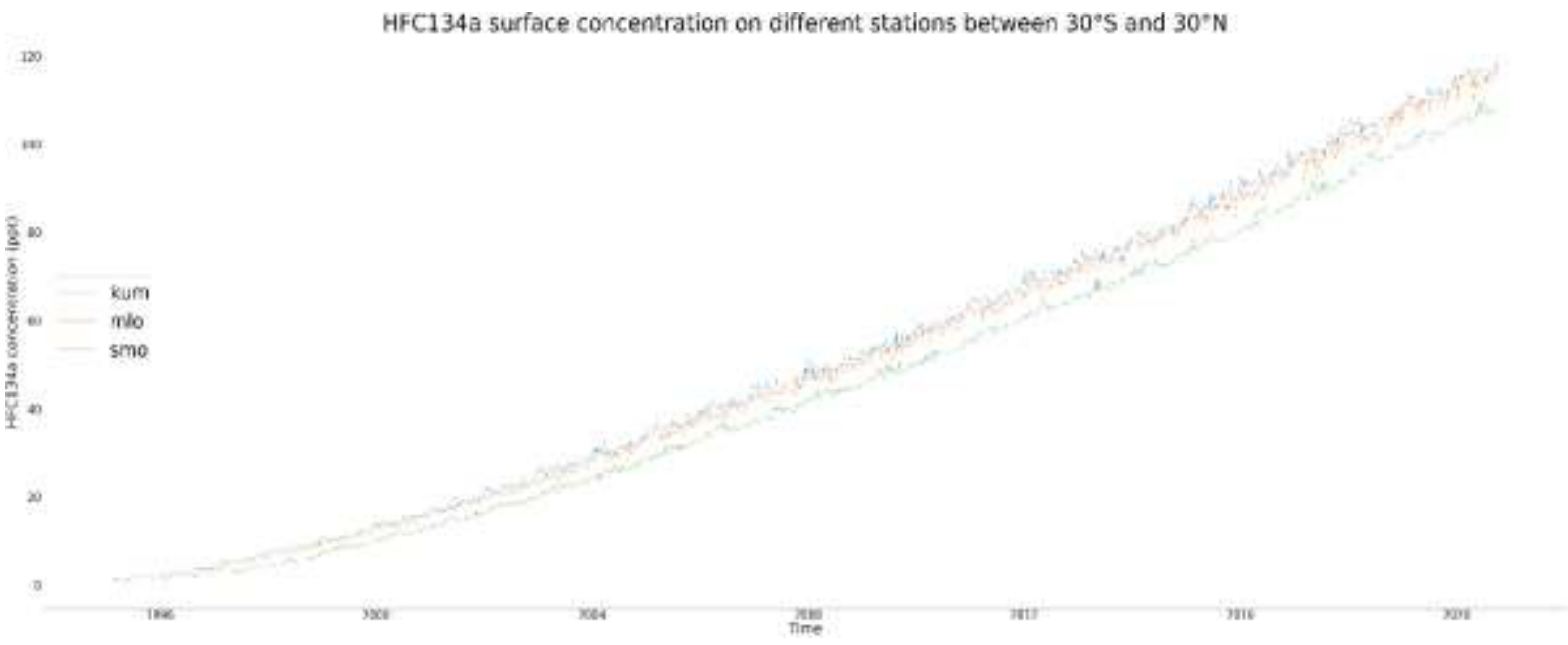

Figure D6 Time series plot of surface level HFC134a concentrations from different sites around the world between $30^{\circ} \mathrm{S}$ and $30^{\circ} \mathrm{N}$ from 1996 to 2020 
HCFC141b surface concentration on stations between $90^{\circ} 5$ and $30^{\circ} \mathrm{S}$

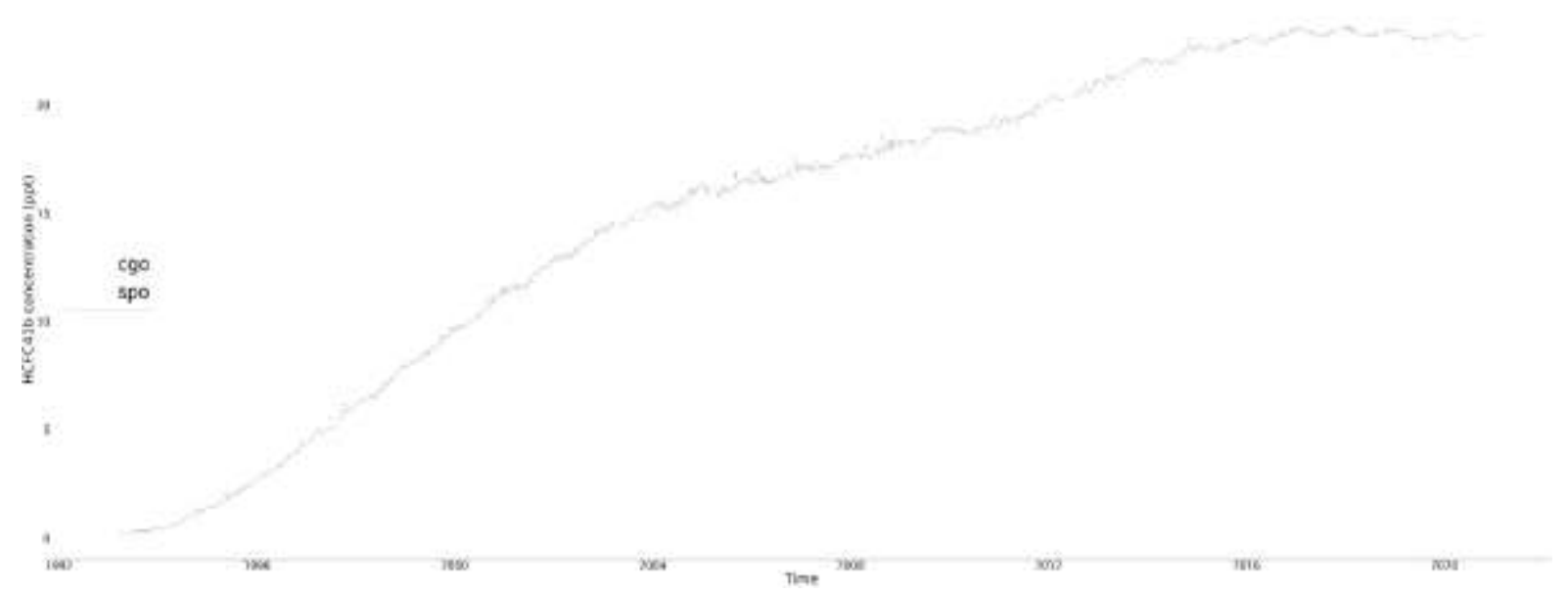

Figure D7 Time series plot of surface level HCFC141b concentrations from different sites around the world between $90^{\circ} \mathrm{S}$ and $30^{\circ} \mathrm{S}$ from 1992 to 2020

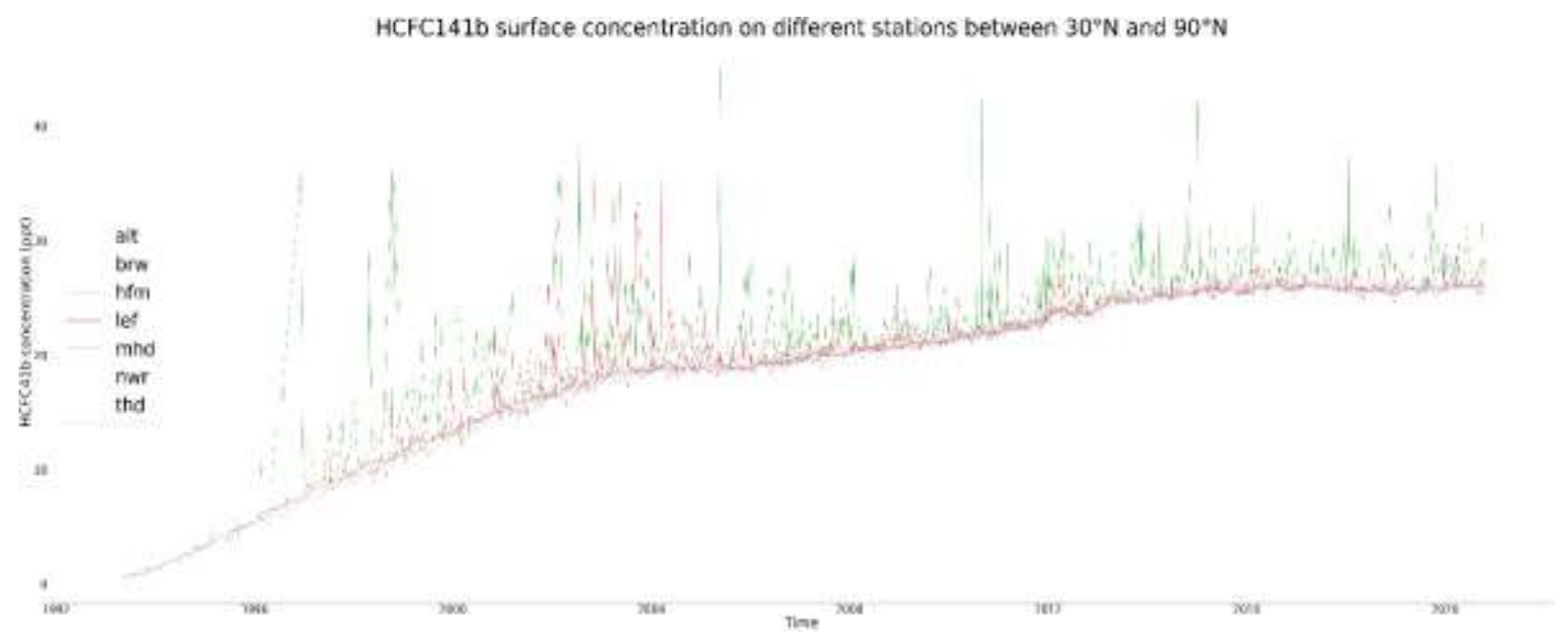

Figure D8 Time series plot of surface level HCFC141b concentrations from different sites around the world between $30^{\circ} \mathrm{N}$ and $90^{\circ} \mathrm{N}$ from 1992 to 2020 


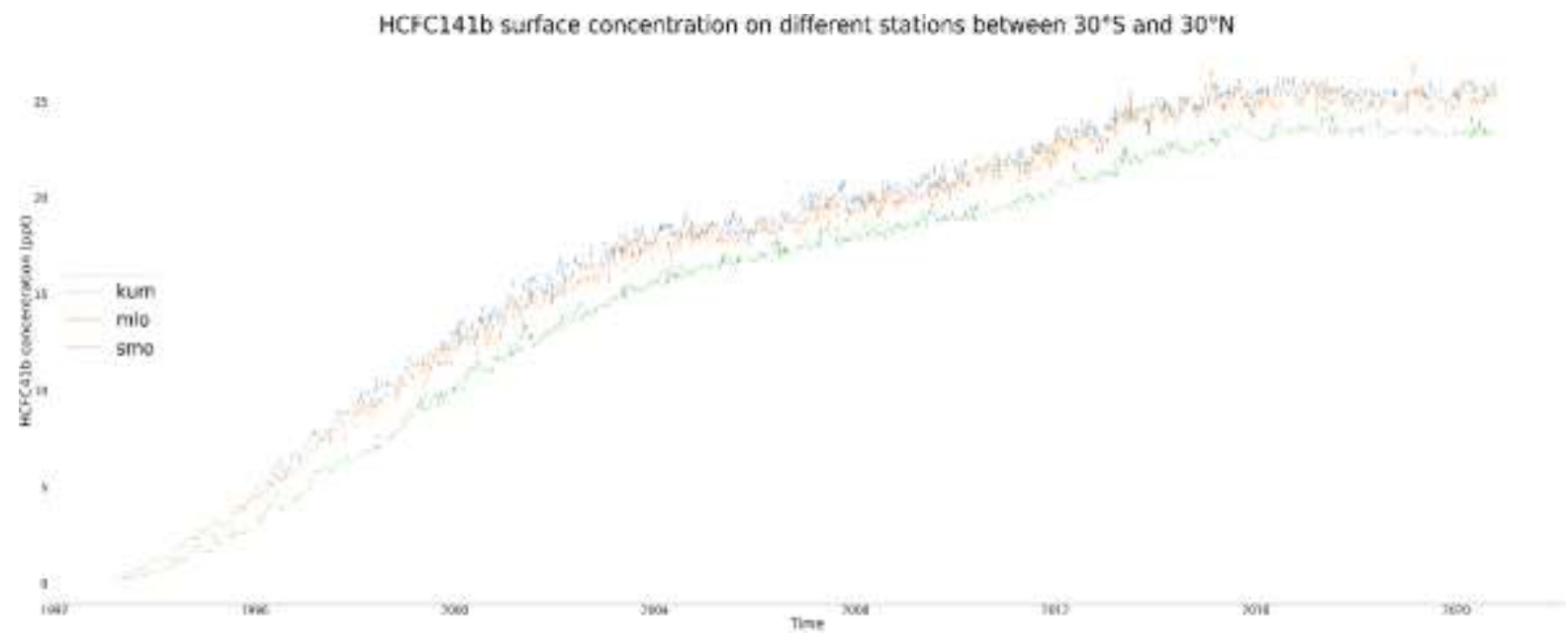

Figure D9 Time series plot of surface level HCFC141b concentrations from different sites around the world between $30^{\circ} \mathrm{S}$ and $30^{\circ} \mathrm{N}$ from 1992 to 2020

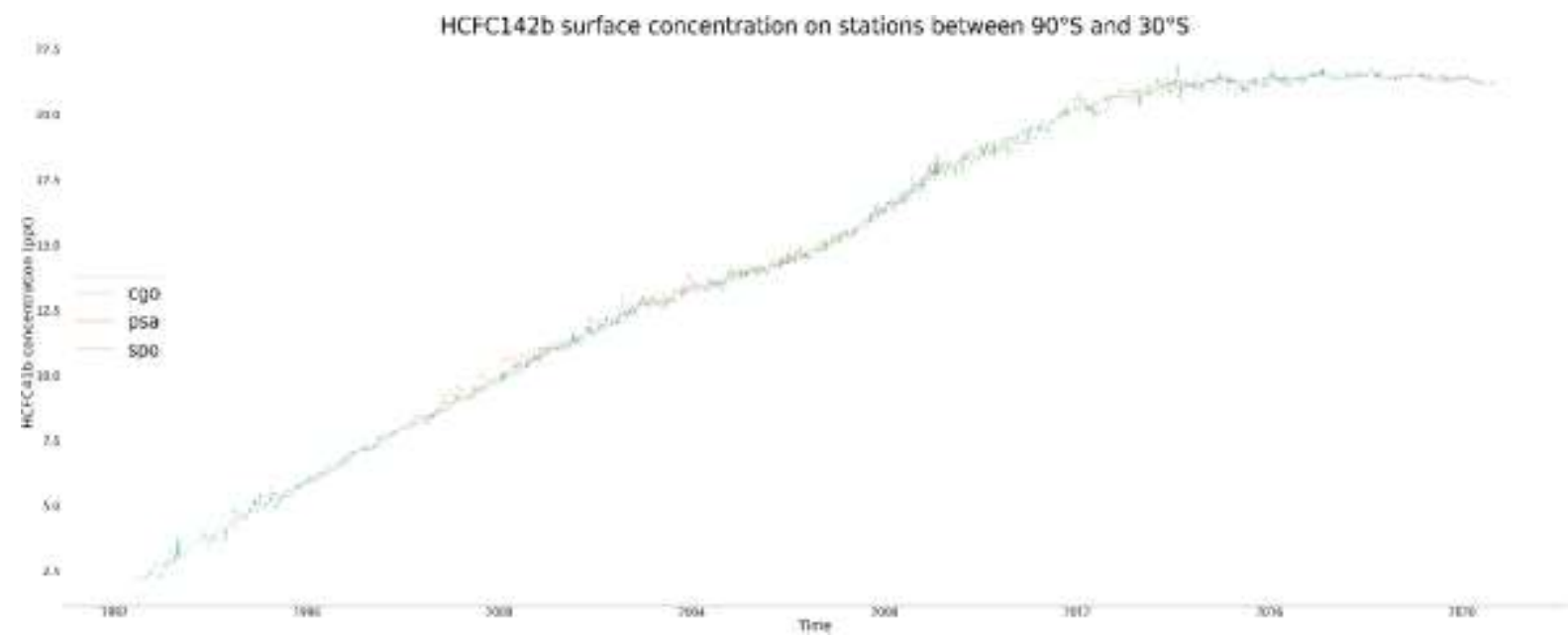

Figure D10 Time series plot of surface level HCFC142b concentrations from different sites around the world between $90^{\circ} \mathrm{S}$ and $30^{\circ} \mathrm{S}$ from 1992 to 2020 
HCFC1420 surface concentration on different stations between $30 \% \mathrm{~N}$ and $90^{\circ} \mathrm{N}$

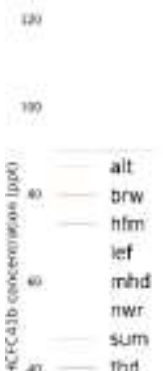

HCFC1420 surface concentration on different stations between $300 \mathrm{~N}$ and $90 \%$

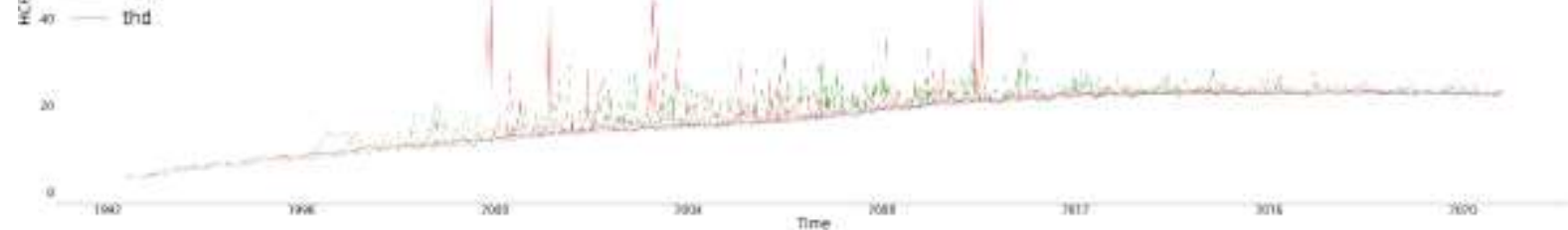

Figure D11 Time series plot of surface level HCFC142b concentrations from different sites around the world between $30^{\circ} \mathrm{N}$ and $90^{\circ} \mathrm{N}$ from 1992 to 2020

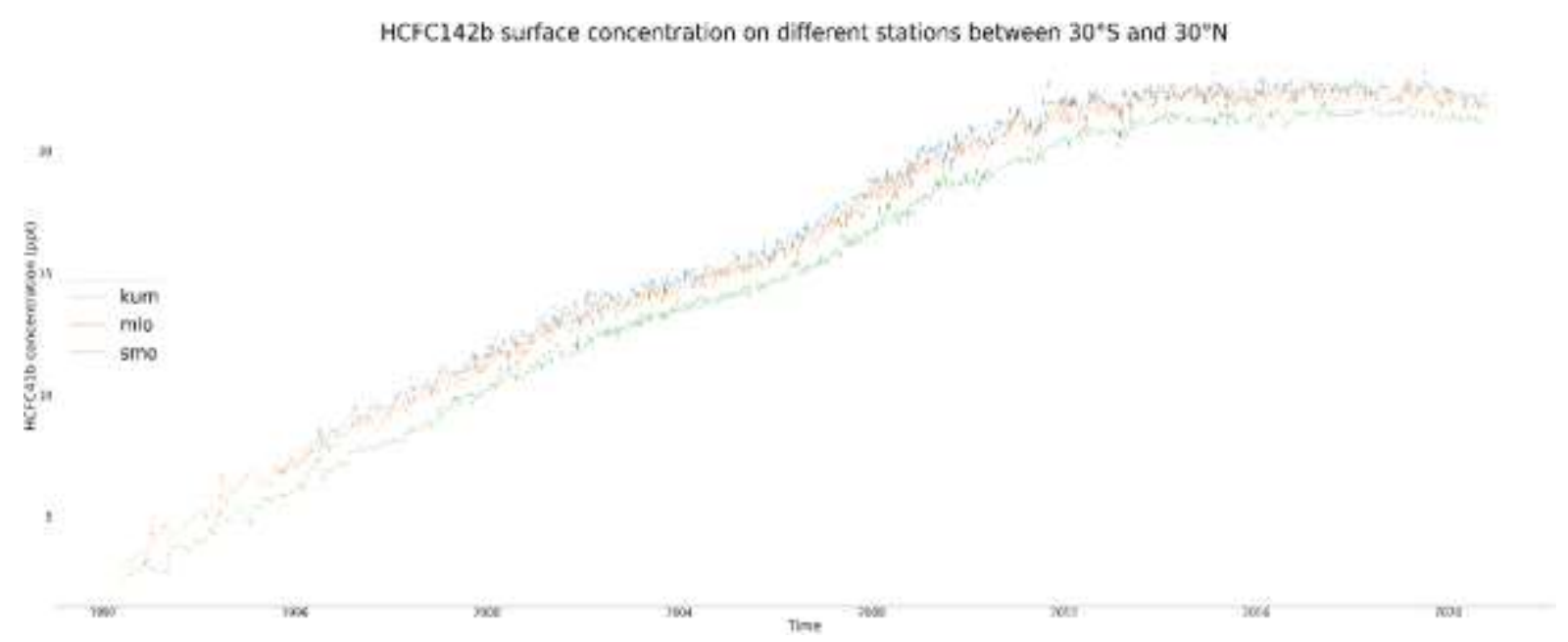

Figure D12 Time series plot of surface level HCFC142b concentrations from different sites around the world between $30^{\circ} \mathrm{S}$ and $30^{\circ} \mathrm{N}$ from 1992 to 2020 